\title{
Making Sense of the World We Live In \\ Editorial Practices and Picturing Science in LIFE Magazine: 1936-1955
}

\author{
By K. A. Williams \\ B.A., Saint Mary's University of Minnesota, 2005 \\ M.A., McGill University, 2009
}

\begin{abstract}
A thesis presented to
Ryerson University

in partial fulfillment of the requirements of

Master of Arts in the Program of

Film and Photographic Preservation and Collections Management
\end{abstract}

Toronto, Ontario, Canada, 2017

(C) K. A. Williams 2017 


\section{Author's Declaration Page}

I hereby declare that I am the sole author of this thesis.

I authorize Ryerson University to lend this thesis to other institutions or individuals for the purpose of scholarly research.

I further authorize Ryerson University to reproduce this thesis by photocopying or by other means, in total or part, at the request of other institutions or individuals for the purpose of scholarly research. 


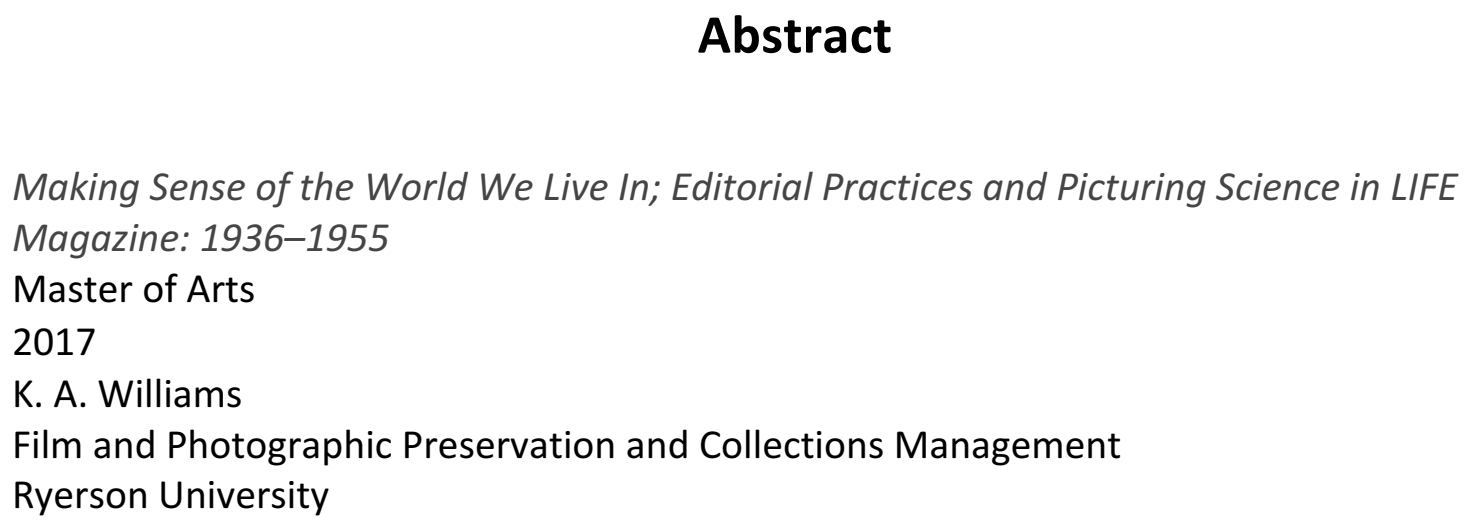

Making Sense of the World We Live In examines how editorial practices communicated different images of science to the readers of LIFE magazine between 1936 and 1955. Selected essays published between 1936-1955 in various sections of LIFE, as well as the thirteen issues series, "The World We Live In" published between 1952-1954 serve as the primary sources for this thesis. An introduction, literature survey, and methodology section establish the historical context of science communication and LIFE magazine. An appendix and list of illustrations provide quantitative data and selected images used in this thesis. Three analysis chapters discuss how editorial practices including layout, colour, the role of the photographer, and section placement in LIFE produced different stories of science for specific audiences. These chapters also consider how the story of science was integrated by editors into larger political narratives of American hegemony published in the magazine. 


\section{Acknowledgements}

To Thierry for wisdom, to Neve for nuance, to Vesper for moxie, to Brett for support, to the Six for stability, to Don for listening, to Gareth for sense, to Raquel for encouragement, to Rachel for optimism, to Laura for curiosity, to Chandra for patience, to Oliver for gratitude, to Miles for rhythm, to Leonard for beauty, to Debby for life.

Thank you. 


\section{Table of Contents}

List of Illustrations........................................................... vi

1. Introduction ........................................................................ 1

2. Literature Survey............................................................... 3

3. Methodology......................................................................... 12

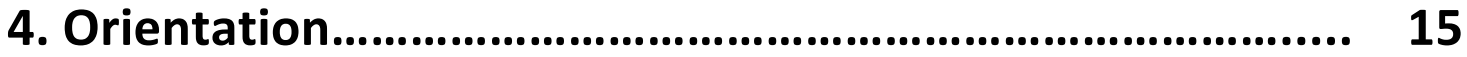

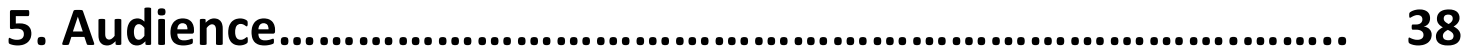

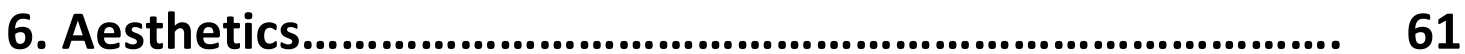

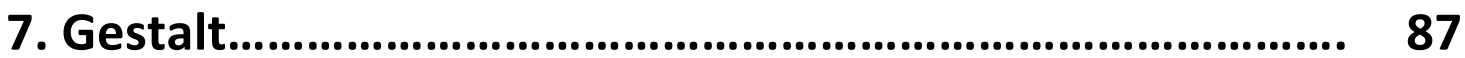

8. Conclusion........................................................... 99

9. Appendix A....................................................... 102

10. Bibliography.................................................... 106 


\section{List of Illustrations}

Fig. 1 - "Fort Peck Dam, Montana," photographed by Margaret Bourke-White, LIFE, November 23, 1936, Cover.

Fig. 2 - "War's Ending," Drawn by E. G. Leydenfrost, LIFE, August 20, 1945, 25.

Fig. 3 - "War's Ending," Photographed by United States Army Air Force, LIFE, August 20, 1945, 26.

Fig. 4 - "War's Ending," Photographed by United States Army Air Force, LIFE, August 20, 1945, 27.

Fig. 5 - "The Atomic Bomb: It's First Explosion into a New Era," Photographed and illustrated

by B. B. Culver, Lotti Jacob, Alfred Eisenstaedt, Fritz Goro (as F. W. Goro), Peter Stackpole, et al., LIFE, August 20, 1945, 92-93.

Fig. 6 - "The Atomic Bomb: It's First Explosion into a New Era," Photographed by Fritz Goro, LIFE, August 20, 1945, 88.

Fig. 7 - "The Atomic Bomb: It's First Explosion into a New Era," Photographed by Fritz Goro, LIFE, August 20, 1945, 90.

Fig. 8 - "Transport Panel Board," Photographed by George Karger and Manfred Curry, LIFE, August 23, 1937, 34-35.

Fig. 9 - "Amputee's Gait," Photographed by Gjon Mili, LIFE, July 1, 1946, 90-91.

Fig. 10 - "Amputee's Gait," Photographed by Gjon Mili, LIFE, July 1, 1946, 92.

Fig. 11 - "Amputee's Gait," Photographed by Gjon Mili, LIFE, July 1, 1946, 95.

Fig. 12 - "The Future of the Amazon," Photographed by the Government of Brazil, Scientific American, May 1948, 12-13.

Fig. 13 - "Renaissance Man," Photographed by Fernand Bourges, LIFE, March 3, 1947, 75.

Fig. 14 - "The Pageant of Life," Painted by Rudolph Zallinger, LIFE, September 7, 1953, 6870.

Fig. 15 - "The Earth is Born," Painted by Chelsey Bonestall, LIFE, December 8, 1952, 96.

Fig. 16 - "The Rainforest," Painted by Rudolph Zallinger, LIFE, September 20, 1954, 80-82.

Fig. 17 - "The Rainforest," Illustrated by Rudolph Zallinger, LIFE, September 20, 1954, 83.

Fig. 18 - "The Rainforest," Photographed by Alfred Eisenstaedt, LIFE, September 20, 1954, 86.

Fig. 19 - "The Rainforest," Photographed by Alfred Eisenstaedt, LIFE, September 20, 1954, 96-97.

Fig. 20 - "The Rainforest," Painted by Rudolph Zallinger, LIFE, September 20, 1954, 90-91.

Fig. 21 - "Creatures of the Sea," Photographed by Roman Vishniac, LIFE, November 30, 1953, 98-99.

Fig. 22 - Creatures of the Sea," Photographed by J. R. Eyerman and Otis Barton. LIFE, November 30, 1953, 82.

Fig. 23 - "LIFE Sent Expedition to Tundra," Photographed by Fritz Goro, LIFE, June 7, 1954, 116.

Fig. 24 - "The Earth Is Born," Painted by Chelsey Bonestall, LIFE, December 8, 1952, 45.

Fig. 25 - "The Starry Universe," Painted by Chelsey Bonestall, LIFE, December 20, 1954, Front Cover.

Fig. 26 - "The Starry Universe," Photographed by Mt. Wilson and Palomar Observatories, LIFE, December 20, 1954, 89. 


\section{Introduction}

Science communication historically exists as a nexus between the bodies of professional science, the media, government bodies, and the general public. Science communication in American media became more codified in the early twentieth century as both scientists and the press realized the mutual benefits of working together to disseminate accurate, current scientific information. ${ }^{1}$ The twentieth century's two world wars, particularly the American government's investment into military scientific research during World War II and the atomic detonations that ended the war, had transformative effects on how science was perceived by the American public. In the aftermath of World War II, what science was and how it was useful in the United States became a set of negotiated communications between the American people, the government, scientists, and the press. The main vehicle for these communications until the mid-1950s was print media. ${ }^{2}$ Along with text, images were an important rhetorical tool for increasing public awareness of, and appreciation for, science as a "body of knowledge, science as a way of knowing the world, scientists as individuals, and the particular requests of support and funding that came from scientific institutions. ${ }^{3}$ In turn, public awareness of science influenced what was appropriate and beneficial within the practices of professional science. ${ }^{4}$

LIFE magazine, America's first picture magazine, was published by Henry Luce's TIME Inc., and was enormously successful during these years, when its subscription rates peaked

\footnotetext{
${ }^{1}$ Marcel C. LaFollette, Making Science Our Own: Public Images of Science 1910-1955, (Chicago: University of Chicago Press, 1990), 7-8.

2 After 1955, television access and popularity rose dramatically. See ibid and James L. Baughman, "Who Read LIFE?" in Looking at LIFE Magazine, ed. Erika Doss, (Washington, D.C.: Smithsonian Institution Press, 2001), 4445.

${ }^{3}$ Lewenstein, Bruce V. "The Meaning of 'Public Understanding of Science' in the United States After World War II." Public Understanding of Science, 1, no. 1 (Jan 1992), 45-68, 46.

${ }^{4}$ LaFollette, 4.
} 
in the decade after World War II. ${ }^{5}$ Luce's particular mission for LIFE was to advance middleclass American values through visual narratives of entertainment, culture, and progress (including science and technology), and was carried out in the editorial practices of the magazine. These included its prioritization of pictures, a narrative approach to photography, innovative layouts, a staff of well-known photographers, and differentiated sections of the magazine for publishing a wide variety of content. This thesis examines how these editorial practices communicated different images of science to the readers of LIFE between its formative years, between 1936 and 1955, and how the story of science was fitted into the larger narrative of advancing Henry Luce's vision of an "American Century." ${ }^{6}$ This time period extends from the formation of LIFE magazine to its peak circulation, as well as a formative era of popular science in the United States in the first decade of the post-World War II 'atomic age'. 7

\footnotetext{
5 Ibid, 45.

6 Henry R. Luce, "The American Century", February 17, 1941, 61-65.

7 For use of the term see "The Atomic Bomb: It's First Explosion into a New Era," LIFE, August 20, 1945, 88 and Peter Beacon Hales, "Imagining the Atomic Age: LIFE and the Atom." Looking at Life Magazine, ed. Doss, 110111.
} 


\section{Literature Survey}

This literature survey is divided into four sections, with the aim of situating the timeline and research topic into their relevant historical contexts, and to discuss this thesis's methodological approach.

\section{A) Historical Approaches to Science Images}

Smithsonian historian Marcel LaFollette's 1990 book Making Science Our Own, articulates a timeline for the popularisation of science rhetoric (including the popularisation of the words 'science' and 'scientist') and science-related images into the American mass media from 1910 to $1955 .{ }^{8}$ LaFollete's framework for analysing science in the media was a statistical analysis of nonfiction articles that included the words 'science' or 'scientists' as the author's main subject in eleven popular, moderately-priced, nationally-circulated, general-audience magazines. ${ }^{9}$ Her timeline is organized around economic and political considerations for science research: from increases in budgets and the extension of funding sources during World War I, to the consolidation of federal funding that followed Vannevar Bush's report Science - the Endless Frontier in $1945 .{ }^{10}$ She also considers the rise of American magazines as a dominant form of 'culture consumption' especially from the 1930s to the late 1950 s. ${ }^{11}$ LaFollette argues that the ingratiation of science and the American media was mutually beneficial to scientists and the American public. While the public recognised science's usefulness and placed collective faith in science's role in a "better

\footnotetext{
${ }^{8}$ Marcel C. LaFollette, Making Science Our Own: Public Images of Science 1910-1955, (Chicago: University of Chicago Press, 1990), 8.

${ }^{9}$ Ibid, 24.

${ }^{10} \mathrm{lbid}, 8-15$.

${ }^{11}$ Ibid.
} 
future," many scientists were eager to formalise participation in the media, to "attract public sympathy," and increase funding opportunities for their research. ${ }^{12}$

While LaFollette provides specific justification for her eleven magazine choices, she emphatically iterates (via statistical and image content analysis) that the material (particularly pictures) in these magazines were overwhelmingly uniform and subject to public appetites, a point that has been contested in other secondary historical literature of American print media. ${ }^{13}$ LIFE magazine is not included in her list or her subsequent analysis. Somewhat ambiguously, LaFollette uses the words 'image' and 'images' both literally and metaphorically throughout her text. For instance, the subtitle of the book is Public Images of Science, 1910-1955, which should be read metaphorically because the bulk of her content and statistical analyses are based on the text of the representative articles, not pictures.

Bruce V. Lewenstein, a historian of science communication, has published extensively on the collaborative role that the American government, the professional science community, and commercial publishing played in creating a demand for 'popular science' amongst certain audiences during and immediately following World War II. In his article, "Magazine Publishing and Popular Science After World War II," Lewenstein articulates how certain commercial and editorial decisions determined the failure or success of two popular science publications, Science Illustrated and Scientific American. ${ }^{14} \mathrm{He}$ concludes that the more structured editorial vision and targeted audience of Scientific American ultimately determined its commercial success. However, Lewenstein's conclusions rest on the rationale that interest in popular science content was not sufficiently in demand

\footnotetext{
12 Ibid, 10. Specifically, see the 1920 establishment of the Science Service financed by E. W. Scripps.

13 Ibid, 20. As an example, see Thierry Gervais, with the collaboration of Gaëlle Morel, La fabrique de I'information visuelle: photographies et magazines d'actualité, (Paris: Textuel, 2015), which is discussed later in this survey.

14 Bruce V. Lewenstein, "Magazine Publishing and Popular Science After World War II," American Journalism, 6, no. 4 (1989), 218-234.
} 
during the post-war years to support "an editorial product" aimed at a general interest audience. ${ }^{15}$ This is curious given that he acknowledges that much of the inspiration for Scientific American came from its editors' professional experience as science editors at LIFE, a general interest picture magazine. Lewenstein does not comprehensively address the role of existing general interest magazines played in this time period, nor the varieties and influence of the science content (both pictures and text) that were published in their pages. Other volumes in this section focus exclusively on scientific images as objects of historical analyses. Edited volumes covering a range of subjects seem to be the most effective way of engaging with such a large topic. The Technical Image, edited by Horst Bredekamp, Vera Dünkel, and Birgit Schneider, who are part of an academic working group at the University of Potsdam, is one such work. The contributors endeavour to create a "methodological textbook" for critically encountering technical illustration and 'imagemaking, ${ }^{16}$ analyzed according to a critical approach: including comparing images, iconological analysis, diagrammatics, and chains of representation. Gabriele Werner's discussion of the function of visual documents as both didactic and generative sources of information that are dependent on a dynamic relationship with the viewer is especially relevant. ${ }^{17}$ The Technical Image serves as a useful framework for critical engagement with images of a technical nature.

Greg Mitman and Kelly Wilder's edited volume Documenting the World: Film, Photography, and the Scientific Record focuses on the dynamic relationships between Western scientific communities and the technologies of film and photography, with a focus on perspectives of science and the varying functions of films and photographs in different,

\footnotetext{
15 Ibid, 232.

${ }^{16}$ Horst Bredekamp, Vera Dünkel, and Birgit Schneider, The Technical Image: A History of Styles in Scientific Imagery, (Chicago: University of Chicago Press, 2015), viii.

${ }^{17}$ Ibid, 9.
} 
mutable social and historical contexts. ${ }^{18}$ This volume provides an excellent model for approaching scientific photographs and films as dynamic historical objects, but it skews towards professional scientific content over popular science. There is little to no discussion of the relationship between science photography and the press in this volume.

Ann Thomas and Marta Braun (a curator and historian respectively) published the volume Beauty of Another Order: Photography in Science, a catalogue that accompanied a 1997 exhibition at the National Gallery of Canada. ${ }^{19}$ The essays therein prioritise rigorous critical historical assessments of scientific images, while focussing specifically on the medium of photography and its unique technical, material, and historical considerations. Of particular interest in this volume is Marta Braun's discussion of the history of the photography of motion, ${ }^{20}$ though Kelly Wilder's overview of photography and science, and Corey Keller's exhibition catalogue Brought to Light: Photography and the Invisible, 18401900 are also interesting introductions to the historical, technical, and cultural intersections between photography and professional science. ${ }^{21}$

Taken collectively, this literature demonstrates that there is a growing interest in science images, especially photography, as topics of historical analysis. However, there are many gaps in historical considerations of popular science images in the press: who commissioned them; how were they organised, edited, arranged, and disseminated; and what were their functions in American popular culture outside of professional science practices and formal education?

\footnotetext{
${ }^{18}$ Gregg Mitman and Kelley Wilder, Documenting the World: Film, Photography, and the Scientific Record, (Chicago: The University of Chicago Press, 2016).

${ }^{19}$ Ann Thomas and Marta Braun, Beauty of Another Order: Photography in Science, (New Haven, CT: Yale University Press in association with the National Gallery of Canada, 1997).

${ }^{20}$ Ibid.

${ }^{21}$ Kelley Wilder, Photography and Science, London: Reaktion Books, 2009, and Corey Keller, Brought to Light: Photography and the Invisible, 1840-1900, (San Francisco: San Francisco Museum of Modern Art; New Haven: In association with Yale University Press, 2009).
} 


\section{B) Histories of LIFE Magazine}

Wendy Kozol's LIFE's America, and Looking at LIFE Magazine, edited by Erika Doss (both of whom are historians of American popular and visual culture), are general overviews of the history of LIFE magazine. Both Kozol and Doss address the enduring popularity of LIFE in American culture, with Doss remarking that although it wasn't always the most commercially successful publication, LIFE had (and has) an "iconic presence and cultural prestige." ${ }^{22}$ It is worth noting that current scholarly attention, including this project, is part of the continued veneration of LIFE as a worthy subject of cultural and historical attention.

Within Kozol's volume, the third chapter, "The Kind of People Who Make Good Americans': Nationalism and LIFE's Family Ideal," addresses the instructive and nationalist undertones consistently present throughout LIFE's publication span. This chapter also critically visualises the narrow hegemony of LIFE's ideal readership through analyses of the photographs and advertisements that appeared in the magazine. ${ }^{23}$

In Looking at LIFE Magazine, James L. Baughman's article "Who Read LIFE?: The Circulation of America's Favorite Magazine" explores the dynamics of LIFE's circulation, the relevance of LIFE in Henry Luce's print media empire, and the importance of 'pass along' rates when considering the magazine's overall reach and readership. ${ }^{24} \mathrm{He}$ also considers the spaces in which LIFE was read: primarily in commercial public venues rather than in the home, which is salient when considering its audience, public perception, and cultural relevance. ${ }^{25}$ Additionally, Peter Beacon Hales' chapter, "Imagining the Atomic Age: LIFE and

\footnotetext{
${ }^{22}$ Erika Doss, “Introduction - Looking at Life: Rethinking America's Favorite Magazine, 1936-1972," in Looking at LIFE Magazine, ed. Erika Doss, (Washington, D.C.: Smithsonian Institution Press, 2001), 3.

${ }^{23}$ Wendy Kozol, LIFE's America, Philadelphia: Temple University Press, 1994, 61-64.

${ }^{24}$ James L. Baughman, "Who Read LIFE?: The Circulation of America's Favorite Magazine," in Looking at LIFE, ed. Doss, $44-45$.

${ }^{25}$ Ibid, 48.
} 
the Atom," specifically addresses scientific images in LIFE (and their complications as both objects of science and or popular culture), along the well-trodden path of research on the visual images and impact of nuclear science, nuclear- and thermonuclear devices, and atomic energy in American media and popular culture. ${ }^{26}$ These topics remain the most wellresearched areas of science imagery in LIFE, but also exemplify the need for additional research into the magazine's less well-known subjects, layouts, and photographs related to science.

On more specific subjects within LIFE, Elaine McLemore's doctoral dissertation, War in Words and Pictures: Photography and Aestheticization of Politics in LIFE Magazine, 19361972, considers the history of war photography in LIFE magazine, the influence of founder Henry R. Luce's political inclinations and visions of American exceptionalism, and the narrative role of certain sections within the magazine, specifically the photographic essay. ${ }^{27}$ This dissertation offers an excellent framework for a cultural and historical analysis of a specific concept within LIFE, and demonstrates how photography was a powerful, shifting political narrative throughout the lifespan of the magazine.

Finally, historian Alan Brinkley's biography of Luce is a thorough insight into the life of LIFE's founder and chief editor. The book also offers a comprehensive analysis of the various nuances of the publishers, editors, and influences behind the various magazines of Time Inc., including TIME, Fortune, and LIFE. ${ }^{28}$

\footnotetext{
${ }^{26}$ Peter Beacon Hales, "Imagining the Atomic Age: LIFE and the Atom" in Looking at LIFE, ed. Doss, 110-111.

${ }^{27}$ Elaine McLemore, War in Words and Pictures: Photography and Aestheticization of Politics in LIFE Magazine, 1936-1972, doctoral dissertation, Claremont Graduate University, 2013.

${ }^{28}$ Alan Brinkley, The Publisher: Henry Luce and His American Century, (New York: Knopf Doubleday Publishing Group, 2010).
} 


\section{C) Histories of the Press and Photojournalism}

Situating historical approaches to LIFE magazine within the historiography of print media is particularly relevant for this thesis. Within a generalised historiography of photojournalism, Jason E. Hill and Vanessa R. Schwartz's 2015 edited volume Getting the Picture: The Visual Culture of the News, is particularly useful because it "seeks to properly historicise the media of visual journalism in their particulars as a material and cultural practice." ${ }^{29}$ The articles are written by a variety of scholars in different fields, and cover diverse topics, but the book emphasizes its "interdisciplinary and intermedial approach." ${ }^{30}$ Of particular relevance to this thesis is Nadya Bair's “Never Alone: Photo Editing and Collaboration," which emphasizes the collaborative and multi-faceted process of photography editing. ${ }^{31}$

Also salient is historian of photojournalism Thierry Gervais' 2015 work La fabrique de l'information visuelle: photographies et magazines d'actualité (with contribution from curator Gaëlle Morel), which uses magazines and photographs in magazines as a framework for challenging dominant or traditional narratives in the histories of photojournalism and the press. Gervais organizes his study chronologically around the historical establishment and development of the magazine in news media, and highlights the origins of magazines situated much earlier than expected in the illustrated press. He also considers the importance of people who work 'in the dark' in the selection, organization, and production of news images, such as photography editors and art directors. ${ }^{32}$ Gervais' book offers a

\footnotetext{
${ }^{29}$ Jason E. Hill and Vanessa R. Schwartz, Getting the Picture: The Visual Culture of the News, (London, Bloomsbury Academic, 2015), 3.

30 Ibid.

${ }^{31}$ See Nadya Bair, "Never Alone: Photo Editing and Collaboration," both in Getting the Picture, eds. Hill and Schwartz, 228-235.

${ }^{32}$ Gervais, La Fabrique de l'information visuelle. For additional language support and clarification, Vincent Lavoie's review of this text in the journal Études photographiques was also referenced: see
} 
methodology for historically accounting for the many different people present in the production and dissemination of press images and magazines. Gervais also problematizes considerations of press photographs as objects of value in academic scholarship and art connoisseurship, which ascribe additional, alternative context to the photographic object. ${ }^{33}$ This is relevant because it highlights press photographs' mutable context, and that historical scholarship can be viewed as a kind of iconography (in the productive sense) for certain objects and subjects, such as LIFE magazine and many of its photographs.

\section{D) Visual Culture and Materiality: Methodological Considerations}

Elizabeth Edwards' and Janice Hart's 2004 volume Photographs Objects Histories: On the Materiality of Images, emphasises the material "objectness" of photographs as being worthy of historical consideration. ${ }^{34}$ As described in critiques of earlier works in this survey, ignorance of and lack of critical engagement with the materiality of photographs, drawings, and other 'illustrative' media is all too common in historical scholarship.

Other considerations of things and their 'thingness' can be found in Lorraine Daston's 2004 volume Things That Talk, which is the product of another interdisciplinary academic working group. The contributing authors treat 'things' as dramatis personae which 'talk' (historically as either icons or evidence); that produce original dialogue about their "thingness" and context, and are not merely passive or mimetic objects of outside discourse. ${ }^{35}$ Another division Daston articulates is the paradox between the "meaning and

\footnotetext{
Vincent Lavoie, "Thierry Gervais (avec la collaboration de Gaëlle Morel), La Fabrique de l'information visuelle. Photographies et magazines d'actualité, Études photographiques, Notes de lecture, October 2015; https://etudesphotographiques.revues.org/3570.

33 lbid.

${ }^{34}$ Elizabeth Edwards and Janice Hart, Photographs Objects Histories: On the Materiality of Images, (London: New York: Routledge, 2004), 1.

${ }^{35}$ Lorraine Daston, Things That Talk: Object Lessons from Art and Science, (Cambridge, Mass.: Zone Books, 2004), 10-11.
} 
the matter of a thing." ${ }^{36}$ Daston advocates transparency: "tackling the paradox head on" and "taking for granted that things are both simultaneously material and meaningful." ${ }^{37}$ Both Edwards' and Daston's methodologies offer useful frameworks for foregrounding the production and materiality of photographs in a historical context.

There remains considerable opportunity for historical scholarship of popular science images, especially as it has been used in the press. In particular, this literature survey highlights that relatively little attention has been paid to how photographers, editors, and others involved in magazine production influenced the publication of science content in magazines. While LIFE magazine has received considerable historical attention, there are still many areas that would benefit from relevant critical engagement. Accordingly, this thesis will explore how LIFE's editorial practices communicated popular science content through its pages, specifically focusing on the materiality of the magazines and the approaches of their contributors.

\footnotetext{
${ }^{36}$ Ibid, 15.

${ }^{37}$ Ibid, 17.
} 


\section{Methodology}

Popular science and press photography are two nuanced and interdisciplinary subjects. Given that the general interests of this thesis lie in popular science images in picture magazines, the first research priority has been to gain a better understanding of the subjects of scientific images in publications, specifically in popular science in the twentieth century United States, picture magazines, and press photography through their respective historiographies. This preliminary research thus comprised the literature survey discussed above. It was also important to locate a physical collection of original magazine for research purposes. Fortunately, the Ryerson Image Centre has an entire run of LIFE magazine (19361972), which formed the main collection upon which this paper's research and analysis was based.

The next challenge was narrowing the paper's focus to a specific point of view within LIFE in the immediate post-World War II era. Choosing to focus on postwar science images seemed logical, since the detonation of atomic bombs over Japan in 1945 was a key, cataclysmic event in American science, public awareness, and media coverage. While looking through LIFE, and informed from my secondary research on picture magazines, it was apparent that some sections of the magazine were an important determiner to how subjects were edited and published in LIFE. I noticed that subjects published in the 'photographic essay' and 'pictorial essay' sections of the magazine were longer than others, had more images, and that those images were often laid out in larger sizes and sometimes in colour. Image creators were often listed directly on the article's title page and in the table of contents, akin to the byline typically given authors in typical publications. Other sections such as 'This Week's Events', and topic sections like 'Science', 'Art', or 'Movies' were shorter 
articles, featured smaller, mostly black-and-white images, and were often grouped together in tighter layouts and often without image credits listed with the article. ${ }^{38}$ Based on my observations of the variety of ways that science subjects and science images were published in the pages of LIFE, I was curious about how editorial practices came to treat science content differently throughout these sections of the magazine. This question became the backbone of my research.

While looking through the different sections of the magazine's issues for science content, I discovered a series called The World We Live In that ran in thirteen issues of LIFE, from December 1952 to December 1954. The series was distinctive and featured a large number of credited creators, science subjects, and types of images, including photographs, paintings, and charts. The decision was made to use The World We Live In as a main case study for this thesis. In order to offer an alternative comparison to this science coverage, which were featured as pictorial essays in LIFE, selected science stories from other sections, particularly the 'science' topic section, serve as the other main body of work for analysis.

Each of the thirteen issues of The World We Live In were compiled and analysed by the following categories: number of pages; word count; total number of pictures; number of illustrations; number of photographs; ratios of black-and-white to colour images; and image coverage related to the text and advertisements on each page of the series. A sample of thirteen articles published in the science section of LIFE in 1952 were also compiled and analysed by page length, total number of pictures, and ration of black-and-white versus colour images.

\footnotetext{
${ }^{38}$ General image credits for LIFE magazine could always be found either within the table of contents or in a separate 'credits' section towards the back of the publication, depending on the year.
} 
Other articles, including LIFE's coverage of the atomic bomb - the first article published in each of the science, photographic essay and pictorial essays sections - supporting articles about the process of producing The World We Live In, and the inaugural issue of the magazine Scientific American were also viewed and analysed. The physical issues of LIFE were viewed in their original physical form at the Ryerson Image Centre. Issues of Scientific American were viewed and researched in the magazine's digital archive.

The analytical approach employed in chapters four through seven of this thesis draw from Elizabeth Edwards' and Janet Hart's methodology, which advocates for the materiality of photographs as physical objects in specific historical contexts, ${ }^{39}$ as well as Lorraine Daston's argument for two-sided dialogue with, rather than single-sided interrogation of, historical objects - especially those that exist outside or transcend the traditional disciplinary boundaries of art and science. ${ }^{40}$ Thierry Gervais' research on the many different contributors, such as editors, photographers, publishers, retouchers, or printers who made photography in magazines possible, ${ }^{41}$ and Erika Doss' interdisciplinary approach to covering the history of LIFE magazine, ${ }^{42}$ were also important models for the analysis of this thesis which examines how editorial practices of LIFE magazine communicated science content between 1936 and 1955.

\footnotetext{
${ }^{39}$ Edwards and Hart, Photographs, Objects, Histories, 1-15.

40 Daston, Things That Talk, 10-11.

${ }^{41}$ Gervais, La fabrique de l'information visuelle. See also Nadya Bair, "Never Alone: Photo Editing and Collaboration," both in Getting the Picture, eds. Hill and Schwartz, 228-235.

42 Erika Doss, “Introduction-Looking at LIFE: Rethinking America's Favorite Magazine, 1936-1972." Looking at Life Magazine, ed. Erika Doss.
} 


\section{Orientation:}

'Popular Science' in the Science Service, Henry Luce's 'American Century', and the Origins of LIFE in the 'Atomic Age", 1920-1945.

At the turn of the twentieth century in the United States, public attention and press coverage of scientific activity addressed questions of what was considered legitimate science and who regulated it. ${ }^{43}$ Professional scientific communities were focussed on how to disseminate 'approved' factual information to the American public, particularly in the years following World War I. 'Anti-quack' campaigns sponsored by science associations and positive coverage of the contribution that chemistry played in the war efforts were two such examples of efforts to promote 'approved' science information. ${ }^{44}$ These types of campaigns also drew attention to large institutional gaps between professional science and the press. Two back-to-back letters were published under the title "The Writing of Popular Science" in the June 2, 1922 edition of Science magazine. The first was by physicist N. Ernest Dorsey, who complained that the press was failing in their duty to educate the lay public about understanding of the relationship between variables in science and developing scientific knowledge. ${ }^{45}$ The second was by J. O'H. Cosgrave, the Sunday editor of New York's World Magazine, who bemoaned that his earnest efforts to publish "the truth" about science were consistently being hampered by the lack of writers who were qualified to relate science content, and by the failure of "American men of science" to "present their ideas in the simple language and with the clarity of expression which are so necessary if one is going to

\footnotetext{
43 LaFollette, 4.

44 The American Medical Association launched a news bureau dedicated to countering bogus medical claims in 1910. and American chemists ran a twenty-year 'Chemists' Crusade' which began in World War I. See Bruce V. Lewenstein, "The Meaning of Popular Understanding of Science in the United States After World War II," Public Understanding of Science 1, no. 1 (January 1992), 45-68, 46.

${ }^{45}$ Science was owned and published by the American Association for the Advancement of Science (AAAS). N. Ernest Dorsey and J. O’H. Cosgrave, "The Writing of Popular Science," Science 55, no. 1431 (June 2, 1922 ), 594.
} 
awaken the interest of the 'man in the street."'46 Science catered to a professional scientific audience, and the fact that these letters were published together highlights the perceived gap between institutional science and the mainstream press.

Rising costs of labour and printing, and difficulties in producing consistent, quality content, were ongoing problems in American print journalism at the turn of the twentieth century. To address them, publishers increasingly turned to syndicated material, large amounts of which could be obtained cheaply, allowing publishers to maintain the upper hand in "labour dictation" against printing and production unions. ${ }^{47}$ The syndicate model allowed for newspaper unions (which were different from labour unions) to provide content on a variety of subjects - fiction, fashion, personality and celebrity coverage, current national and world events - in a pre-filled, partially-printed format. ${ }^{48}$ Local editors would purchase these partially-filled papers and fill the rest with local news. One of the foremost exponents of the syndicate model was Edward. W. Scripps.

Scripps came from a publishing family, and by 1907 operated twenty-four newspapers across the Midwestern United States that relied heavily on syndicated content, ${ }^{49}$ but he was troubled by the lack of quality science material available to him. He wrote in 1919 that "all the best writing by men of exceptional ability on all such [scientific] subjects, appears only in scientific publications and books which are absolutely unknown to the public at large. ${ }^{50}$ Accordingly, Scripps and zoologist William Emerson Ritter founded the American Society for the Dissemination of Science (soon shortened to the Science Service) in 1921, as

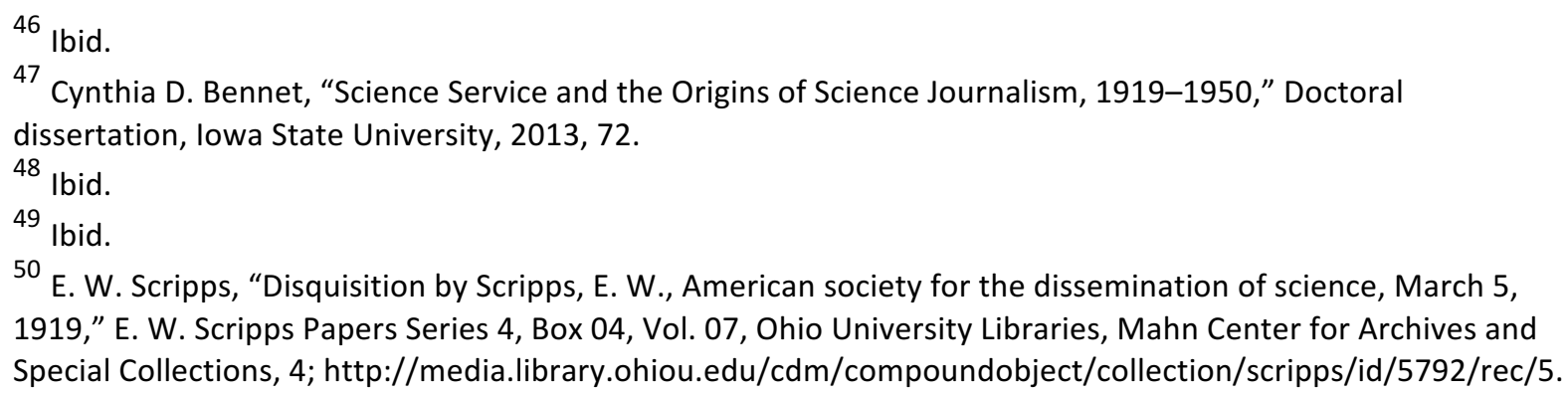


a news syndicate dedicated exclusively to science content. Elected members of the service included professional scientists, who monitored the quality of scientific content and were "encouraged to contribute articles for publication," as well as a journalist whose duty was to ensure that articles submitted for publication would "permit them to find a place in and be welcomed by the daily press and news weeklies of general circulation, as distinguished from special class circulation." ${ }^{51}$ Gaining organizational support was critical to the Science Service's legitimacy as a bridge between institutional science and the mass media. Scripps and Ritter engaged endorsements and participation from key science organizations, including the National Academy of Sciences, National Research Council, and the American Association for the Advancement of Science to bolster their legitimacy. ${ }^{52}$ To promote and sell the Science Service, Scripps employed young and dynamic salespeople, such as Hallie Jenkins, who helped to place articles, profitably, in publications such as Good Housekeeping, the Independent, and Popular Science Monthly within its first six months of operation. ${ }^{53}$

In a continued effort to expand its delivery of quality scientific content to a wider public, the Science Service also started a new weekly publication, the Science News-Letter, in March 1922. This was aimed at educational audiences, and the publisher provided subscriptions for 'personal use' to libraries, study clubs, and classrooms. ${ }^{54}$ Both the Science Service syndicate network and Science News Letter continued to grow over the next decade, so that by 1932 the Science News Letter had almost 13,000 annual subscribers, and one in three newspaper readers in the United States had an opportunity to read an article

\footnotetext{
51 Ibid, 1.

52 Dorothy Nelkin, “The Culture of Science Journalism," Society 24, no. 6 (1987), 17-25, 18.

53 For additional information on Hallie Jenkins, see Marcel LaFollette "Science Service, Up Close: Hallie Jenkins, On the Road, On her own Terms," The Bigger Picture (blog) Smithsonian Institution Archives, March 16, 2017, https://siarchives.si.edu/blog/science-service-close-hallie-jenkins. For Science Service's initial success, see Bennet, 76.

54 The hyphenated title was dropped a few years into publication. Bennet, 87.
} 
published by the Science Service on a weekly basis, according to internal reports. ${ }^{55}$ The 1930s remained profitable, and the Science Service survived the Great Depression through shrewd business tactics, while increasing its revenue, readership, and credibility. By the onset of World War II, after more than twenty years in business, it was still the world's only science service syndicate, and served approximately 200 magazines and newspapers worldwide, and its Science News Letter had 35,000 annual subscriptions by $1940 .{ }^{56}$ By coordinating efforts between professional scientists and the American press, the Science Service's aggregated syndicate and Science News Letter offered the first codified, credible, widespread dissemination of science content in the United States.

During the same first twenty years that E. W. Scripps was publishing the Science Service, another titan was building an American magazine empire. Henry R. Luce, along with his friends Briton Hadden and Robert Livingston Jr., started the magazine Time on March 3, 1923. By 1927, Time was a stable, profitable magazine that was growing steadily in circulation and popularity, and Luce and Hadden began to consider starting another publication. ${ }^{57}$ When Hadden died suddenly in 1929 , Luce consolidated, starting the business magazine Fortune as the sole head of Time Inc. in February 1930.

Fortune was not a typical business publication. Luce had a particular vision to emphasize design as a core element of Fortune, and to make it "a beautiful magazine." ${ }^{58} \mathrm{He}$ had a commitment to photography, and by employing photographer Margaret BourkeWhite began to formulate the aesthetic tastes of Time Inc. Bourke-White was relatively unknown when Luce employed her, half-time, in 1929. Her series of photographs for the

\footnotetext{
55 Bennet, 92.

56 Bennet, 104.

57 Brinkley, 123.

58 Brinkley, 151.
} 
Otis Steel Company, in which she displayed her technical skills with a large-format camera and a particularly modern aesthetic for industrial and urban scenes, caught his attention. ${ }^{59}$ Many of Bourke-White's photographs, such as those of Chicago's Swift Meatpacking Plant in the inaugural issue of Fortune, emphasized an "enthusiasm for the machine-age aesthetic" that was favoured by Luce. ${ }^{60}$ In subsequent years, Bourke-White's photography became a staple of Fortune and helped shape its aesthetic, establishing the appetite for photography that defined Luce's next publication, LIFE.

LIFE was developed in the early 1930 s by Luce from a myriad of inspirations, including the commercial success of Fortune, the layouts and design choices of earlier picture magazines such as the Berliner Illustrirte Zeitung, Vu, and Vanity Fair, the success of Luce's radio programme and newsreel The March of Time, and input from colleagues like Kurt Korff and Ralph Ingersoll. It was also partially conceived by Luce's second wife, Clare Boothe, whom he wed in $1935 .^{61}$ The young publication also benefitted directly and indirectly from an influx of European talent fleeing Nazi Germany and European political upheaval in the late 1930s and early 1940s. ${ }^{62}$ Along with Kurt Korff, this group included Kurt Safranski, who would go on to found the New York-based Black Star photographic agency that supplied LIFE with much of its early photography. Others fleeing troubles abroad were photographers Alfred Eisenstaedt, Man Ray, and André Kertész, and the veteran

\footnotetext{
59 John Robert Stromberg, Art and "Fortune": Machine-Age Discourse and the Visual Culture of Industrial Modernity, Doctoral dissertation, Boston University, 1999, 70-72. See also Gervais, La fabrique de l'information visuelle, 147.

60 Brinkley, 157.

${ }^{61}$ Korff was an editor at the Berliner Illustrirte Zeitung before fleeing Nazi Germany for the United States, and served as a consultant on the early development of a picture magazine for Luce and Time Inc. in 1934-1935. Ralph Ingersoll was an editor at The New Yorker before Luce recruited him as an associated editor for Fortune in 1930. See Brinkley, 160-161, 209.

62 Gervais, 149.
} 
photography editor Alexander Liberman, who initially joined rival publishing house Condé Nast upon his arrival in the United States in $1941 .^{63}$

Luce's general concept for LIFE hailed from the early 1930s, but the actual look, layout, and title came rather late in the magazine's development. Clare Boothe had been a proponent of the title "Life" for quite some time, but Luce was finally able to purchase the rights to the existing, financially burdened Life, a humor magazine, in early October 1936 for $\$ 92,000$, less than eight weeks before the first reconstituted issue debuted. ${ }^{64}$ The magazine went through multiple mockups in early 1936, but these struggled to achieve the level of sophistication and modernity that Luce and his editorial team desired. Early efforts were described as "sensationalist" and a "jumbled mélange of celebrity portraits and underworld scandal." ${ }^{\prime 65}$ During these initial attempts, John S. Martin, a cousin of Luce's late business partner Briton Hadden, headed the editorial team, but Luce's continued dissatisfaction with the magazine dummies and mediocre feedback from trusted colleagues, along with Martin's personal problems, led to an editorial shake-up in October $1936 .{ }^{66}$ With only a few weeks to press and many concrete issues left unresolved, Luce replaced Martin with his deputy, John Billings. Under Luce, with Billings now at the helm as managing editor and with veteran Time picture editor Daniel Longwell migrating into the same role at LIFE, things began to take shape.

The magazine debuted on November 23, 1936. At ten-and-a-half by fourteen inches, LIFE was intentionally slightly larger than many of its competitors. Continuing her work for

\footnotetext{
63 Ibid.

64 Brinkley, 215.

65 Ibid.

66 Ibid, 217.
} 
Fortune, Margaret Bourke-White's commanding black-and-white photograph of the Fort Peck Dam in Montana filled the cover (Fig. 1).

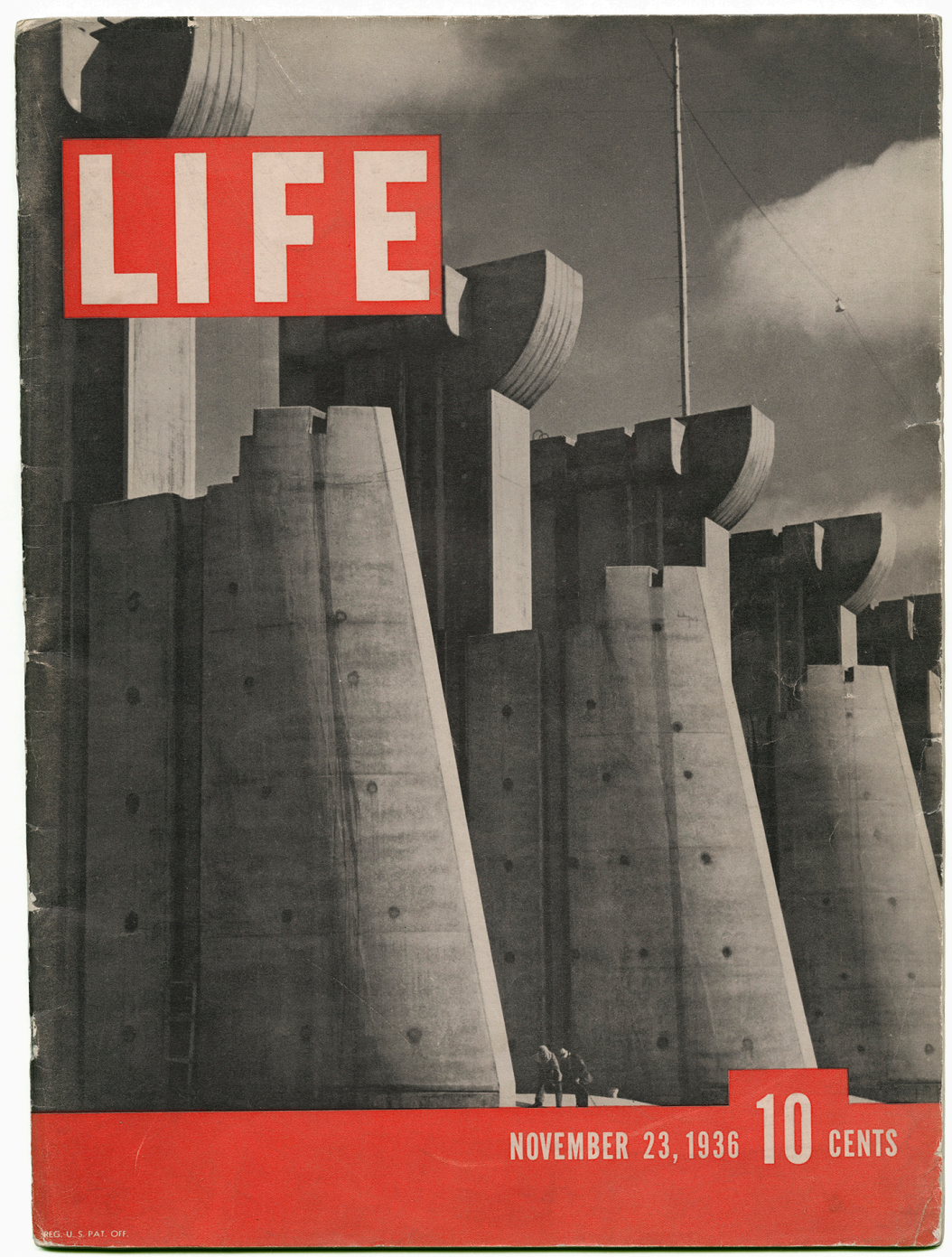

Fig. 1. "Fort Peck Dam, Montana," photographed by Margaret Bourke-White, LIFE, November 23, 1936. From the collection of the Ryerson Image Centre.

The simple red logo and lower masthead's horizontal orientation served as colorful, perpendicular graphic counterparts to Bourke-White's single photograph. The design success of LIFE's cover was influential and within a few years had spawned many copycats across various competing picture magazines. ${ }^{67}$ The rest of the first issue was also impressive: it numbered one hundred pages (including a small number in color) and was

${ }^{67}$ For a more detailed description, including illustrated examples, see Gervais 152-153. 
comprised of over 250 photographs, the majority of which were presented as sequences in balanced compositions and were often anchored by singular, dramatic images that took up the majority of a spread or page. ${ }^{68}$ Bourke-White's cover photograph accompanied a thoughtful, human-interest story about the workers and townspeople of Fort Peck, whose lives had been changed by Roosevelt's New Deal policies. The story was authored by Archibald MacLeish who, along with Luce, had a hand in writing LIFE's poetic prospectus: "To see life ... and to take pleasure in seeing; to see and be amazed; to see and be instructed..." honed the editorial vision for the fledgling magazine. ${ }^{69}$ The magazine's exaggerated size, layout, and number of pictures emphasized the physical pleasure of seeing the magazine and turning its pages. Looking at LIFE was meant to be a seductive, tactile, and entertaining experience. Though situated as a general interest magazine, LIFE'S 'seeing' was a particular type of observation: it personified and glorified progress, modernity, and the social, political, economic development of middle-class America. Nowhere was this heralded more effectively in LIFE's inaugural issue than by the photograph on page two of the magazine, which showed a doctor in a surgical mask holding a newborn child with the caption "Life begins." "70

LIFE's first issue was remarkably successful, especially given its rather late assemblage, but the magazine took a few years to become financially viable and visually coherent: photography editor Daniel Longwell remarked that in hindsight "LIFE was not a magazine until two years after its publication. ${ }^{\prime 71}$ With hundreds of photographs published in each issue, LIFE relied heavily on both its relationships with photographic agencies such

\footnotetext{
68 Ibid.

${ }^{69}$ See Brinkley, 213-214.

70 “LIFE Begins," LIFE, November 23, 1936, 2.

71 James L. Baughman, Henry Luce and the Rise of the American News Media, (Boston: Twayne Publishers, 1987), 95.
} 
as Black Star for much of its more generic content, and on the magazine's staff

photographers who often shot the cover photographs and its leading photographic essays. LIFE capitalized on the photographers' raw talent, which it developed in the pages of its issues. In turn, some photographers became increasingly well-known via the magazine's commercial success. Luce recognized that LIFE's presentation of photographs could harness the photographer's powerful, particular point of view.

In the April 26, 1937 issue, Luce and his editorial team presented a codified vision for the role of photography in LIFE in an article called "The Camera as Essayist." Rather than merely being "a reporter" of events, the camera could "also be a commentator" and "can interpret as it presents." ${ }^{72}$ The article reinforced this authorial connection by arguing that the issue's subsequent photographs of Vassar College, by Alfred Eisenstaedt, were as legitimate and codified a narrative as the prose of Joseph Addison, and listed several key photographic essays from LIFE's early issues as further evidence. ${ }^{73}$ This perspective privileged the photographer, who could step out from behind the anonymous mechanism of the camera. Historian of photography Thierry Gervais notes that "with the advent of the photographic essay, photography is no longer presented as a window open to the world, but a representation, intimately associated with its referent." ${ }^{\prime 74}$ Though several isolated photographic essays appeared in LIFE in its first six months of publication, the photographic essay section of the magazine debuted officially in the August 30, 1937 issue. Only a minority of photographic essays were taken by a single photographer, but overall the

\footnotetext{
72 “The Camera as Essayist," LIFE, April 26, 1937, 62.

73 Ibid.

74 Gervais, 169.
} 
section gave Luce a reason to publicize and personify talented the photographers whose work was published there. ${ }^{75}$

Along with the photographic essays, Luce's vision for LIFE was codified by the escalation of America's involvement in World War II. While the United Sates didn't join the war until the Japanese attack on Pearl Harbor on December 7, 1941, Luce was keenly aware of the scope of the war from its beginning in 1939, and was eager to publicize American involvement as appropriate and necessary. In February 1941, while Franklin D. Roosevelt's government was still considering the United States' position in the international conflict, Luce published an editorial in LIFE, titled "The American Century." In it, he called for an end to the World War I-era American foreign policy of isolationism, and for the United States to claim its place as a global leader through a new type of 'internationalism', dominated by American values. ${ }^{76}$ Luce wrote that "the $20^{\text {th }}$ century is the American century ... and the issues which the American people champion revolve around their determination to make the society of men safe for the freedom, growth, and increasing satisfaction of all individual men." ${ }^{77}$ In contrast to the military conquests of European Fascists, Luce rooted American hegemony in its cultural and technological advances, positing that "accidentally and really in spite of ourselves, we're a world power in all the trivial ways - in very human ways ... America is already the intellectual, scientific, and artistic capital of the world." ${ }^{78}$ Further, as a result of this perceived dominance, Luce argued that American internationalism was necessary and benevolent: "we must undertake now to be the Good Samaritan of the

\footnotetext{
75 Ibid. For a detailed discussion of the photographic essay category in LIFE, see Gervais, 165-184.

76 Henry R. Luce, "The American Century", LIFE, February 17, 1941, 65.

77 Ibid, 64-65.

78 Ibid, 65. Note Luce's calculated use of the words 'trivial' and 'human' to differentiate the American position from the 'monstrosities' of Hitler.
} 
world." ${ }^{79}$ Luce foresaw a global future formulated around the particular brand of American capitalism and social values which were touted in the pages of LIFE; "a picture of an America which will send out through the world its technical and artistic skills. Engineers, scientists, doctors, movie men, makers of entertainment, developers of airlines, builders of roads, educators. Throughout the world these skills, this training, this leadership is needed and will be eagerly welcomed." ${ }^{80}$ His 'call to arms' was cultural and scientific, not just military, and based on his vision of American exceptionalism.

The devastating attack on Pearl Harbor in December 1941 was a convenient development of Luce's brand of American internationalism. The unprovoked attack launched the United States into the war and offered the government, the American public, and the media an uncomplicated, dominant narrative of 'victory culture' to unite behind. ${ }^{81}$ Luce and his editors worked diligently to promote this narrative throughout the war. Historian of art Elaine McLemore writes that "LIFE's photographic essays represented a form of political imagining that thrived during World War II ... Luce used his magazine as mouthpiece for his beliefs and, while LIFE chose to publish images that reflected the talent, training, and intention of photographers, their selections supported the magazine's corporate, editorial, and cultural demands." ${ }^{82}$

Science topics suited Luce's wartime narrative. In an article titled "Science and the Future," published in the October 20, 1941 issue, the magazine lauded the recent discoveries of atomic energy, molecular biology, photosynthesis, and astronomy, but

\footnotetext{
79 Ibid.

80 lbid.

${ }^{81}$ For a more detailed analysis of the concept of 'victory culture' see Tom Engelhardt, The End of Victory Culture: Cold War America and the Disillusioning of a Generation, (Boston: University of Massachusetts Press, 2007), and Elaine McLemore, "War in Words and Pictures: Photography and Aestheticization of Politics in LIFE Magazine, 1936-1972," Doctoral dissertation, Claremont Graduate University, 2013.

82 McLemore, 1-3.
} 
cautioned that "in this hour of imminent triumph, science is threatened by a terrible perversion of its powers, launched by a dictatorship that denies the freedom by which science lives." ${ }^{83}$ It is no small irony that the developing atomic science that LIFE so vigorously praised would shortly be used by the United States to end the war and cause catastrophic loss of life. Luce's definition of 'perversion' of science was in its betrayal of democracy rather than its human consequences.

A new scientific and social American landscape began with that cataclysmic ending to World War II. Science definitively proved its worth to the American war effort and introduced a new era of uncertain peace and progress: the atomic age. ${ }^{84}$ Few subjects in American history have been covered more comprehensively than the socio-political, scientific, and cultural events preceding and following the two atomic bombs dropped on Hiroshima and Nagasaki in the first week of August $1945 .{ }^{85}$ What the public saw in the aftermath was principally informed by media coverage. Peter Bacon Hales remarks that "to the people of Japan and to most of the peoples of the world, the dominating image of the atomic age is one of holocaust - horrible pictures of blindness, deafness, pain, disease, loss, and death ... but the dominant American version of the atomic age was a presentation for a

\footnotetext{
83 "Science and the Future," LIFE, October 20, 1941, 74.

84 "The Atomic Age," LIFE, August 20, 1945, 32.

85 Cynthia Kelly, Bruce Cameron Reed, and Richard Rhodes have written excellent histories of The Manhattan Project. Paul Boyer has written a thorough account of the fallout and cultural legacy of the atomic bomb in the United States. Peter Bacon Hales has covered the photographic iconography of the atomic bomb and its publication in LIFE. John O'Brian has examined pictures of atomic energy in a sociocultural context: see Cynthia Kelly and Richard Rhodes, The Manhattan Project: In the Words of Its Creators, Eyewitnesses, and Historians, (New York: Tess Press, 2010), Bruce Cameron Reed, The Physics of the Manhattan Project, (Berlin: SpringerVerlag GmbH, 2015), Richard Rhodes, The Making of the Atomic Bomb, (London: Simon \& Schuster, 2012), Paul Boyer, By the Bomb's Early Light: American Thought and Culture at the Dawn of the Atomic Age, (New York: Pantheon, 1985), Peter Bacon Hales, "Imagining the Atomic Age: LIFE and the Atom," in Looking at Life Magazine, edited by Erika Doss. Washington, D.C.: Smithsonian Institution Press, 2001, 102-115, and John O'Brian and Jeremy Borsos, Atomic Postcards: Radioactive Messages from the Cold War, (Chicago: Intellect, University of Chicago Press, 2011).
} 
witness, a passive consumer located at some distance, protected and privileged. ${ }^{\prime 86}$ In this American framework, the single, iconic image of the mushroom cloud "rising above enemy lands, paradise islands, or wasteland deserts" is an oft-repeated visual narrative throughout the mainstream media, representing the distanced, dualistic presence of victory and destruction. ${ }^{87}$ The mushroom cloud imagery was a considerable part of LIFE's initial coverage of the bombings. In the August 20, 1945 issue of LIFE, directly above the blaring title "The War Ends" in the current events section, the editorial team chose to lead off their coverage with an illustration of the bombing of Hiroshima (Fig. 2). The caption read "This drawing show more graphically than the aerial photographs (pp. 26-27) effect of atomic bomb hit on Hiroshima, smoke billows at 40,000 feet." ${ }^{88}$ The article followed with two large, full-bleed, blurry, black-and-white aerial photographs, one of each mushroom cloud over the cities of Hiroshima (Fig. 3) and Nagasaki (Fig. 4).

\footnotetext{
${ }^{86}$ Peter Beacon Hales, “Imagining the Atomic Age," 103-104.

87 Ibid, 105.

88 "War's Ending" LIFE August 20, 1945, 25.
} 


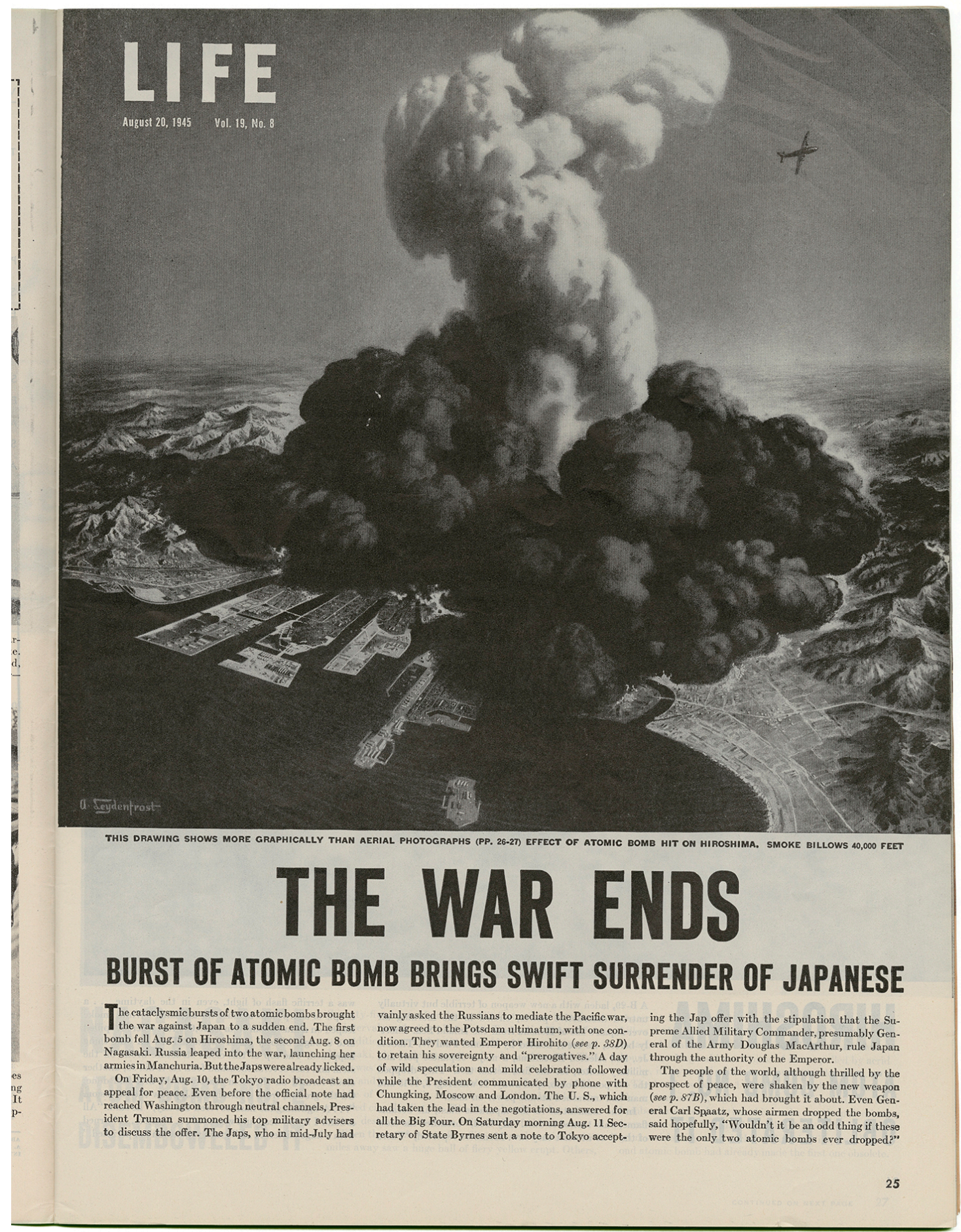

Fig 2. "War's Ending," Drawn by E.G. Leydenfrost, LIFE, August 20, 1945, 25. From the collection of the Ryerson Image Centre. 


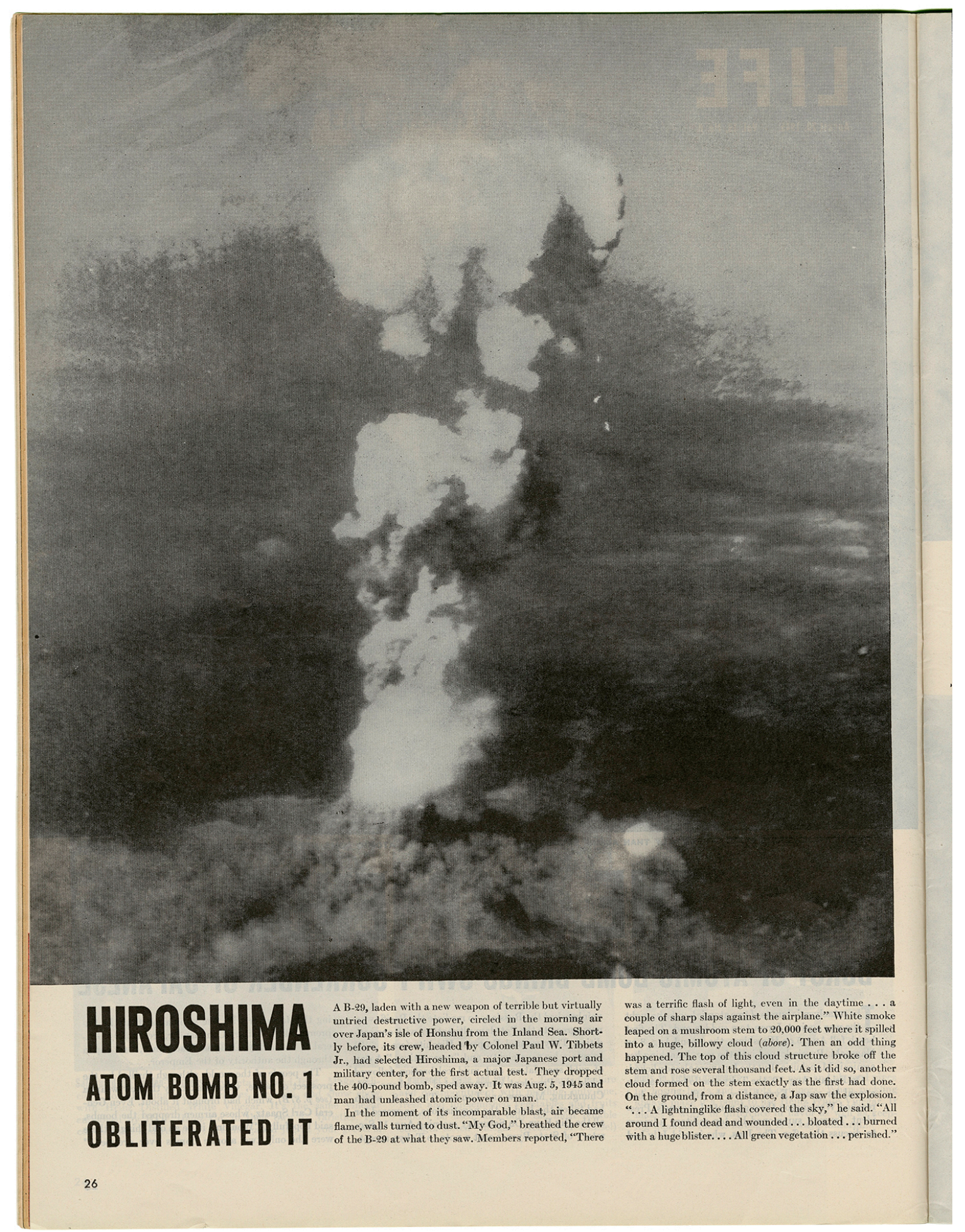

Fig. 3. "War's Ending," Photographed by United States Army Air Force, LIFE, August 20, 1945, 26. From the collection of the Ryerson Image Centre. 


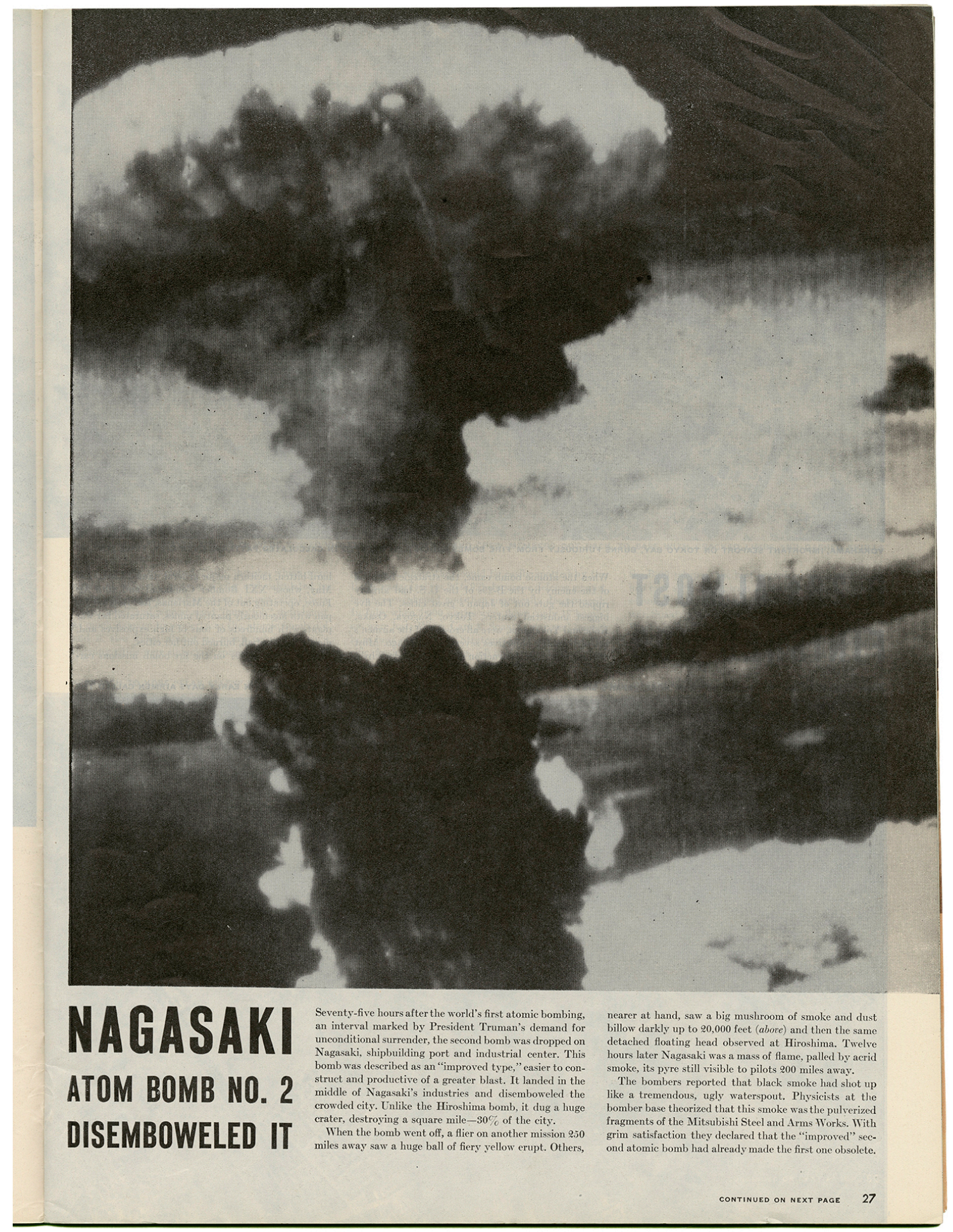

Fig. 4. "War's Ending," Photographed by United States Army Air Force, LIFE, August 20, 1945, 27. From the collection of the Ryerson Image Centre. 
After the mushroom clouds, four smaller, half-page landscape black-and-white photographs were laid out symmetrically across two pages, showing aerial views of seaports of Yokohama and Kobe, where B-29 bombers dropped additional smaller bombs as a part of the larger campaign. The article concluded with two more large black-and-white photographs of Hiroshima's harbour, one before the atomic bomb was dropped, and the other showing large amounts of visible destruction in its aftermath. The photographs in this article serve as the evidentiary witness to the bombings, while the graphic drawing combines the perspectives of the photographs into a single coherent visual narrative. LIFE editors used the photographs to provide a testament to what happened, emphasizing the drama and immediacy of the action from the perspective of the bomber midair. Meanwhile, in the drawing, the Hiroshima harbour and its surrounding landscape is small and identifiable, but is obscured by a gigantic, bulbous cloud of black smoke that pales as it rises into the sky away from the city. In the upper right-hand corner, a plane wheels away from scene, victorious in its mission. The drawing synthesizes each of the photograph's individual perspectives and the separate bombings into a single mushroom cloud, which in turn becomes definitive imagery of American dominance and the war's ending. The subject matter is further unified through repetition in the page layout of the article. Each page features a portrait, black-and-white, three-quarter page image presented in succession with similar headline and text placement along the bottom quarter of each page. In each image, the mushroom cloud is centred and maintains an aerial perspective in both the photographs and the drawing. This perspective reinforces the physical and metaphorical distance between victory and defeat, and allowed American readers to 'witness' the bomb without facing its horrific consequences on the ground. 
Along with the mushroom clouds that lead off its coverage of the war's ending, the August 20, 1945 issue's two photographic essays devoted themselves to the science behind the atomic bombs. Titled "The Atomic Bomb: It's First Explosion into a New Era" and "The Manhattan Project: Its Scientists Have Harnessed Nature's Basic Force," the essays used photographs, drawings, and charts to give readers a basic understanding of uranium, plutonium, and subatomic physics that developed the atomic bombs. ${ }^{89}$ This victorious result of scientific effort was presented in the article as "the result of high intellectual and moral courage, sacrifice, and utopian planning." ${ }^{90}$ This narrative was further legitimatised in the second photographic essay by a spread of eighteen black-and-white portraits presented in two symmetrical grids on each page, reminiscent of a high school yearbook, that traced the scientific lineage of the atom back to Sir Isaac Newton (Fig. 5).

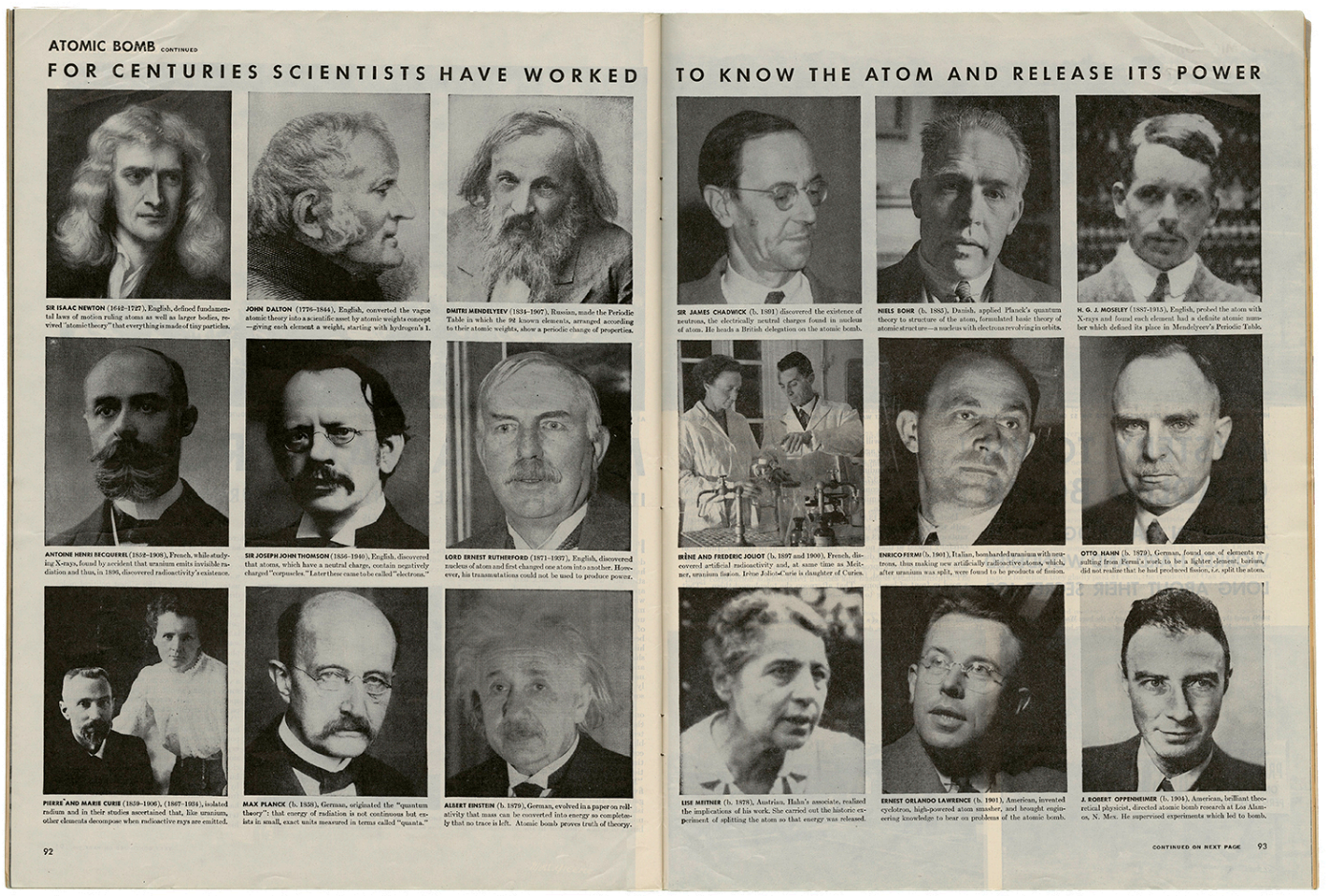

Fig. 5. "The Atomic Bomb: It's First Explosion into a New Era," Photographed and illustrated by B. B. Culver, Lotti Jacob, Alfred Eisenstaedt, Fritz Goro (as F. W. Goro), Peter Stackpole, et al., LIFE, August 20, 1945, 92-93. From the collection of the Ryerson Image Centre.

\footnotetext{
89 "The Atomic Bomb: It's First Explosion into a new Era," LIFE, August 20, 1945, 87C.

90 Hales, 108.
} 
With the exception of two double portraits, each picture is cropped similarly to a vertical bust of each scientist with a short biography listing names, background, and professional contributions underneath the image. The layout establishes a 'family tree' for atomic science; a way to personify and legitimize this particular scientific work back hundreds of years.

The photographic essays' other images are artful portrayals of men at work in the service of scientific progress. A high contrast, full page photograph of the Van de Graaff generator designed at MIT visually registers only vague circular shapes, reminiscent of atoms atop a column, and the silhouette of a man on a ladder, who is reflected against the interior wall of the generator (Fig. 6). This is paired with half-page vintage photographs made by Fritz Goro six years prior, in 1939 , which show scientists in pensive conversation at the Columbia University Cyclotron and the dramatic, tightly framed view of the screen of the voltage indicator at the moment it registered the voltage peaks of ${ }^{235}$ Uranium-235 atoms splitting. The subtitle reads "Many years of atom smashing preceded bomb." ${ }^{91}$ The theme and layout are replicated similarly on the next spread, this time with drawings by Matt Greene showing the next stage in atomic progress. On the left page of the spread is a full-bleed, dramatic, dusky drawing of the first trial bomb atop a latticed metal tower near Alamogordo, New Mexico (Fig. 7).

91 “The Atomic Bomb: It's First Explosion into a new Era" LIFE, August 20, 1945, 89. 


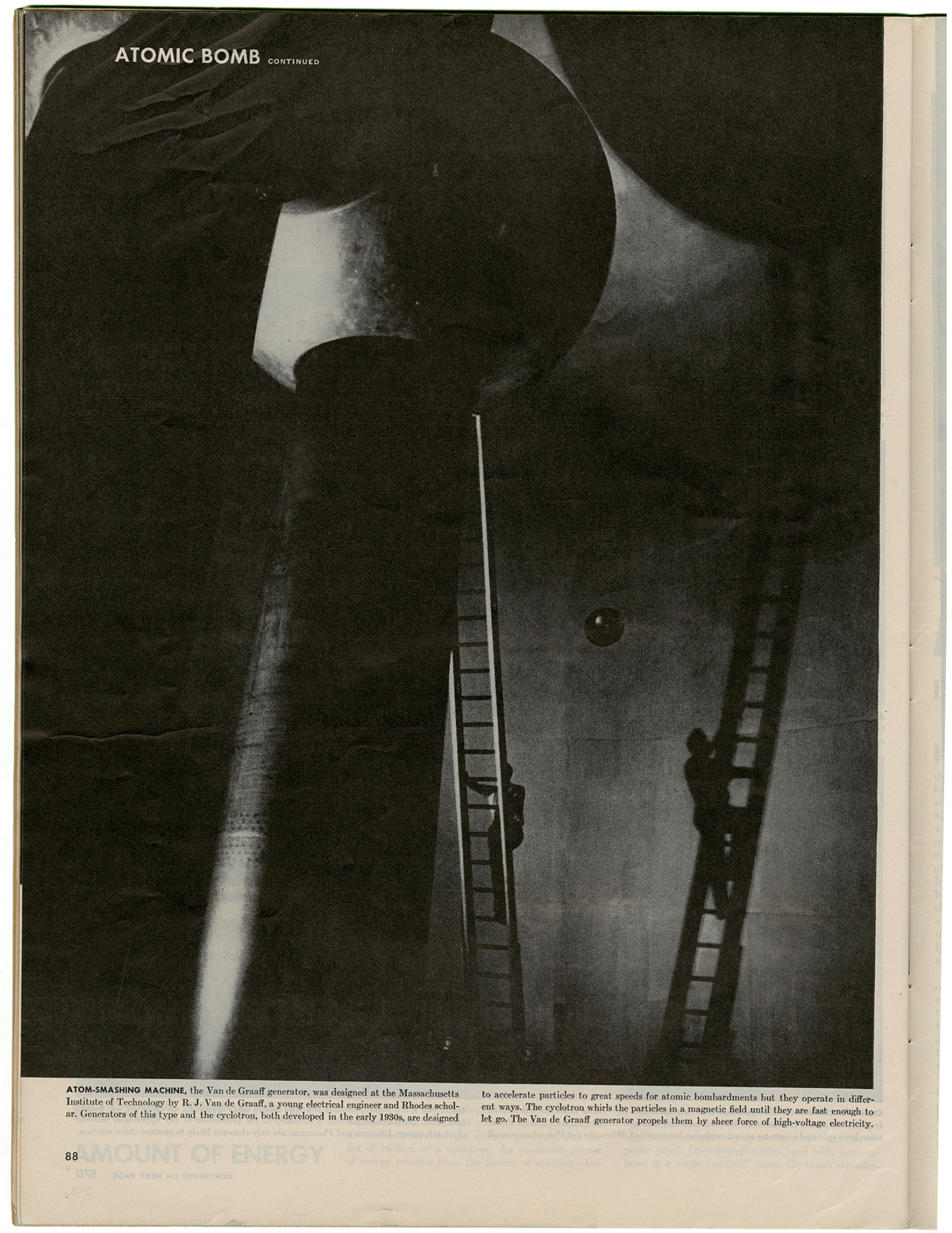

Fig. 6. "The Atomic Bomb: It's First Explosion into a new Era," Photographed by Fritz Goro, LIFE, August 20, $1945,88$. From the collection of the Ryerson Image Centre. 


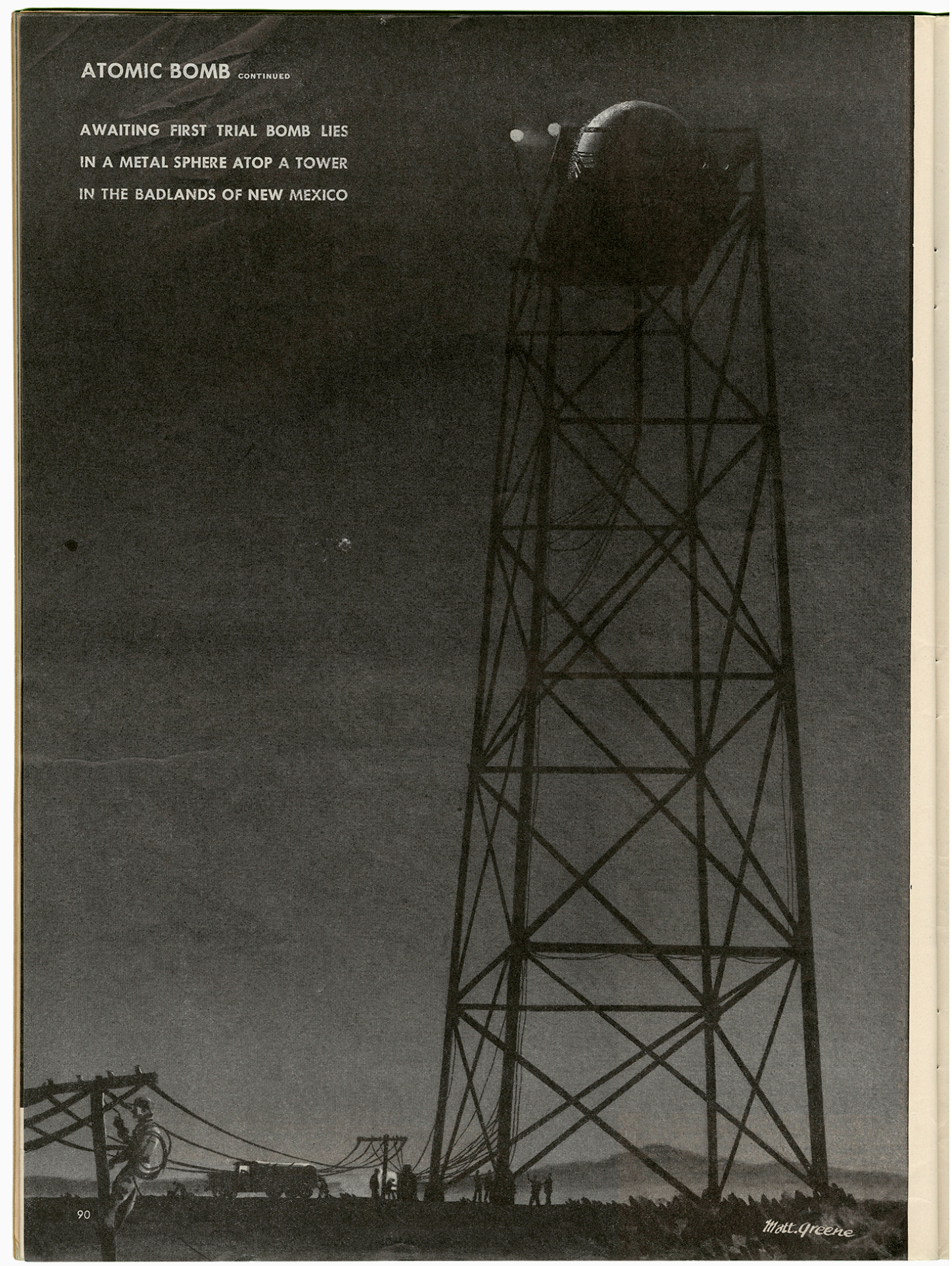

Fig. 7. "The Atomic Bomb: It's First Explosion into a New Era," Photographed by Fritz Goro, LIFE, August 20, 1945, 90. From the collection of the Ryerson Image Centre.

Tiny silhouettes of men working on electrical wiring can be made out along the bottom edge, but they are dwarfed by the size and scope of the tower. The bomb itself looks almost 
planetary and is only partially visible through the inky black night, suspended prior to detonation near the upper edge of the drawing. The dramatic tonal ranges and heavy contrast in Goro's photograph of the Van de Graaff generator and in Matt Greene's drawing of the Alamogordo test site heighten the drama of the narrative buildup to the bomb's explosion. The two images' artistic composition of anonymous, tiny humans next to giant scientific instruments fortify the physical presence and impact of atomic energy in the narrative of scientific progress. The human silhouette becomes an 'everyman' representation for the numerous people who contributed to the advancements of atomic energy.

The facing page continues with a description of the first explosion in New Mexico. The upper half of the page features another Greene drawing of masked scientists flattened against the earth, backs illuminated by the blinding flash of the test bomb. A headline below reads "Manhattan Project: Its scientists have harnessed nature's basic force." ${ }^{92}$ The remainder of the page is divided into three columns, the outer two devoted to a textual account describing the vivid experience of the first bomb test. The middle column features an additional illustration, portraying the aftermath of the blast. Greene's final drawing is familiar subject matter, a depiction of the first mushroom cloud rising above the desert. The mushroom cloud provides a visual connection of the timeline of events between the detonations of the test bomb in Alamogordo and the two bombs over Hiroshima and Nagasaki. These two photographic essays establish and legitimize a story of scientific progress of atomic energy, and American scientists' mastery of atomic energy parallels the triumphant narrative of America's military victory over Japan. Parsing the science used in

92 Francis Sill Wickware, “Manhattan Project: Its Scientists Have Harnessed Nature's Basic Force” LIFE, August 20, 1945, 91. 
constructing the atomic bombs further reframed them as productive objects of scientific inquiry rather than only as weapons of mass destruction. The current events and photographic essays sections of LIFE were two of the three most common categorizations of science in the magazine through the end of the war.

Articles in the August 20, 1945 issue function in tandem to convey a visual narrative of the triumph of atomic energy. The current events section depicts the mushroom cloud as a lasting visual icon of the atomic bomb's military victory in World War II, while the photographic essays establish American scientists' mastery of atomic energy in the service of scientific progress. This narrative of scientific progress in turn serves the more generalized agenda of American dominance that was consistently promoted by Luce and his editorial team throughout the pages of LIFE. 


\section{Audience}

Editing Scientific Content, Communicating through Images, and the 'Technocratic Elite' in the Science Section of LIFE

The bombings in Japan marked a public end to the war, but they also brought to light several years' worth of covert research under The Manhattan Project and other military projects. The American Government's wartime investment in scientific research now had political, social, and economic potential in the postwar era, upon which the administration was eager to publicize and capitalize. In November 1944, President Franklin D. Roosevelt sent a letter to Vannevar Bush, the Director of the Office of Scientific Research and Development for the U.S. government, requesting his recommendations on some key points in the general developments of science and science communication identified during the war years. They included:

1) Making the public aware of the positive and successful contributions of science and scientists to the war effort, knowledge of which could be used to stimulate new industry efforts and job growth;

2) Increased contributions to advancements in medicine and public health;

3) The scope of government participation and the role of government funding in scientific research; and

4) "Discovering and developing" an appreciation for science in America's youth to ensure a consistently bright future for American scientific research. ${ }^{93}$

Bush's answer was a report to Roosevelt's presidential successor, Harry S. Truman, entitled Science - the Endless Frontier, delivered in July 1945, mere weeks before the atomic

\footnotetext{
93 Franklin D. Roosevelt, Copy of letter from Franklin D. Roosevelt to Vannevar Bush, November 17, 1944. In Ava Helen and Linus Pauling Papers, Oregon State University Libraries Special Collections and Archive Research Centre, 1-2;

http://scarc.library.oregonstate.edu/coll/pauling/war/corr/sci13.006.4-roosevelt-bush-19441117-01.html
} 
bombs were dropped. In his report, Bush articulated that scientific research must now be a civic (rather than military) "freedom of inquiry" based on "curiosity for exploration of the unknown" with a "healthy competitive scientific spirit," and must remain unbridled by the constraints of specific application or government regulation. ${ }^{94}$ To support this goal, Bush also recommended increases in federal funding for basic research and the establishment of a National Foundation to support research within the science industry and universities. ${ }^{95}$ Bush's perspective was not universally supported, but his approach reinforced the government's goals of expanding American influence in the fields of science and technology - specifically for maintaining domination in global affairs and in the escalating struggle for global power with the Soviet Union. ${ }^{96}$ Bush was also supported by many in the professional science community who prioritized intellectual freedom and a self-regulating approach to research and policy making.

The report was persuasive, and government funding for academic science research increased. Congress approved the formation of the National Science Foundation, a federal agency, to promote these endeavours in $1950 .{ }^{97}$ Though the foundation dispensed funds and championed scientific progress, government regulation of research was minimal. Control mainly remained within the professional scientific community who were also trusted to self-regulate. ${ }^{98}$ While scientists maintained operational autonomy from the American government, they were more beholden than ever to the public. Scientists, scientific progress, and atomic energy were frequently characterized in the mainstream

\footnotetext{
94 Vannevar Bush, Science - the Endless Frontier: A Report to the President on a Programme for Postwar Scientific Research, July 1945, Reprint, National Science Foundation: Washington D.C., 1960, 12.

95 Ibid, xix, 16.

96 LaFollette, 16.

97 National Science Foundation, "NSF at a Glance," National Science Foundation; https://www.nsf.gov/about/glance.jsp, accessed May 10, 2017.

98 LaFollette, 15.
} 
press simultaneously as heroes and antiheros. ${ }^{99}$ The scientific and technical progress of the war years and the American government's enthusiasm for a healthy science industry also drove an appeal for more science communication. Professional science now discussed public knowledge of science as a civic duty. ${ }^{100}$ Bruce V. Lewenstein writes that in the context of postwar America, many scientists thought that "if democracy were to support science, and democracy required an informed public, then the public had to be informed, whether or not it asked for information about science." ${ }^{101}$ Regardless of any latent public knowledge of science in the immediate postwar years, the American government and professional science community's contrived problem of the public understanding of science created a demand for more popular science content. ${ }^{102}$

This cause was readily taken up by commercial publishing, science associations, science writers, and educational institutions, who also stood to benefit, both intellectually and commercially, from a more informed public. These organizational bodies also functioned as conduits through which information passed from the professional scientific community to the lay public, and visa-versa. Although emerging scientific knowledge was 'translated' from its genesis in private, professional spaces (the laboratory and the academy) to areas of public consumption such as the press, the relationship between industry and public was one based on reciprocal exchange. Public opinion influenced science as much as science influenced public opinion. Marcel LaFollette writes that "what

\footnotetext{
99 See Peter Beacon Hales' discussion of LIFE's “double path" coverage of Hiroshima survivor Kiyosji Kikawa in 1947, the human effects of atomic war in Japan in 1952, and H-bomb testing casualties aboard the vessel Fukuryu Maru in 1954 for negative accounts of the consequences of atomic energy and the darker symbolic effects of science, Hales, 110-115.

100 Bruce V. Lewenstein, “'Public understanding of science' in America, 1945-1965”, Doctoral Dissertation, University of Pennsylvania, 1987, 39.

101 Ibid, 40.

102 Lewenstein, 41-49.
} 
Americans believed about science determined what they expected of it" and "what they believed about scientists affected what they allowed scientists to do."103

The American 'public' was in reality a series overlapping 'publics' across broad swaths of politics, culture, race, gender, class, profession, and education in American society. Identifying different publics was also a profitable enterprise. Commercial publishing made its livelihood out of recognizing and successfully targeting specific demographics of Americans. As science became increasingly public and relevant to American interests, so too did it become more commercially viable to the American media. Promoting scientific progress as an ideology in the postwar years became a common interest of the American government, institutional science, and certain areas of commercial publishing. However, doing this successfully amidst the diverse demographics of Americans and the competing priorities of various invested parties was no small feat. Communicating science effectively was a matter of recognizing one's audience. An editors' ability “to describe science so that each description would make sense to their readers" and "fit with that audience's general beliefs about science, [would also] enhance the publication's marketability." ${ }^{104}$

In its position as a general interest magazine, LIFE covered a wide variety of science content in different contexts. Along with occasional science coverage in the magazine's current events and photographic essays, LIFE had a series of reoccurring topic-based sections that debuted within the first year of its publication, and provided additional structure for Luce's editorial vision of the magazine. Along with the categories 'At Home', 'Abroad', and 'Sport', the 'Science and Industry' section first appeared in the August 23, 1937 issue of LIFE. Both of the science section's inaugural articles were on transoceanic

\footnotetext{
103 LaFollette, 4.

104 Ibid, 5.
} 
transport and were featured as the cover stories for the issue. LIFE's typical full-page, fullbleed cover image that week was a tightly-cropped black-and-white photograph of a spinning propeller engine taken by Clyde H. Sunderland. ${ }^{105}$ The issue's lead science story, titled "Transport Panel Board" in the table of contents, is actually a single, elaborate image covering the entire spread on pages $34-35$ of the issue (Fig. 8).

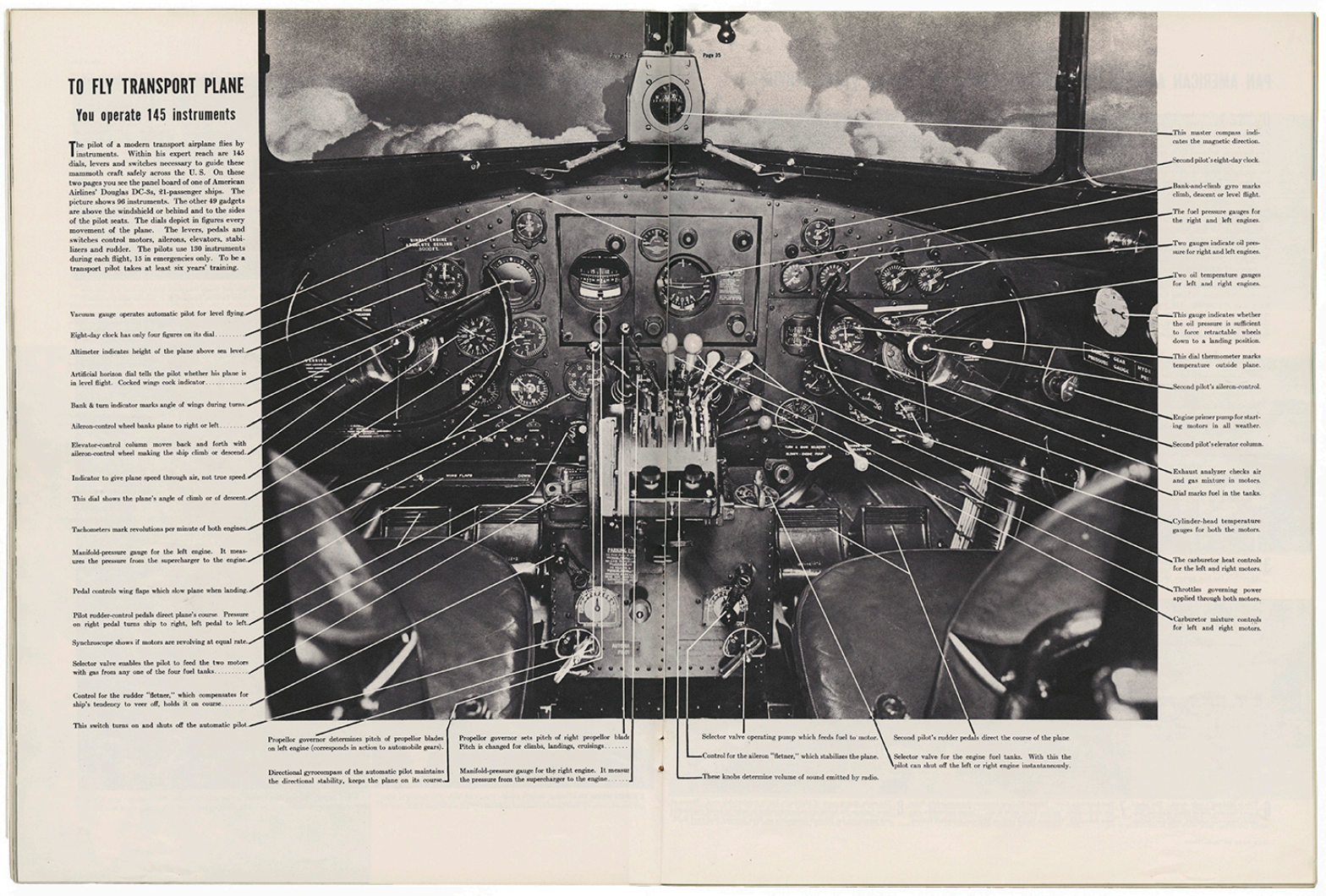

Fig. 8. "Transport Panel Board," Photographed by George Karger and Manfred Curry, LIFE, August 23, 1937, 34-35. From the collection of the Ryerson Image Centre.

The black-and-white photograph is a picture of the instrument panel board of a Douglas DC-

3 aircraft owned by American Airlines. The photograph bleeds to the upper edge of the magazine and is laid out with a uniform white margin around the remaining three sides. In the available white space of the margins, the panel's ninety-six visible instruments (of the aircraft's overall total of 145) are identified by title and function. The photograph is a wide 105 “Table of Contents," LIFE, August 23, 1937, 15. 
angle shot taken from just behind the pilot and co-pilot's seats to maximize the total number of visible instruments on the panel. This perspective also shows the lower half of the cockpit windshield. In LIFE's spread, the tops of puffy white clouds are visible through the cockpit, giving the allusion of the aircraft being airborne. This adds a sense of drama to viewing the image when one realizes that the pilot and co-pilot seats are empty and the headline at the upper left blares "To fly transport plane you [author's emphasis] operate 145 instruments." ${ }^{106}$ The resulting layout is a dizzying array of highly technical instruments and their descriptions, but also an exotic, personalized invitation to adventure in the skies.

This dual narrative was achieved through editing. The image presented in the August 23,1937 issue is actually a composite of two photographs. ${ }^{107}$ The first part of the composite, the photograph of the Douglas airliner cockpit, was taken by contributing LIFE photographer George Karger and was commissioned specifically for the issue. The second photograph, the 'cloud background', is a photograph by scientist Manfred Curry from his book The Beauty of Flight, originally published in 1932, five years prior to this issue. ${ }^{108}$ Combined together in the final spread, the annotated composite photograph conveys a realistic picture of what a pilot might see midflight, the dense technical breakdown of the aircraft's instrument panel, and a sense of drama for the average reader imagining themselves facing the same instrument panel without the six years of pre-requisite training required to actually fly such an aircraft. ${ }^{109}$ This image also introduces the 'bigger picture' of the new science section in the magazine: accurate, highly technical content edited to educate and inform, but also personify and connect with LIFE's readers through visually arresting narratives. Content

\footnotetext{
106 "Transport Panel Board," LIFE, August 23, 1937, 34.

107 The composite image is denoted in the image credits of the issue, with proper credit given to each photographer: Karger for the cockpit and Curry for the sky. "LIFE's Pictures," LIFE, August 23, 1937, 66. 108 "Transport Panel Board," LIFE, August 23, 1937, 35. 109 Ibid.
} 
presented in the science section of LIFE focused on informing readers about emerging concepts or noteworthy achievements across a range of scientific fields.

The science section appeared regularly, but not always weekly, in the pages of LIFE. Like many of the other specific topical sections, it appeared when there was content to fill it. In a sample of three different years $(1938,1945$, and 1952) spaced evenly seven years apart, the science section or a section topic related to science occurred regularly in approximately seventy percent of the issues in all three sampled years. ${ }^{110}$ Over the course of this time period, the number of science articles in these sections increased from 0.84 articles per issue in 1938 to 1.25 articles in science related topic sections per issue in $1952 .{ }^{111}$ In a sample of thirteen issues from 1952, science section articles averaged 2.2 pages long and featured 5.4 images per article. ${ }^{112}$ Within the thirteen sampled articles, eighty-one percent of the pictures were published in black-and-white and all were photographs, save for two charts. ${ }^{113}$ Pictures were incorporated into every article but their medium, number, size, and layout per story varied widely. As a generalization from the sampled articles in 1952, images were usually published at a half-page size or smaller and were laid out as single images or in a diptych.

Advertisements were either interspersed between the pages of the story or shared space on a single page. Surrounding advertisements regularly corresponded to the science section's general topic, emotional mood, visual subject matter, or layout by the editors. In his discussion of the pairings between advertisement and content related to atomic bombs within the pages of LIFE (not just the science section), Peter Bacon Hales remarks that "the

\footnotetext{
${ }^{110}$ See Appendix A, Graph 1 for more detail.

111 Ibid.

112 See Appendix A, Table 1 for more detail.

${ }^{113}$ See Appendix A, Table 1 and Graph 2 for more detail.
} 
conjunctions" of pairings between advertisements and content "ranged from pure chance to a highly complex and orchestrated program of sequencing watched over by the editors and approved by the advertisers." ${ }^{114}$ LIFE's science editors had a hand in many of these layout choices, but also had to work in tandem with the other editors of the magazine and commitments to the advertisers, who often bought (in advance) certain 'preordained' spaces and layouts set aside throughout each issue. ${ }^{115}$ The basic technical constraints and priorities of printing also played a role in determining the overall layout of the magazine, especially for essays with colour images or advertisements, whose location was determined first and was the least flexible when sequencing the rest of the issue.

As a recurring, synoptic view of a diverse array of scientific content organized around the professional fields of science, the science section in LIFE patterned itself on the syndicate model of science communication introduced by the Science Service in the early twentieth century. Articles in the science section of LIFE were concise, using plain language and simple layouts to efficiently convey meaning or introduce a new topic of understanding. This differed consistently from science coverage in other sections in LIFE, especially in text and article length. For instance, science coverage of the ongoing atom bomb tests in Nevada's Yucca Flats are reported in a 1952 article in the science section, which is three pages long. ${ }^{116}$ This particular article is longer and more lavish than the average for a science section article, ${ }^{117}$ being 290 words long and featuring a total of seven photographs, two of which are published in colour. This can be contrasted to an article on the same subject in

\footnotetext{
114 Hales, “Imagining the Atomic Age," 115.

115 See Hales' description of the Campbell's soup company advertisement for an example of this phenomenon. Ibid, 117.

116 "New Looks at the A-Bomb," LIFE, May 26, 1952, 49-52.

117 See Appendix A, Table 1 for more detail.
} 
“This Week's Events' in March 1953. ${ }^{118}$ In the latter case, the five-page article features ten black-and-white photographs, and is well over 1000 words in length. ${ }^{119}$

Scientific concepts published in the science section were scientifically and technically accurate, but also were presented simply enough to educate and connect readers to meaning. Pictures also supported this framework. Gerard Piel, LIFE'S science editor from 1939 to 1945 , noted in a 1965 interview that pictures had "two primary functions" within this kind of science journalism: to show objects and concepts of study to which science often assigned new and complicated names; and to help readers understand the relationships between things that often occurred "at complex and profound levels," since the nature of science "is concerned with ... the interaction of more than two variables" and often difficult to grasp. ${ }^{120}$

An article titled "Amputee's Gait," from the science section in the July 1, 1946 issue of LIFE, is an excellent case study of how content, photography, and advertising were interplayed by editors in the science section. "Amputee's Gait" starts on page 91 of the issue and finishes on page 95. The article's content occupies two-and-a-half of these pages, with pages 93,94 and half of page 95 devoted to advertisements. The article is comprised of three short paragraphs of text and is just 288 words long, not including title or captions. ${ }^{121}$ "Amputee's Gait" covers two areas of scientific and technical areas of interest: the first is how photographer Gjon Mili creates stroboscopic photographs to track the gait of a veteran amputee wearing an artificial leg; and the second is scientific analysis of the veteran's locomotion, tracked in Mili's photographs for therapeutic rehabilitation. By analysing Mili's

\footnotetext{
118 “A-Bomb vs. House," LIFE, March 3, 1953, 21-25.

119 Ibid.

120 Gerard Piel, interview by James Macandrew, Conversations with Editors Part III, Camera Three, WCBS-TV, July 4, 1965, on Vinyl LP, 1965.

121 “Amputee's Gait”, LIFE, July 1, 1946, 91-95.
} 
photographs, doctors are able to better understand the mechanical function of artificial limbs, which can subsequently be re-engineered or modified to better suit the patient, while also adjusting the therapeutic approach that use to teach proper balance, stride, and body position while learning to walk again. ${ }^{122}$

Each of Mili's stroboscopic photographs is a complex work of technical expertise. Mili, who studied electrical engineering at MIT, was a specialist in motion and stroboscopic photography, and regularly contributed to publications and studies on the subjects of physics and movement. ${ }^{123}$ Mili's photographs for the LIFE article were taken in cooperation with the U.S. military's Walter Reed Hospital, and were part of a larger study of motion that numbered more than 800 images by the time he took the "Amputee's Gait" photographs. ${ }^{124}$ In order to simplify the process of taking each stroboscopic photograph, the article refers to these images as "repetitive flash photographs" and explains that Mili had attached three small electric lights - one each to the hip, knee, and foot - of the veteran amputee and had used "a repetitive-flash time exposure" to track "the exact movements of these parts of the body." ${ }^{125}$ Readers are shown two half-page, horizontal black-and-white images on the first page of the article. The upper image is a stroboscopic photograph exposed to show a man with a normal gait walking forward. The caption to this image explains that the man's gait is smooth and the leg bends only slightly to absorb the body's weight while moving forward. ${ }^{126}$ The lower image is very similar, except that now the veteran amputee is shown walking forward using an artificial leg. In both stroboscopic images on this page, the

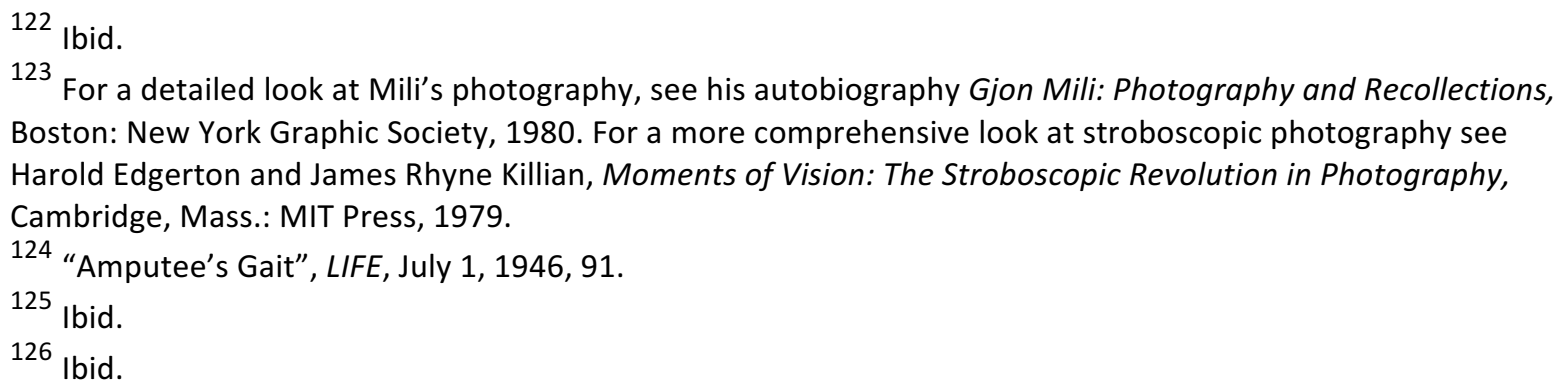


walking man and his various body parts are identifiable. Even a cursory comparison of the two photographs reveals that the stride of the amputee veteran is exaggerated compared to "the stride of the normal man"; his artificial leg is raised much higher off the ground as he moves forward. These two photographs are horizontally bisected by the title and two paragraphs of text on a narrow white band of space (Fig. 9).

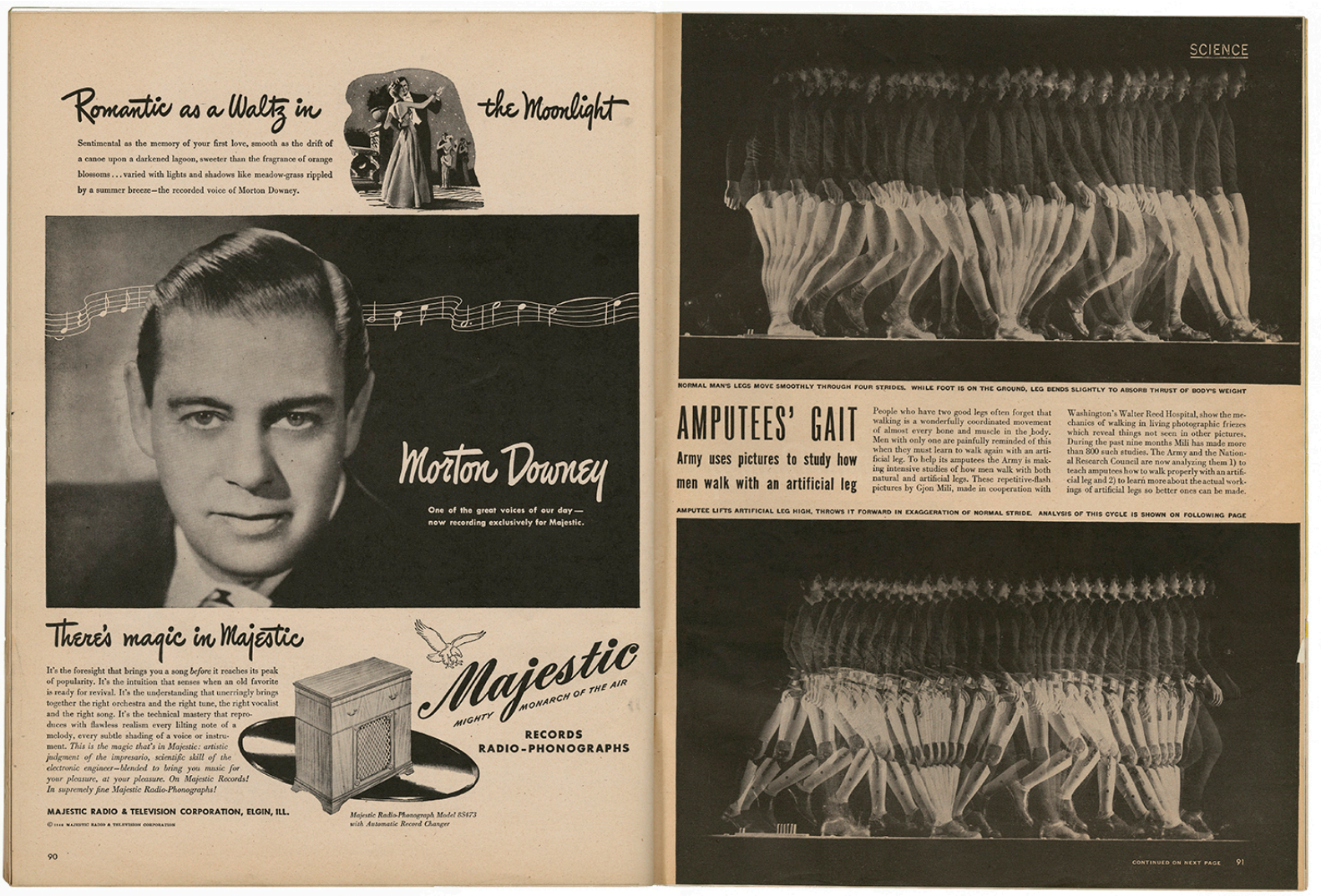

Fig. 9. "Amputee's Gait," Photographed by Gjon Mili, LIFE, July 1, 1946, 90-91. From the collection of the Ryerson Image Centre.

This layout is cheekily mirrored on the facing page by an advertisement which features an inverted layout of the article page. Two similarly wide white bands of space with text and graphics are bisected by a single half page, the portrait of singer Morton Downey against a mostly solid black background. The photograph is annotated by a drawing of a musical staff of white notes 'running through' his head in a similar fluid, forward motion to the walkers in the facing article. An additional nod to comical irony (though trending towards poor taste, 
given the subject matter on the facing page), is the text and graphics on the upper white band of the layout, which shows a drawing of young couple in eveningwear dancing gracefully while the headline in fancy script reads "Romantic as a waltz in the moonlight." The lower band of white space features a drawing of the latest model of Majestic record player (advertised as radio-phonographs), with additional information about Majestic Records and the company logo. The precise inversion of layouts along with such a darkly humorous subject paring make it difficult to believe this advertisement-article spread was merely a product of chance.

On the following page of the article, four more pictures concisely convey to the reader the second scientific concept of the article: how doctors analyze Mili's stroboscopic photographs (Fig. 10). A half-page horizontal image shows a full body view of the veteran with the artificial limb walking forward. It is almost identical to the lower photograph from the previous page, except that the exposure is now subtly darker, which allows the three light trails on the man's hip, knee, and foot to be more clearly visible. This picture establishes a baseline for the rest of the photographs in this layout, and reminds readers of what they saw on the previous page of the article.

Below, the lower half of the second page is divided into four quadrants. The upper left quadrant contains a short text summary of how the three lights helped doctors analyze the veteran's gait, and how his original artificial limb was swapped for an experimental model with an adjustable knee bolt. The veteran was photographed again walking with the artificial joint to see if there was an improvement between it and the static artificial limb. The three remaining quadrants are identically-sized stroboscopic photographs of the various tests. However, in these three photographs the man's body has disappeared and only the light trails at his hip, knee, and foot appear against a solid black background. 
Amputees' Gait continueo

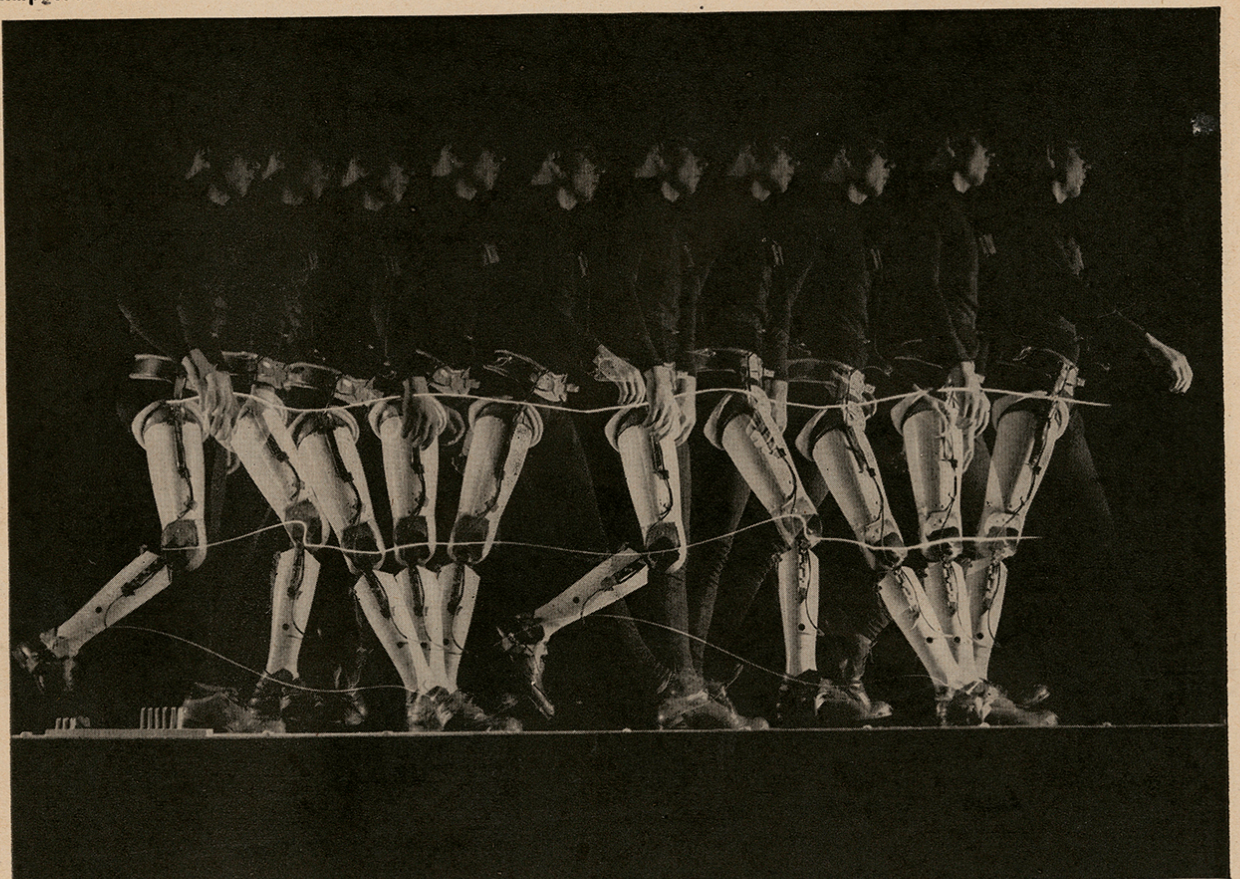

THREE WHITE LINES made by lights trace the various motions of an artificial

foot is placed on the ground. In the pictures below, which are made by the same three THREE LIGHTS ANALYZE LEG MOVEMENTS

The differences between the strides of normal men and amputees are most (1) light bulb at his hip, knee and ankle. During a repetitive-flash time exposure the bulbs trace the exact movement of these parts of the body. After study. ing these pictures, the Army doctors who worked with Mili found that the biggest difference between normal and artificial gait was that an artificial leg drops jerkily at the knee once in each step. To smooth out this jerkiness the Army men made a special experimental leg with an adjustable knoe belt.

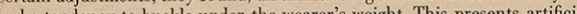
limb desing proper knee setting which will also have a locking device to prevent buckling.

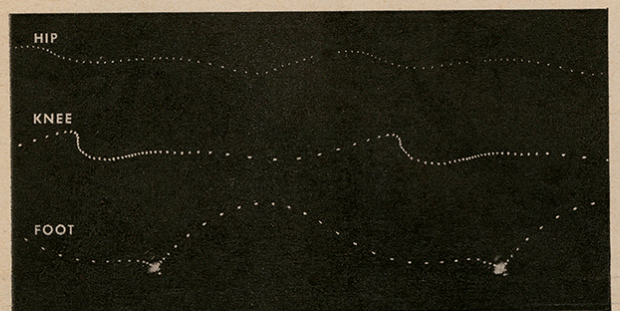

ARTIFICIAL LEG with badly placed knee bolt shows an exaggerated drop in cen: ter line with each step. This forces an amputee into a gait which is jerky and tiring.

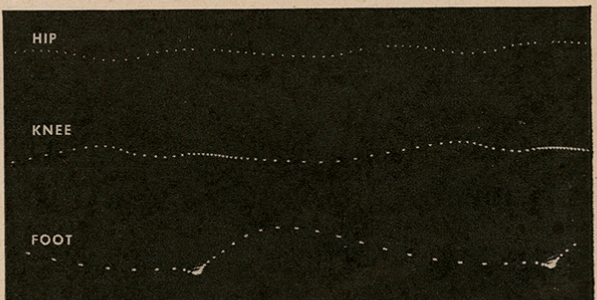
NORMAL LEG has a knee line which moves in a smooth, continuous curve. Big
curve in the middle of the bottom line is where foot is lifted to clear the ground.

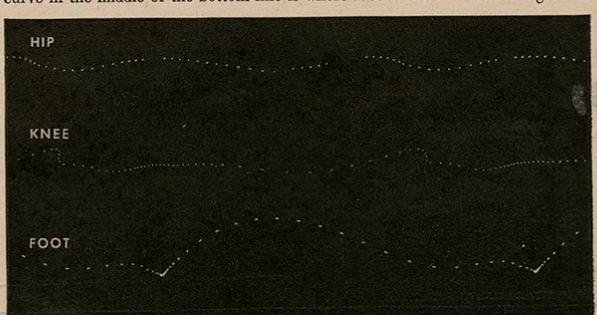

IMPROVED SETTING of knee bolt makes drop in center line smaller. High curve in the botion line shows amputee must lift foot higher than norme to d ground.

Fig. 10. “Amputee's Gait," Photographed by Gjon Mili, LIFE, July 1, 1946, 92. From the collection of the Ryerson Image Centre.

Though visually abstract, these three photographs appear the most scientifically readable in that all unnecessary visual information has been removed, leaving only the data. These three more abstract stroboscopic photographs also illuminate the photographs' different 
audiences. For the medical professional analyzing the light trails for therapeutic purposes, the photographs' beauty is arbitrary and the additional visual information to tell 'who's who' is unnecessary due to the specialist gaze. But for a more general audience, the photographs' unusual 'look' and visual allure is primary. Mili's stroboscopic photographs are eye-catching and seductive, beckoning to a casual reader flipping through the issue. One doesn't quite know what they are looking at first. Upon stopping at the page to decipher meaning, the reader relies on building a narrative between the images in the article, as well as the text, before understanding these photographs' scientific utility. By anchoring this page with the larger photograph where the amputee's body is still visible, the editor is reminding readers what the light trails represent and how to comprehend the relationship with the more abstract images below.

The three more abstract photographs were also laid out across the quadrant with this in mind. The upper right image shows the light trails of a normal leg. The bottom left image shows the first attempt with the original, fixed artificial limb. The bottom right image is the second test, showing the results of the new experimental limb with the adjusted knee bolt. In this arrangement, the three photographs can be read both left to right and top to bottom to convey the successful results of the new limb. From left to right, one sees a noticeable difference in the lights. The jerky movements of the original limb and large variations in height and depth in the light trails have been replaced by a smoother movement and more uniform light patterns as one reads right to the picture showing the improved limb. This is also confirmed by reading top to bottom, which compare the improved results to that of the baseline image of a normal leg. Here, one can see that the light patterns in the top and bottom images are very similar in sequence and depth, revealing that the artificial limb with the adjustable knee joint resembles a much better, 
more natural walking experience than the original, fixed limb. The captions on these three images are titled "normal leg," "artificial leg," and "improved setting" to reinforce this conclusion to the reader. ${ }^{127}$ The final two photographs, oriented vertically on the left half of page 95, which share space with a Noxzema advertisement, are more traditional reportage (Fig. 11).

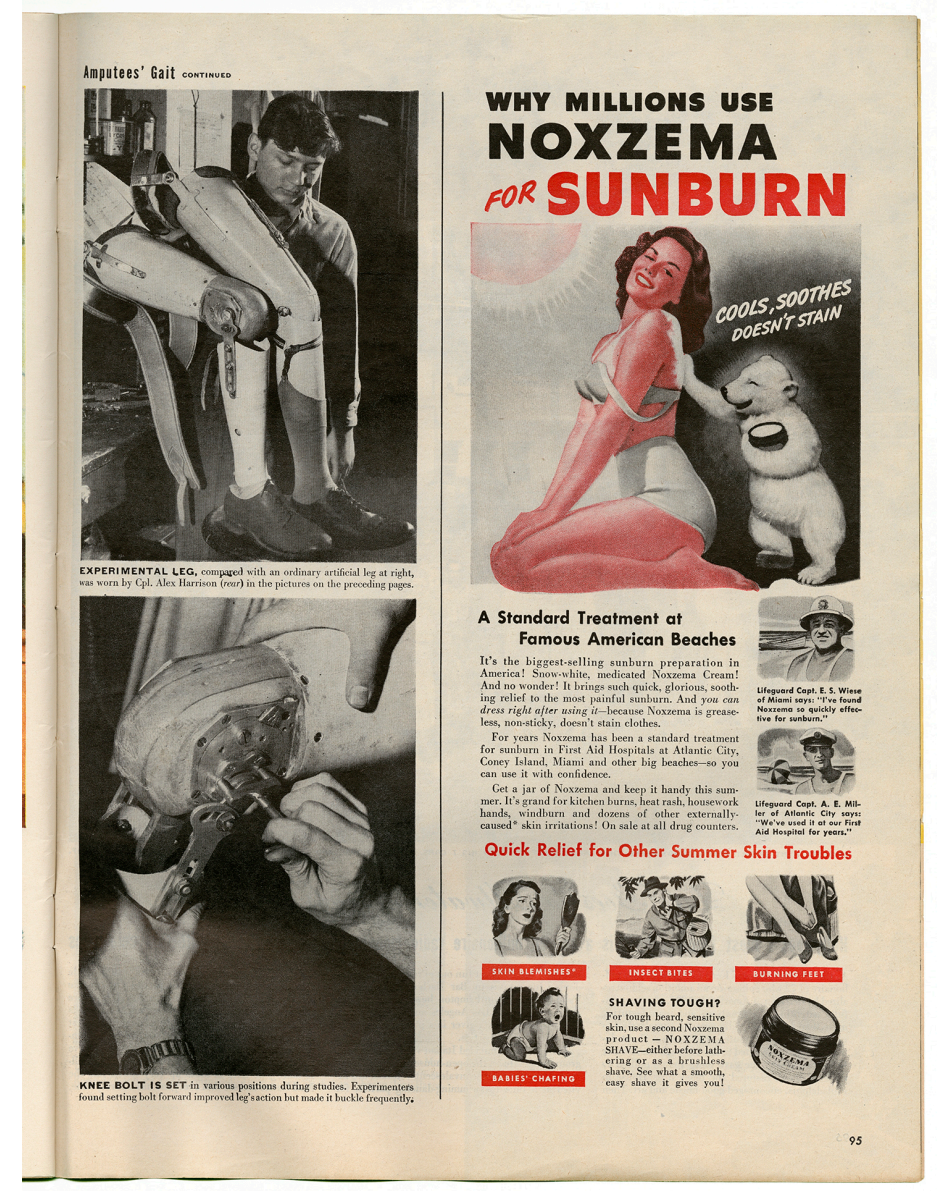

Fig. 11. "Amputee's Gait," Photographed by Gjon Mili, LIFE, July 1, 1946, 95. From the collection of the Ryerson Image Centre.

The upper photograph is a side-by-side comparison of the original and experimental artificial limbs, which are lined up next to each other for reference. The lower photograph is

127 Ibid, 92 
a close-up shot of the knee bolts in the experimental limb being adjusted, since it tended to buckle under the body weight of the wearer and merited further testing.

"Amputee's Gait" is successful on a number of levels. The limited text is informative, and concise, conforming to the typical layout in the science section. The stroboscopic photographs convey two complex, interrelated technical and scientific concepts: how stroboscopic photography functions and can be used to track movement; and how comparing these specific photographs can provide information to medical professionals who are working to improve prosthetic limbs and the physiological experience of amputees. The editorial use of photographs in these two pages achieves the two primary functions of pictures in science journalism that Piel mentioned: to simplify new technical concepts; and to foster understanding of the complex relationships between variables. ${ }^{128}$ Through exposure settings, sequencing, and layout, Mili's images function simultaneously as beautiful photographs, a droll canvas to juxtapose advertisements, bodies of scientific evidence, and a visual narrative of the experiments to LIFE readers. The technical complexities of stroboscopic photography are simplified by showing the bodies of the men walking, and allow the reader an identifiable subject in the image before reducing the exposure and the information in the image to light trails. Additionally, the complex scientific analysis of the amputee's gait with various artificial limbs is conveyed by sequencing the stroboscopic photographs of the amputee with those of a man who has a normal walking gait. Finally, the arrangement of these photographs across the two pages allows them to be read in multiple ways, which allows the reader to successfully build the narrative of the experiment, and to comprehend the relationship between the patterns of light trails and the various gaits and limbs being analysed.

${ }^{128}$ Camera Three, Conversations with Editors Part III, 1965. 
"Amputee's Gait" is an excellent example of what the science section could offer within its typical structure. Articles covered a broad range of concepts using a concise format, limited text, and strong, visually arresting narrative photographs. In this case, the photographic narrative was the one Piel identified and relied upon: to use photography to simplify technical concepts and vernacular and to help the reader successfully understand complex relationships between scientific variables.

By all accounts, this was a successful formula. Over Gerard Piel's six-year career as science editor for LIFE, from 1939 to 1945 , Bruce V. Lewenstein notes that Piel developed a "working relationship" with many scientists, and observed that "scientists of all disciplines were intensely interested in the stories he prepared for LIFE." ${ }^{129}$ This enthusiasm from the professional scientific community also raised the issue in Piel's mind that "nowhere could he find a place to read about the developments of science in a wide range of fields." ${ }^{130}$ There seemed to be a gap in the market and Piel, with his fellow LIFE editor Donald Flanagan (who served as Piel's successor and LIFE's science editor from 1945 to 1947) and businessman Donald H. Miller Jr., bought the rights to the aging, financially troubled magazine Scientific American, which had started as a four-page weekly newspaper in 1845 under inventor and publisher Rufus M. Porter. Informed by their professional experience, the partners relaunched Scientific American in May 1948, targeting the technical readers that "they had discovered reading the science section of $L I F E .^{\prime 131}$ Using the editorial practices they honed at LIFE, Piel, Flanagan, and Miller formulated a popular science magazine for a specific type of public, "the intelligent layman", directed at and using language understood "by that of

\footnotetext{
129 Lewenstein, "Magazine Publishing and Popular Science", 220.

130 Ibid.

131 Ibid.
} 
the scientist outside his own field."132 "Before the immense range of scientific knowledge," the editors noted, "all men, not excepting scientists, are laymen." ${ }^{133}$ This corresponded to the partners' practical business model, which "planned to sell subscriptions to scientists, engineers, professional workers, business owners, and executives." ${ }^{134}$

Scientific American magazine was a mix of structure and novelty that drew some inspiration from the science section at LIFE, but differed in other ways. Each issue contained articles covering the "'three main divisions' of science - physical, biological, and social - as well as stories on engineering and medicine." ${ }^{135}$ Like LIFE's science section, these articles focused primarily on summary reports of emerging concepts in science and technology. As with its narrowly defined, technically inclined audience, Scientific American editors chose not to cover other wider topic is science such as the role of science in American society and politics, economic and cultural overlaps, or epistemological dilemmas within the profession itself. For instance, developments in the understanding and application of the scientific method and issues of ethics in scientific practice were outside the scope of the magazine. ${ }^{136}$ Pragmatic concerns around budget in early issues led to a hallmark editorial policy of Scientific American. Instead of employing science journalists to write articles for the magazine, which the partners quickly realized was cost prohibitive, they invited scientists themselves to write articles on topics within their areas of expertise. Once submitted, scientists' words were then "helped" by editing and illustrations to best convey "scientific information" in plain English as a "joint effort of the best talents of scientist and journalist

\footnotetext{
132 “An Announcement to Our Readers," Scientific American 178, no. 1 (January 1948), 3; doi:10.1038/scientificamerican0148-3.

133 Ibid.

134 Lewenstein, "Magazine Publishing and Popular Science”, 225.

135 Bruce V. Lewenstein, "The Meaning of 'Public Understanding of Science' in the United States After World War II," Public Understanding of Science, 1, no. 1 (January 1992), 45-68, 51.

136 Peter Middleton, Physics Envy: American Poetry and Science in the Cold War and After, Chicago: University of Chicago Press, 2015, 200.
} 
working in close collaboration." ${ }^{137}$ Each article underwent several revisions via the in-house editorial staff, who rewrote as much as necessary "to ensure the magazine's sense of its own mission." ${ }^{138}$ Edited drafts, when returned to their original authors were accompanied by an "elegantly crafted" letter from general editor Dennis Flanagan explaining the purpose of the changes was to ensure "accessibility" to the general reader. ${ }^{139}$ This was met with a variety of reactions, from enthusiasm to consternation. However, after a series of negotiations and often accompanied by images, articles were published with consent, solely under the scientist's name. This was crucial, as it offered the magazine a degree of honesty and safeguard against the liability of error. ${ }^{140}$ Further, this editorial policy "placed the magazine within the world of science, whereas the customary journalistic stance is that of an outsider looking in."141

An editorial architecture for pictures was also key to the success of Scientific American. Like LIFE, each Scientific American cover followed a strict prescriptive format. The cover was anchored by a single, square coloured illustration on a rotating series of solid coloured backgrounds from a muted, dusky palette. Piel and Flanagan changed the existing squat, blocky logo of the trade publication to an elongated, all caps, serif typeface to reflect its new, elevated vision of science. ${ }^{142}$ The large black logo anchored the space above the image, while the lower area featured a brief description of the image subject, the price of the magazine, and the month of publication. By rotating the background colour, Piel and

\footnotetext{
137 “An Announcement to Our Readers," Scientific American, 178, no. 4 (April 1948), 147.

138 Middleton, 200.

139 Brian Hayes, “Dennis Flanagan, 1919-2005," American Scientist 93, no. 2 (March-April 2005), 1; http://www.americanscientist.org/issues/pub/dennis-flanagan-1919-2005. 140 Ibid. 141 Ibid.

142 Jen Christiansen, "Evolution of the Scientific American Logo," Scientific American (blog), March 6, 2014, Accessed on May 14, 2017; https://blogs.scientificamerican.com/sa-visual/evolution-of-the-scientificamerican-logo/.
} 
Flanagan made sure readers could distinguish between issues at a glance and its simplicity was juxtaposed against the intricacy of the illustration and the elegant script of the typefaces.

The inaugural issue in May 1948 featured articles on topics including "The Future of the Amazon," "Vesalius: Discoverer of the Human Body," "The Dust Cloud Hypothesis," "The Luminescence of Living Things," and "Smelting Under Pressure" amongst others. ${ }^{143}$ Each of the articles in the first issue was an average of four pages long, 3000 words, and included five pictures. ${ }^{144}$ Images accompanying the articles were informative but secondary to the article's text. For instance, within the 3,500-word article "The Future of the Amazon," which covers five pages near the front of the magazine, there are five photographs and one map of the Amazon river basin. Three of these photographs are small thumbnail sizes images while the remaining two photographs are larger vertical images spanning the majority of a single column on the first and second pages. The final right hand column on the fourth page and the entirety of the fifth page are devoted to a large coloured topographical map of the Amazon. While the oceans and sky above the map are blue, the map itself is black-andwhite, probably to save on the costs of printing multiple colours. The article's largest opening photograph is credited to Kurt Severin from the Black Star photography agency, while the four remaining photographs of local flora and historical buildings used in the article are credited to the Brazilian government. ${ }^{145}$ The map was made by Emil Lowenstein. ${ }^{146}$ The subject matter in the photographs provide a visual overview of topics

\footnotetext{
143 "Table of Contents," Scientific American, May 1948, 9.

144 Ibid, 9.

145 Ibid, 8.

146 Ibid.
} 
covered in the article, but are small, simplistic, and certainly secondary to the text which is highly technical and detailed by comparison (Fig. 12).

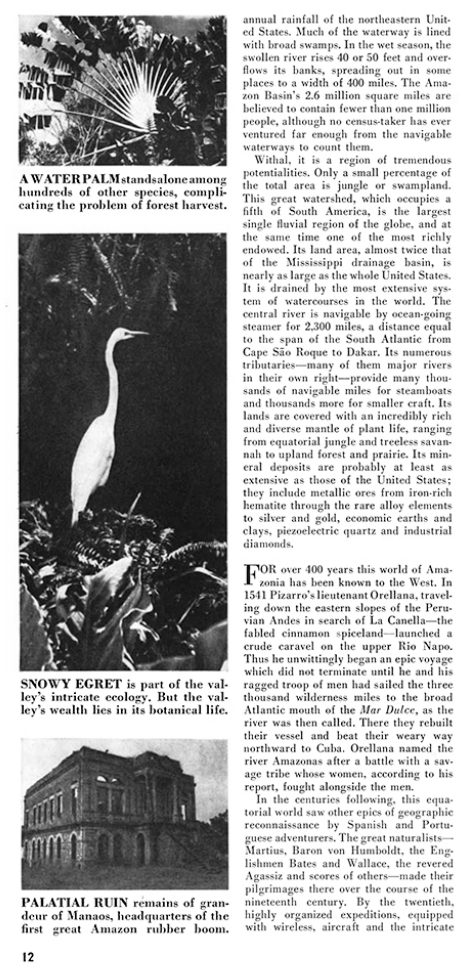

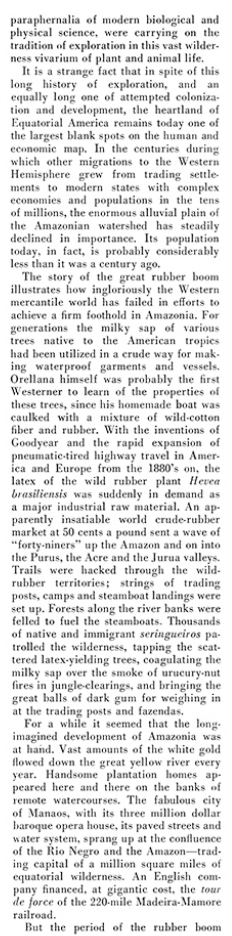

Put the period of the rubber boon
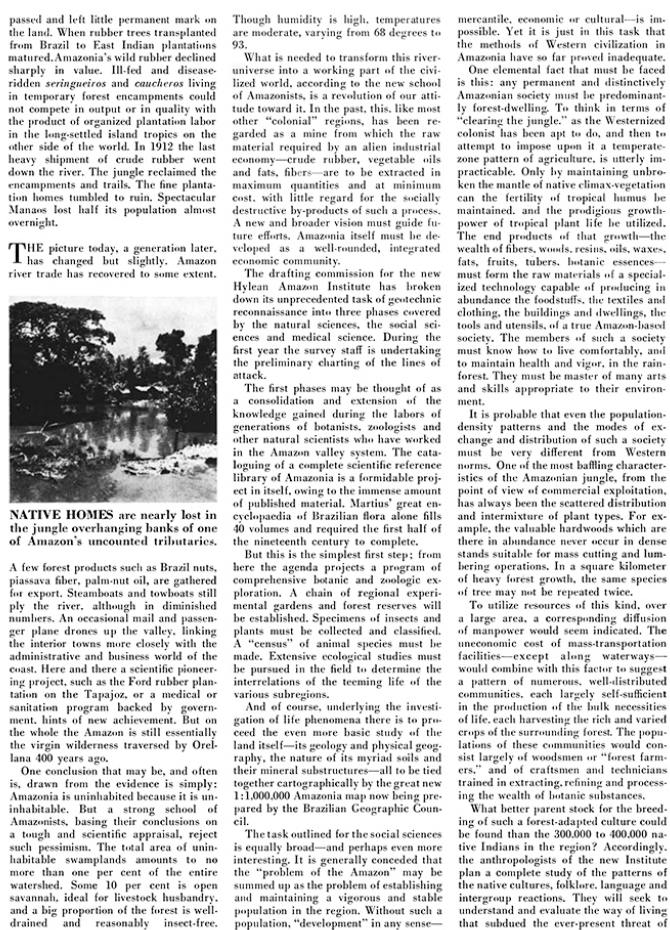

Fig. 12. "The Future of the Amazon," Photographed by the Government of Brazil, Scientific American, May $1948,12-13$.

Even the map, which is larger and more detailed than the photographs, is a simplistic view of the Amazonian waterways, with no additional annotations or visual information for how it relates to the text or general conclusions of the article. The caption for the map offers only that it is "a spherical projection from the North" depicting the "great valley" of the Amazonian river basin which covers 2.6 million square miles of the continent. ${ }^{147}$ The images featured in "The Future of the Amazon" act as an illustrative summary of some major points in the article, but their size, subject matter, and layout do not give any indication to the specific points of view or conclusions made within the article. Their creators, process, and perspectives, even the images within the layout, are meant to disappear behind a unified,

147 "The Future of the Amazon," Scientific American, May 1948, 14. 
uncomplicated objectivity where the text is paramount. As the first article in the first issue of the 'new' Scientific American, there was obviously room to grow. Scientific American would become well-known for their scientific drawings and paintings that accompanied many published articles and it was Gerrard Piel, editor for both magazines, who so clearly articulated the power of scientific images could play in translating technical content and helping viewers understand relationships between scientific variables. ${ }^{148}$ But unlike the science section of LIFE, photography never played a dominant narrative role in the early years of Scientific American and the images that it published always played a supporting role to the articles' more detailed, technical text. Piel and Flanagan drew inspiration from LIFE's cover format, from the 'syndicate' style structure of the science section, article length, and selected use of images to illustrate concepts. However, they differed from LIFE'S science section in that they ignored its dominant narrative photography component and relied on a much higher ratio of text to images, almost inverted when one compares the layouts of "The Future of the Amazon" to "Amputee's Gait." In many ways, this ratio mirrors the publication type and readership differences between the two magazines: Scientific American's entire publication was aimed at a technically literate audience within the area of professional science, whereas LIFE's single science section within a general interest picture magazine matched its smaller subset of technically elite readers within the larger strata of people who read LIFE. Yet by defining both the content and revenue streams of the publication to those with professional interests in science, Piel, Flanagan, and Miller made the "essential distinction between a mass public and a more limited audience ... 'a' public was not the same as 'the' public." ${ }^{149}$ The successful launch of Scientific American affirmed a

\footnotetext{
148 Camera Three, Conversations with Editors Part III, 1965.

149 Ibid.
} 
more circumscribed professional audience also existed amongst LIFE's readership in the immediate postwar years.

Building upon the earlier syndicated model within science journalism, the science section was a short, summary visual presentation of emerging scientific concepts and technical advances. LIFE's editorial practices of using a small amount of strongly composed black-and-white images with limited text and thoughtful sequencing to convey complex topics and make connections between scientific variables captured the interests of more technically inclined, professional audience that read the magazine. The dominant use of photography as a narrative tool employed in the science section aligned to LIFE's identity as a picture magazine and the generalized picture of technology, modernity, scientific progress as symbols of American hegemony that occurred regularly throughout its pages. 


\section{Aesthetics}

'Pass Along' Readers, Pictorial Essays, and the Adventure of Science in LIFE.

Piel and Flanagan found a particular readership of "technocratic elite" within the pages of LIFE's science section that "already existed, but had not yet found a common voice" until they created Scientific American. ${ }^{150}$ But overall, LIFE was still a general interest magazine dedicated to a wider public. While this larger audience certainly included people outside of the professional interests of science, it didn't necessarily mean encountering the mythical 'mass-circulation' public that is often tendered in historical accounts of LIFE as “America's magazine." ${ }^{151}$ Magazines were a specialized form of mass-media and enjoyed smaller rates of engagement than other mediums like newspapers, radio, film, and eventually television. ${ }^{152}$ Baughman writes that LIFE's readership "emerged as anything but representative of the national population. It was middle class, often very comfortably so ... and despite the claims of in-house publicists, only one out every four Americans regularly read Luce's most popular magazine." 153 LIFE's claim to fame was its "pass-along" factor, the highest of any mass-circulation magazine of its time. ${ }^{154}$ Baughman mentions personal memories of reading LIFE in a barbershop as a child, and that it was widely acknowledged as the ubiquitous "doctors' office magazine." ${ }^{155}$ However, he argues for a distinction between the "waiting room reader" who consumed the magazine in a much less frequent and more

\footnotetext{
150 Ibid.

151 The particular line of historiography that "everyone in America read LIFE" is misrepresentative and overly generalized. For a detailed account of who read LIFE, see James L. Baughman's appropriately titled "Who Read LIFE?: The Circulation of America's Favorite Magazine" in Looking at Life Magazine, ed. Doss, 41-54.

152 Baughman, "Who Read LIFE?," 43.

153 Ibid, 44.

154 Ibid, 42.

155 Ibid.
} 
casual manner than the "year-in, year-out" subscriber. ${ }^{156}$ Advertisers in particular were wary of speculative pass-along numbers, and made their own financial wagers calculated by differentiating between "thumbers" and "readers." ${ }^{157}$ That said, LIFE's influence was not necessarily equivalent to its number of readers, and "who read LIFE may have mattered much more than how many." ${ }^{158}$ Baughman notes that LIFE's "reliance on visual imagery" may have been a strong contributor to its wider influence. ${ }^{159}$

There has also been some ambiguity over the use of the terms 'science' and 'popular science.' Marcel LaFollette writes that "twentieth-century Americans shared not one public image of science but many," and that "scientists and journalists alike used the term science interchangeably to refer to the research process, the body of knowledge, and the professional community of scientists." ${ }^{160}$ However, LaFollette's use of the word 'image' in her "quantitative analysis of nonfiction magazine articles on science and scientists from 1910 to $1955^{\prime \prime}$ is classified around the 'mental image' of science and scientists implicit in the mutual communication between magazines and readers. ${ }^{161}$ Her subsequent analysis relies only on the titles, texts, authors, and professions from the science articles published in her sample of mass-circulation magazines. In doing so, LaFollette ignores a fundamental element from the "image of science" - the pictures themselves. Also fundamental is a consideration of who contributed to the images' creation and production - editors, artists, photographers, and others - for what purpose was the image made, and how pictures

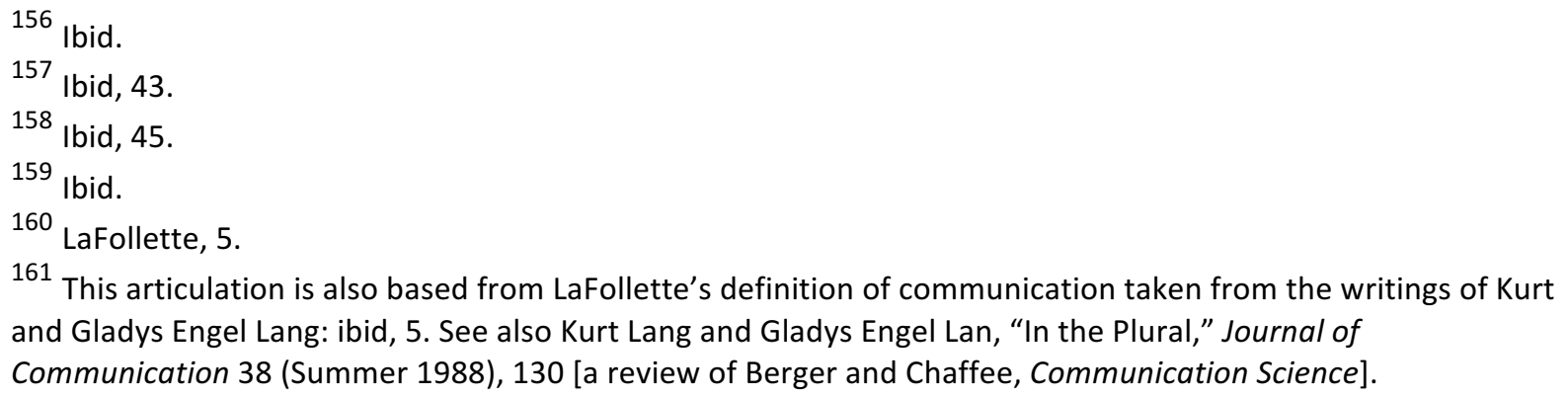


functioned alongside text within magazine layouts. Thus, picturing science communication in magazines as an historical exercise must start with the object itself, and interpreting the dynamic meanings constructed between magazines and publics must rely as much or more on the interplay of these qualitative contexts as on quantitative analysis of image subject matter or headline topics. ${ }^{162}$

A pertinent example can be found in science content that LIFE published outside of its typical 'This Week's Events' or science section headings, with the introduction of the new pictorial essay category in LIFE in March 1947. By this time, the magazine was already well known for its photographic essays, which often prioritized and personified the creative vision of the photographer or editors, and articulated a subjective, rather than objective, point of view. From the beginning, LIFE recognized the artistic and aesthetic qualities of photography and the unique styles within its stable of talented staff photographers. Thierry Gervais points out the "precise aesthetic" of Alfred Eisenstaedt that "concealed his presence as a photographer in order to emphasize the spontaneity, genuine or simulated, of characters and situations." This differs greatly to the aesthetic of Henri Cartier-Bresson, who is recognized for his "balanced compositions," or that of Gordon Parks, who was renowned for his "dense and dark production of black-and-white photographs" in gritty and dramatic locations. ${ }^{163}$ Editors too, had different aesthetic preferences and creative visions for the various sections of $L I F E$, and so every layout in any given issue was a series of creative negotiations that had to fit within the larger narrative of the section and the magazine.

\footnotetext{
162 This analysis is designed to enhance, not ignore, the already excellent work done in the field of examining and interpreting popular science content in the press by LaFollette and others. See Marcel LaFollette, Making Science Our Own: Public Images of Science 1910-1955, Chicago: University of Chicago Press, 1990, Lewenstein, Bruce V. "Magazine Publishing and Popular Science After World War II." American Journalism, 6, no. 4 (1989), 218-234, Dorothy Nelkin, "The Culture of Science Journalism," Society 24, no. 6 (1987), 17-25, and Daniel Patrick Thurs, Science Talk: Changing Notions of Science in American Popular Culture (New Brunswick, NJ: Rutgers University Press, 2007).

163 Gervais, 171-172.
} 
The pictorial essay was the first section of LIFE to explicitly emphasize the aesthetic qualities of the pictures by concentrating on the photographers and artists who created them. In this context, qualities like the "artistic sensibilities" of the photographer or illustrator, size, quality, colour, and layout of the images, and the overall length of each essay were all editorial priorities. ${ }^{164}$ Pictorial essays were on average longer than photographic essays, and further defined by the particular attention paid to the reproduction of the images, which were published in colour more often than in any other section of LIFE during this era. ${ }^{165}$ Though outnumbered by photographs, pictorial essays were also more likely than photographic essays to feature other visual mediums, namely drawing and painting. Pictorial essays prioritized representation and reproduction over reportage and realism. Though they covered a wide range of subjects, pictorial essays favoured topics related to art, culture, and history.

The first pictorial essay debuted on March 3, 1947 and was titled "Renaissance Man." ${ }^{166}$ It features an introduction and fourteen pages of a lush visual narrative of the life of Aeneas Sylvius Piccolomini (fl. 1405-1464 A.D.), more commonly remembered by his professional title, Pope Pius II. ${ }^{167}$ The essay gives the 'life and times' of Piccolomini and his home city of Siena through a series of exquisite reproductions and original artwork, including photographs. Especially notable are the four full-page colour reproductions of frescoes by Renaissance painter Pintoricchio from the Piccolomini Library in Siena (Fig. 13).

\footnotetext{
164 Gervais, 180. For an example of how a photographer's "artistic sensibilities" contextualized the shift between photographic essay and pictorial essay, see Gervais' discussion of W. Eugene Smith, 174-180. 165 Ibid, 180-181.

166 “Renaissance Man,” LIFE, March 3, 1947, 71-83.

167 Ibid.
} 


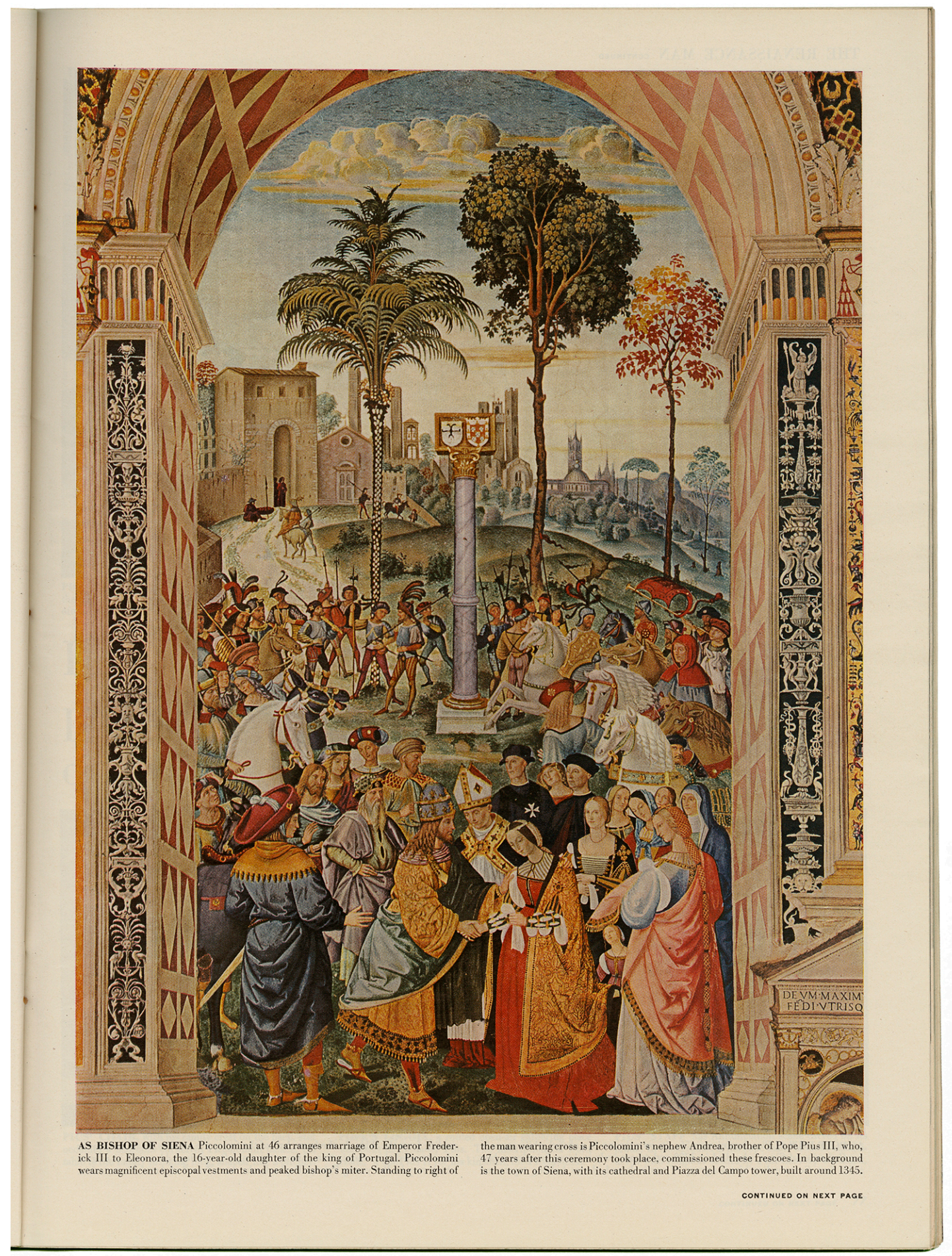

Fig. 13. "Renaissance Man," Photographed by Fernand Bourges, LIFE, March 3, 1947, 75. From the collection of the Ryerson Image Centre. 
This essay is also different from most other articles in LIFE because it is uninterrupted by any advertisements, which became a common editorial feature of subsequent pictorial essays. $^{168}$

Given this milieu, it seems interesting that editors chose to debut one of LIFE's most comprehensive science endeavours in the pictorial essay section of the magazine. Science topics were relatively scarce in the section's pages. Of the 104 pictorial essays published between March 1947 and December 1954, only twenty-four were on topics related to science. ${ }^{169}$ Yet on November 24, 1952, in a single page advertisement, LIFE's editors announced that in two weeks, in the December $8^{\text {th }}$ issue, they would begin a dozen-article, two-year undertaking of "the greatest science stories we have ever produced." ${ }^{170}$ The editors further promised that The World We Live In series would bring together a "score of artists and photographers" who would be "directed by a special research team" to "translate the newest of scientific findings into the finest of paintings and photographs" to tell "the great events of our planet's tumultuous lifespan." ${ }^{171}$ The predictions turned out to be partly correct. The World We Live In was published over a two-year timespan, from December 8, 1952 to December 20, 1954 but it was comprised of thirteen articles rather than twelve. The series' first article was titled "The Earth is Born," and covered geological principles of the earth's land formation and early structural changes. The subsequent essays were organized around topics related to geography, geology, paleontology, zoology, atmospheric science, astronomy, marine science, and ecology, with a particular emphasis on

\footnotetext{
168 Gervais, 180.

169 Thirteen out of twenty-four science related pictorial essays published between 1947 and 1954 were a part of The World We Live In series.

170 "Announcing the Greatest LIFE Science Series - The World We Live In," LIFE, November 24, 1952, 129.

171 Ibid.
} 
the earth's biomes. ${ }^{172}$ Save for the first and last issues, as well as two issues that discussed evolution, articles were organized around themes rather than chronologically.

The thirteen essays of The World We Live In conformed to many of the general editorial practices commonly found in other pictorial essays, and indeed all thirteen articles were published in the pictorial essay section of LIFE. On average, the essays were twentyone pages long, comprised of 7,000 words, and included thirtyone pictures. Though 7,000 words seems lengthy, an average of approximately twenty percent of the total page area in each essay was made up of text. Seventy percent of the remaining surface area was devoted to images, while the remaining ten percent were advertisements. ${ }^{173}$ Without exception, advertisements were only placed in the last twenty percent of each essay and always after the bulk of the large illustrations and photographs. Of the 394 pictures that were published in the thirteen essays, sixty-eight percent were photographs, while the remaining thirty-two percent were drawings, paintings, charts, and graphs. ${ }^{174}$ This is somewhat misleading on a per-issue basis however, as some essays were comprised exclusively of drawings and charts. ${ }^{175}$ Illustration-heavy essays included: Issue I: "The Earth is Born," covering the earth's early geological land formation; Issue V: "The Pageant of Life," which covered prehistoric animals, chiefly dinosaurs; and Issue VI: "The Age of Mammals," which discussed prehistoric mammals and where the editors made the choice to show animals in instructive groups according to habitat. In contrast, some issues were the opposite, and were comprised almost exclusively of photographs. These included the two issues dealing with marine topics

\footnotetext{
172 See Appendix A, Table 2 for more details.

173 Analysis of surface area was done by eye, examining each page of each of the thirteen essays on a fourquadrant grid, and rounding up to the nearest quarter of a page. All percentages listed here are approximate averages based on extrapolation from the totals of all pages in the series, including advertisements.

174 See Appendix, Graph 4 for more details. Other mediums besides photography are listed collectively as 'illustrations.'

175 Ibid. This graph shows the wide variation between photographs and other illustrations between issues.
} 
(Issue VII: “Creatures of the Sea," and Issue VIII: "The Coral Reef) and Issue X: "Icebound

Barrens of the Arctic Tundra." Over fifty photographers and a dozen illustrators contributed images to The World We Live In. Every essay featured custom photographs and illustrations. Commissioned work made up the majority of the series' visual content. ${ }^{176}$ Of the remaining images, some photographs from previous assignments by LIFE photographers were used, a small minority were stock or commercial photographs, and still others were photographs from specialized science institutions or equipment, such as the images from the Mt. Wilson and Palomar Observatory telescopes featured in the concluding essay, "The Starry Universe." ${ }^{177}$ In contrast, the text for the entire series was written exclusively by Lincoln Barnett, a regular writer for LIFE and author of a book on Albert Einstein.

The lengthy, lavish, and colourful characteristics common to pictorial essays were employed throughout individual issues of The World We Live In. A hallmark of the series were its gatefold layouts; foldout illustrations or graphs that spanned three full pages on each side (Fig. 14). These were often paired together, front to back, with two gatefold illustrations covering six full pages of the issue. Seventeen gatefolds appeared across the series' thirteen essays, with an additional three further spreads that were vertically oriented across two pages, requiring the reader to physically turn the magazine in order orient the picture. All of these twenty multi-page layouts were printed in colour. These unusual layouts brought an exoticism to the magazine.

\footnotetext{
176 This conclusion was drawn from looking at the image credits in each of the thirteen essays to verify which pictures could be confirmed as specifically commissioned for the series. While there is a verifiable majority of commissioned images in the entire series, there are several pictures where the image credit does not provide conclusive evidence either way, which is why more detailed analysis has not been undertaken at this time.

177 “The Starry Universe," LIFE, December 20, 1954, 44-70.
} 


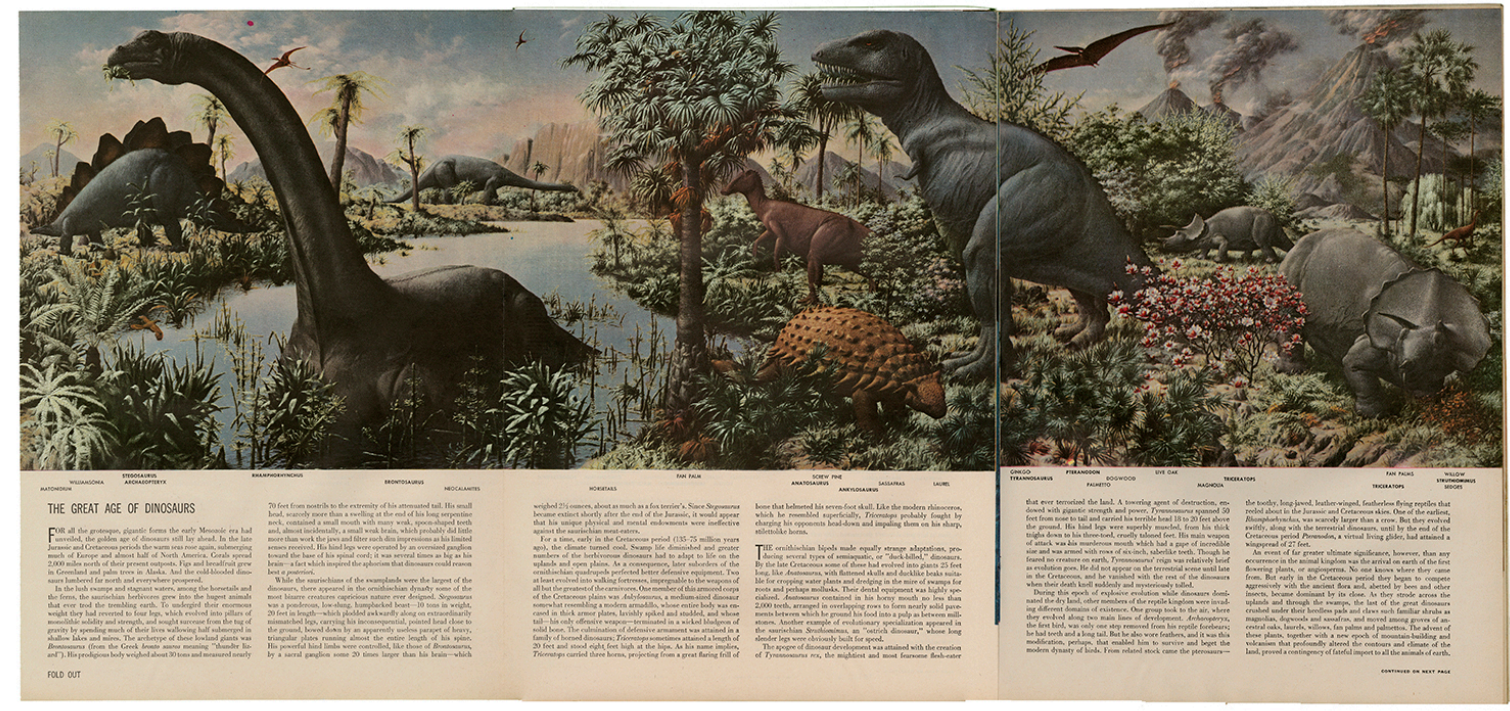

Fig. 14. "The Pageant of Life," Painted by Rudolph Zallinger, LIFE, September 7, 1953, 68-70. From the collection of the Ryerson Image Centre.

Gatefolds demanded the reader's undivided attention, not only because they were unusual, but also because it was easy to turn right past them. Opening them correctly asked the reader to be a attentive; noticing the slightly narrower page and illustrations that didn't bleed correctly across the gutter because they actually opened the opposite direction, finding the small 'fold out' direction printed discreetly in the bottom corner of the page, and being careful not to tear pages when opening three-page layouts fully flat to reveal the lavish illustration in all its glory. Gatefolds and vertical layouts greatly enhanced the reader's tactile experience, and added a layer of intrigue and discovery when reading the essays in the series.

Colour was another hallmark of The World We Live In. More than seventy-five percent of its visual content was printed in colour. ${ }^{178}$ This was a sharp contrast to other science content published in LIFE. In a sampling of thirteen articles of the science section published in 1952, the same year The World We Live In debuted, the sampled articles had

178 See Appendix A, Graph 2 for more details. 
less than a quarter of the visual content of an equal number of pictorial essays, seventy total images in the science section to 394 images published across the series' thirteen essays. ${ }^{179}$ The percentage of content published in colour is similarly inverted. More than eighty percent of the pictures (which are all photographs save for one chart in this sample) are published in black-and-white. ${ }^{180}$

While the pictures in the science section were often engaging in their own right (such as Gjon Mili's stroboscopic photographs discussed in the previous section), colour was an additional, striking feature that immediately attracted attention, regardless of content. It is the same reasoning that drew advertisers to fund full-page colour advertisements throughout the pages of LIFE. However, colour images in other areas of the magazine during this era were much less common. In the entire April 5, 1954 issue of LIFE, which included the ninth essay of The World We Live In, only one other full colour picture was published: a single page story on an aquamarine gemstone. ${ }^{181}$ This is contrasted against the twenty-onepage pictorial essay also published in the April 5 issue, which appeared entirely in colour. ${ }^{182}$ Technical information conveyed in the series was also simultaneously enhanced and simplified when printed in colours, and the great majority of the charts and graphs of The World We Live In feature multiple, bright colours that would draw the reader in and make complex information easier to synthesize. An example of this is a highly technical, yet colourful and innovative, chart in the inaugural issue "The Earth is Born." (Fig. 15).

\footnotetext{
179 Ibid.

180 Ibid.

181 “Green Gold," LIFE, April 5, 1954, 111.

182 "The Land of the Sun," LIFE, April 5, 1954, 72-93. See also Appendix A, Graph 3, Issue 9.
} 


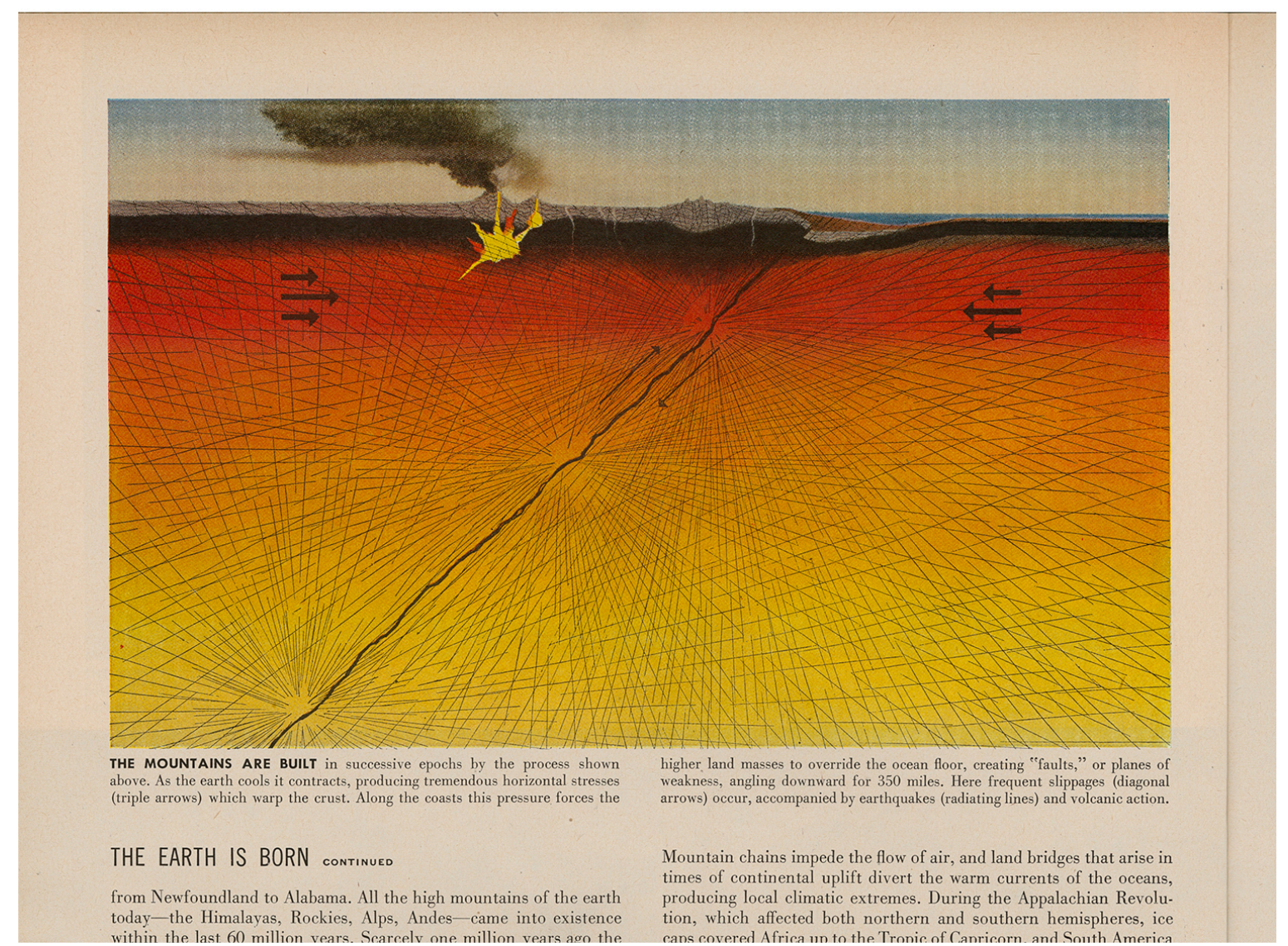

Fig. 15. "The Earth is Born," Painted by Chelsey Bonestall, LIFE, December 8, 1952, 96. From the collection of the Ryerson Image Centre.

The chart shows how mountains are built through 'slippage' - weak faults in the earth's crust - as well as through earthquakes and volcanic activity. The bright colours in the chart give the illusion of the earth's magma while overlapped diagonal (depicting 'slippage') and radiating lines (depicting earthquakes) show fault movement. Arrows instruct pressure points and the upward thrust of the earth's crust. ${ }^{183}$ By applying colour effectively in visual content like this chart, the two key principles of visual content for science journalism that LIFE science editor Gerrard Piel previously articulated - to simplify technical information and terminology, and to assist readers in comprehending the relationships between variables -

183 "The Earth is Born," LIFE, December 8, 1952, 96. This issue depicts contemporary geological principles of 1952 , which slightly predates major advancements in the field, including plate tectonics. 
were applied on an even grander scale in the series due to the size and number of images, the length of the articles, and inclusion of colour. ${ }^{184}$ It also reinforces that colour was specifically used for informational as well as aesthetic purposes throughout the images in the series.

Another obvious example of the use of colour is the twelve issues of the series that ran as cover stories. ${ }^{185}$ Only one of the thirteen essays of The World We Live In did not run as the cover story, and all twelve of the covers were published in colour. Although colour covers were more common than colour articles in LIFE, the bright full-bleed images on the front of the magazine drew additional attention to the series, especially for the casual 'thumbers' in the magazine's pass-along audience. Colour images, along with commissioned photography and illustration, and having almost all of the essays run as cover stories, also confirmed the magazine's commitment to producing the series and the considerable labour and expense that went into making each of the essays. All of these characteristics enhanced the conceptual format of the series as a 'portfolio' of science. An advertisement for the series in the December 8, 1952 issue of LIFE reads "Most of the photographs, maps, paintings, and charts ... will be printed in full-color. The individual essays, collected, will create for your library a record like none we can believe you will find elsewhere." ${ }^{\prime 186}$ Colour amplified the aesthetic qualities of each issue, but it also enhanced the scientific information being conveyed through the images, and brought the essays together as a single folio: a series specifically designed to be retained long-term for reference and entertainment.

\footnotetext{
184 Camera Three, Conversations with Editors Part III, 1965.

185 See Appendix A, Table 2 for more details.

186 “...and after 'The Earth,'” LIFE, December 8, 1952, 173.
} 
The personalities and particular styles of the series' myriad of talented artists and photographers were also celebrated throughout the essays. Contributing artists and photographers' names were listed in a recurring format on the title page of each issue in the series. ${ }^{187}$ Generous alleys between the credits and the surrounding text, as well as two horizontal lines (one above and one below) helped differentiate between the other elements on the page and draw the eye to the listed names. This design detail was repeated by the editors at the end of each issue, where the names of contributing scientific researchers and organizations were listed. ${ }^{188}$ In this format, the visual and scientific contributors bookended each issue and were given equitable attention by the editors. Certain issues paid additional attention to the illustrator(s) or photographer(s). Issue V: "The Pageant of Life," featured gatefold reproductions of paintings by notable artist Rudoph Zallinger, one of which was adapted from his mural The Age of Reptiles (1947), which hangs in Yale University's Peabody Museum of Natural History. ${ }^{189}$ The gatefold version in The World We Live In was reproduced from his preliminary studies for the mural. In a strange reversal, LIFE commissioned an additional original painting by Zallinger depicting the evolution of animals in North America for the next issue of the series, which was called "The Age of Mammals." Zallinger treated this commission as a preliminary study for another mural, which was later also acquired by the Peabody Museum. Artists and photographers were as integral to the series as its scientific contributors. Crediting both of these groups of professionals equitably further underscores the importance that was placed of the quality of the pictorial content as well as the scientific information presented in the essays. Naming both artists and scientists added legitimacy and integrity to their respective contributions.

\footnotetext{
187 For an example see "The Face of the Land," LIFE, April 5, 1954, 73.

188 For an example see "The Face of the Land," LIFE, April 5, 1954, 93.

189 “The Pageant of Life," LIFE, September 7, 1953, 53-74.
} 
LIFE editors also used the specific styles of certain artists in the series to create micronarratives within the essays. An example of this occurs in the eleventh essay of the series. In many ways, Issue XI: "The Rainforest" essay of The World We Live In represented the typical qualities of a pictorial essay in LIFE. The essay is twenty-five pages long with forty pictures - thirty-three photographs and seven illustrations - thirty-six of which were in colour. This essay contains novel layouts, including a three-page vertical gatefold colour painting by Zallinger, which shows the dramatic size of the trees and layers of the rainforest (Fig. 16). The gatefold corresponds to a more articulated diagram on the following page, which breaks down each of the layers of trees (Fig. 17). Most of the pictures in the essay though are Eisenstaedt's vibrant Kodachrome photographs, which serve as aesthetically pleasing micro-perspectives of Zallinger's broad, comprehensive illustrations. For instance, Eisenstaedt's delicate image of the leaf tips of a Bactris palm is an artistic study of pattern with vivid green leaves and raindrops replicated across the image (Fig. 18). The photograph is also a detailed look at how the pointed shape of the plant's leaves facilitate runoff in the lower strata of the rainforest, which corresponds to Zallinger's previous large-scale illustrations of the layers of the trees.

In another spread, five individual colour images taking up approximately ninety percent of the spread highlight individual biological characteristics of different insects of the rainforest. The bottom three images, while individual in subject matter, are laid out cleverly as a triptych. On either side are two images of different species of butterflies, photographed in a similar overhead angle, featuring the insect's wings open and widespread. The middle image is a photograph of a katydid, a member of the cricket family that has a body that resembles a leaf shape. Eisenstaedt has photographed the katydid at eye level and in profile, so that its body almost resembles a single butterfly wing. 


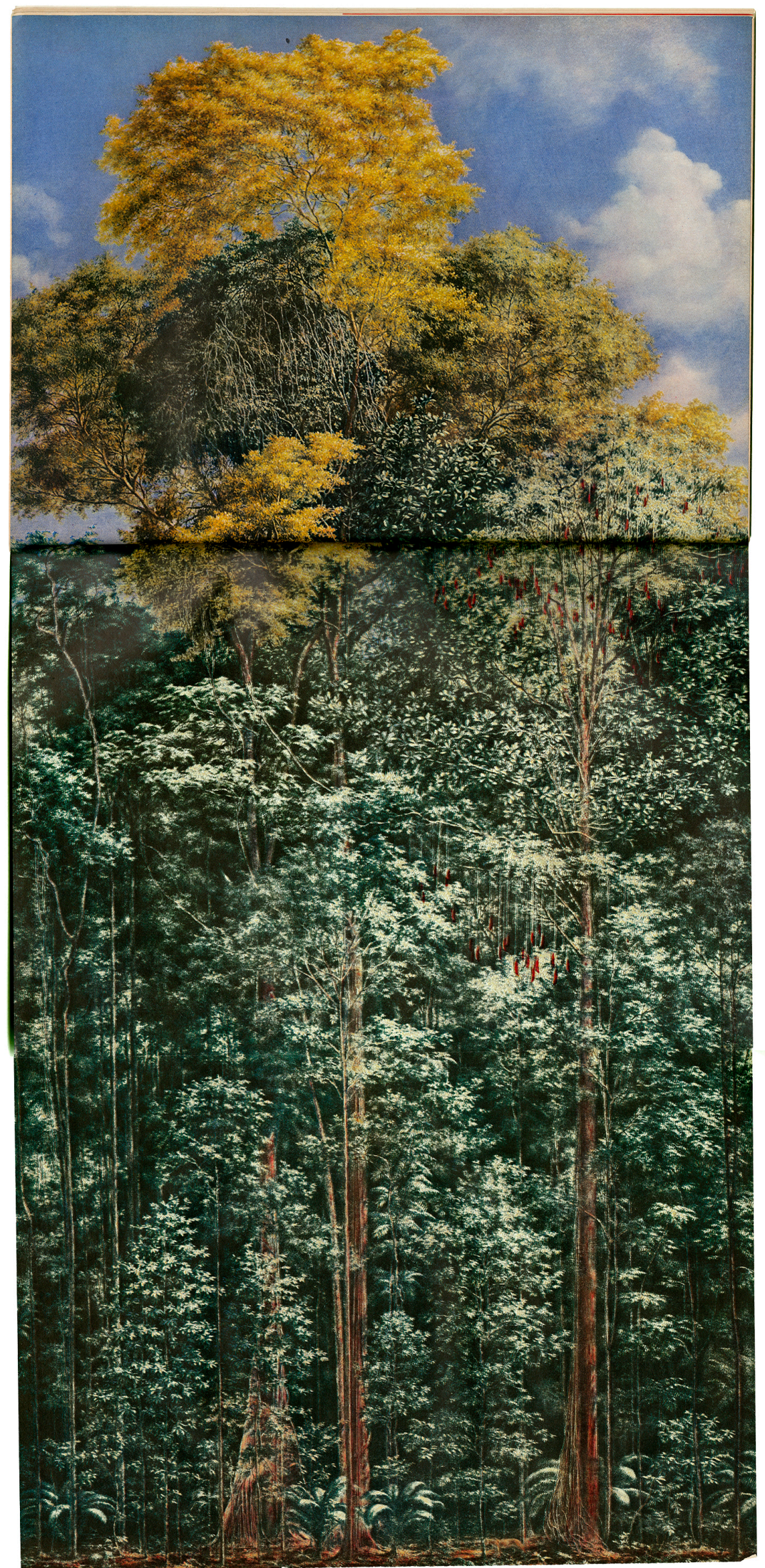

Fig. 16. "The Rainforest," Painted by Rudolph Zallinger, LIFE, September 20, 1954, 80-82. From the collection of the Ryerson Image Centre. 


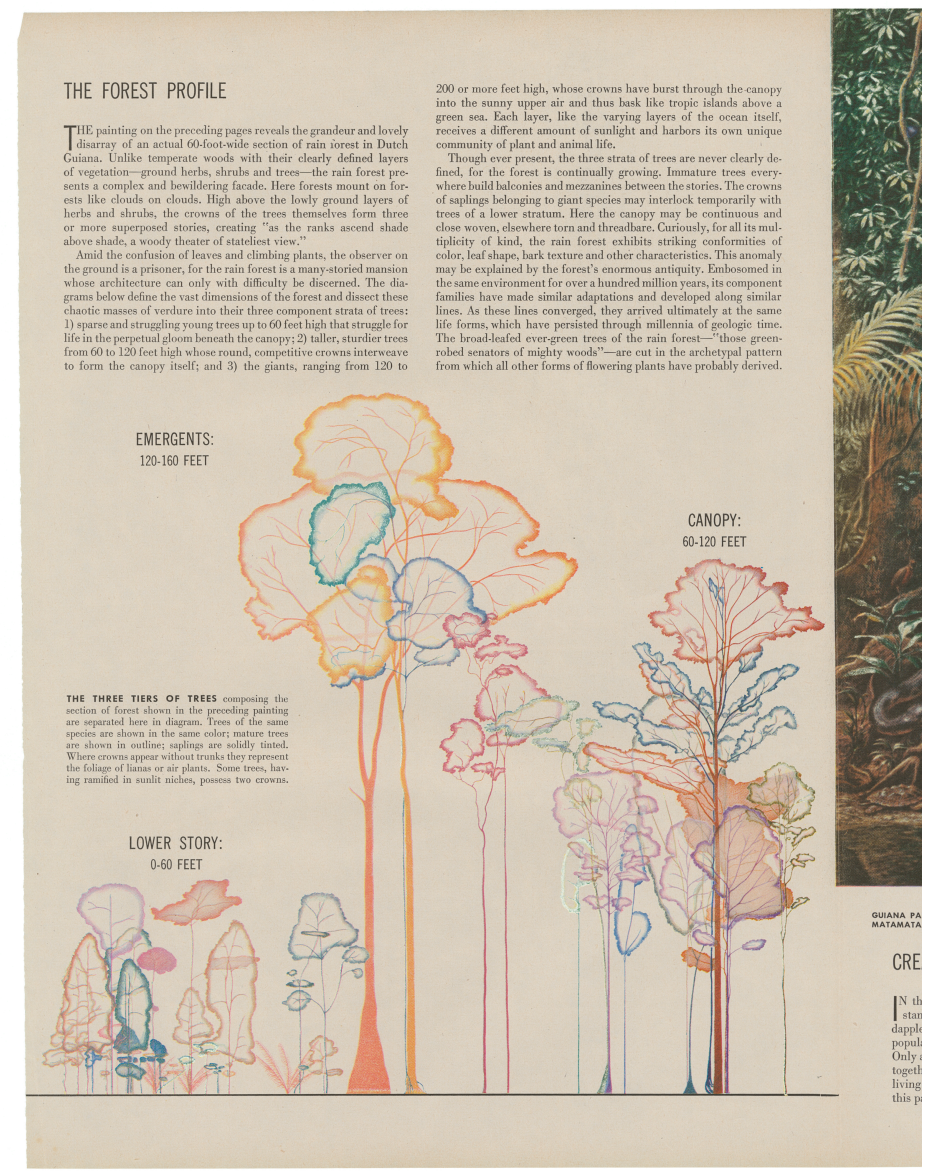

Fig. 17. "The Rainforest," Illustrated by Rudolph Zallinger, LIFE, September 20, 1954, 83. From the collection of the Ryerson Image Centre.

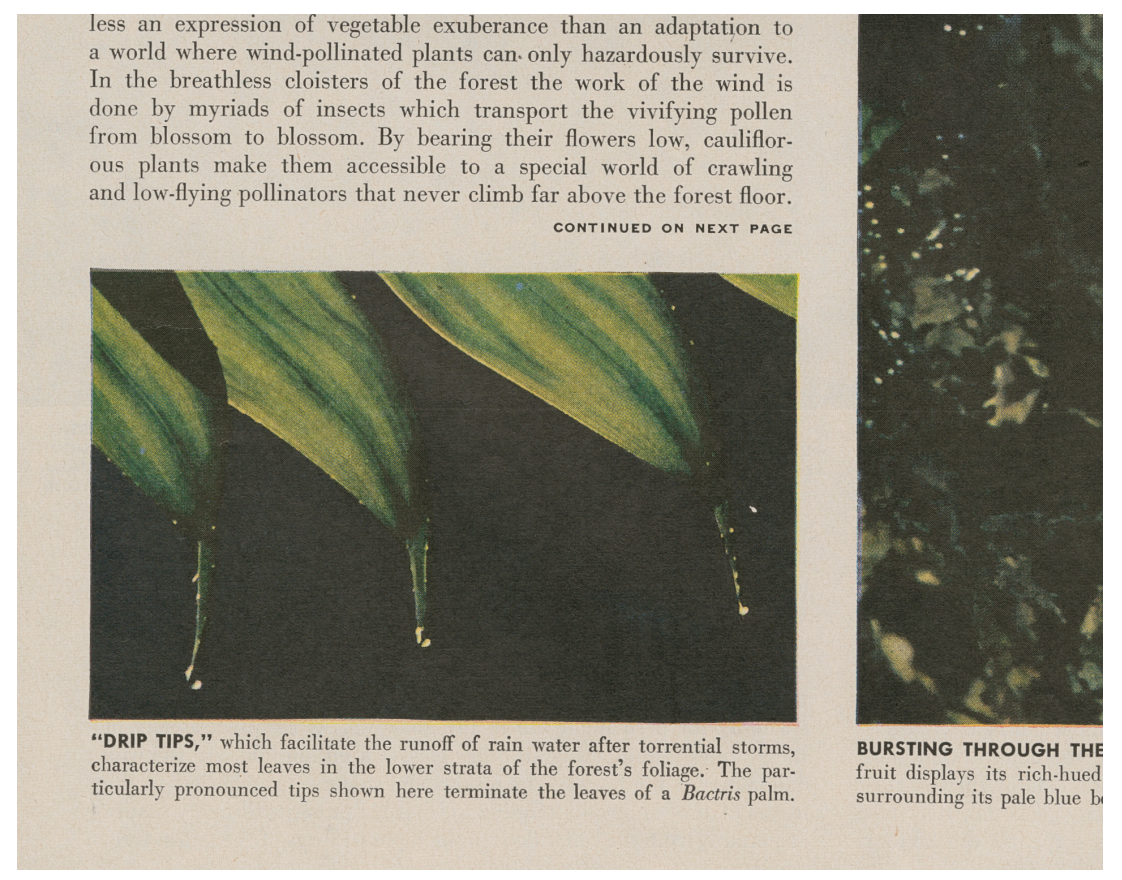

Fig. 18. "The Rainforest," Photographed by Alfred Eisenstaedt, LIFE, September 20, 1954, 86. From the collection of the Ryerson Image Centre. 


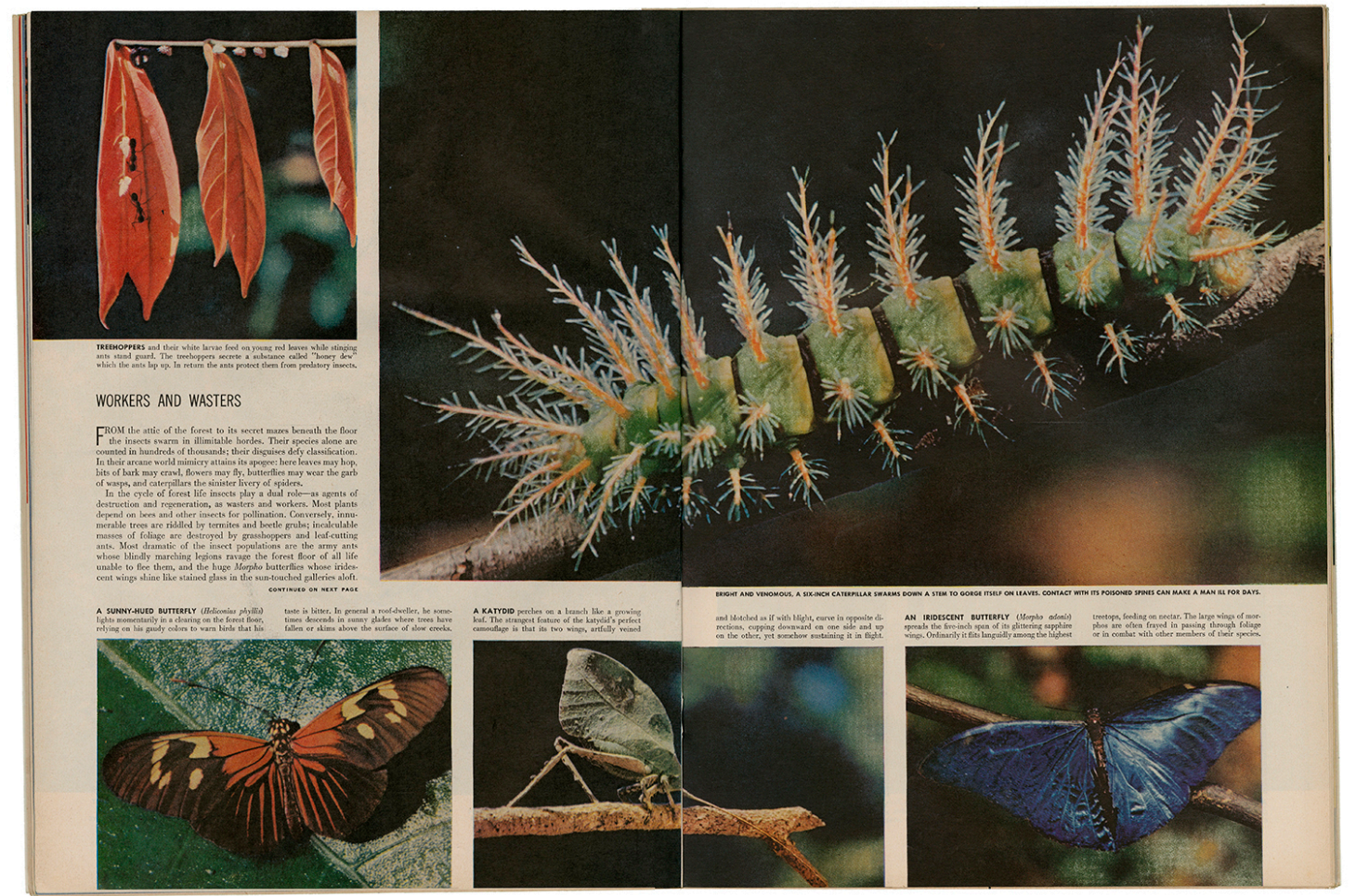

Fig. 19. "The Rainforest," Photographed by Alfred Eisenstaedt, LIFE, September 20, 1954, 96-97. From the collection of the Ryerson Image Centre.

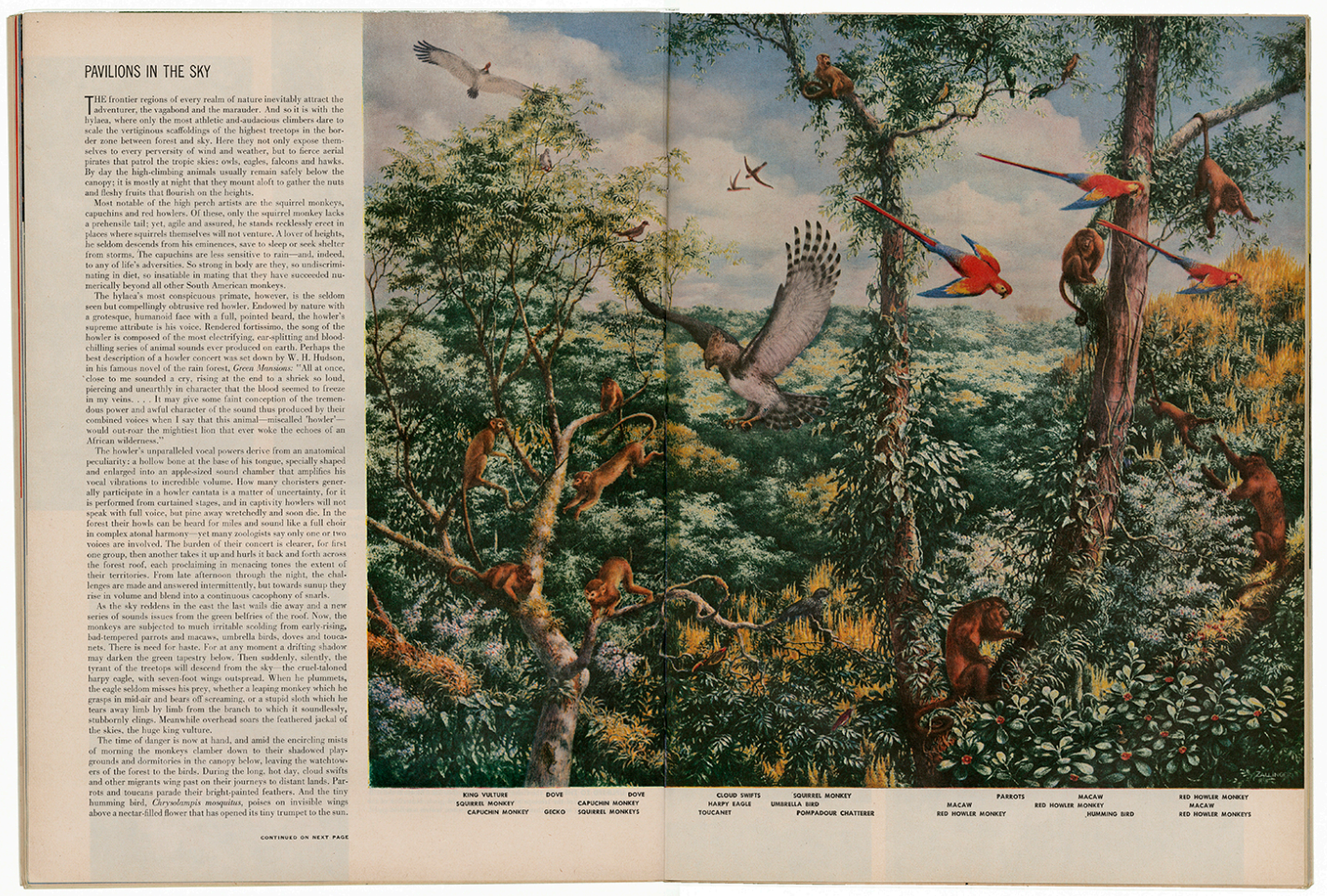

Fig. 20. "The Rainforest," Painted by Rudolph Zallinger, LIFE, September 20, 1954, 90-91. From the collection of the Ryerson Image Centre. 
Though bearing no biological resemblance, the aesthetic symmetry of the sequence and the mimicry of a butterfly wing is visually pleasing and cohesive presentation of these three photographs (Fig. 19). The photographs of insects on this spread also function as a narrative extension of a Zallinger illustration on the previous spread, which depicts some of the insects' natural predators, including swifts, geckos, parrots, and certain species of monkeys (Fig. 20). Once again, the visual effect is inverted: Zallinger's single large-scale colour illustration spans ninety percent of the previous spread and identifies twenty-four different species in the upper section of the rainforest, while Eisenstaedt's five close-up photographs on the following spread fill the same amount of space, but focus on the details of five individual insect species pictured on individual leaves and branches. Eisenstaedt's detailed aesthetic gives each plant and animal an individual and animated uniqueness amongst the myriads of rainforest life. These micronarratives played upon the creators' aesthetic strengths and mediums - Zallinger as a muralist and Eisenstaedt as a photojournalist - but they also provided key conceptual links between images.

Other creators in the series were discussed as characters in their own right. Photographers like Roman Vishniac, Fritz Goro, and Alfred Eisenstaedt were repeatedly profiled as exotic explorers capturing scientific knowledge in remote corners of the globe. Such treatment personified the series and the particular point of view these photographers brought to their respective issues. Additionally, this explicitly public, performative element to the overall presentation of the series 'pulled back the curtain' on any notions of detached scientific 'objectivity.' Rather, The World We Live emphasized its contributors' particular aesthetic choices and the process by which images were made. Photography, more than any other element in the series, told the story of science and invited readers along for the adventure. 
One example of this occurs in the November 30, 1953 issue, "Creatures of the Sea." In the opening remarks above the issue's contents page, the editors recount the adventures of three of the contributors to the "Creatures of the Sea" story: photographers Roman Vishniac, J. R. Eyerman and Fritz Goro, and painter Rudolph Freund. The synopsis notes that Vishniac's assignment was to take photomicrographs of plankton, which involved him sitting in a boat collecting samples "night after night" for over five months. ${ }^{190}$ After collecting the samples, Vishniac would have to "hastily make for shore" before the plankton died "to photograph them under his microscope." ${ }^{191}$ According to the synopsis, Fritz Goro's experience was hardly easier. For the same issue, he spent weeks diving off the coasts of Bimini, the Bahamas and Australia shooting underwater photography. However, his greatest adversary was a three-foot octopus in a Bimini lab who refused to be photographed using Goro's flash setup, turning red and green every time the flash fired. Eventually the octopus escaped through a quarter of an inch-wide crack in the lid of its tank and was found "squirming on the floor of the laboratory" by Goro, who returned the octopus to the ocean, a fitting end to the story. ${ }^{192}$ Tales like these enhanced the exoticism of the series' subject matter and its creators. In this narrative, doing science was an odyssey, full of exciting and daring episodes of adventure.

However, these lighthearted anecdotes belie the level of technical mastery used by the photographers employed to take the photographs in "Creatures of the Sea," and the editorial sophistication of the images' presentation in the publication. On pages 99-100, midway through the essay, a single composite image of forty-seven different photomicrographs of plankton covers three-quarters of the double-page spread. The

\footnotetext{
190 "Salt Water and a Neurotic Octopus," LIFE, November 30, 1953, 23.

191 Ibid.

192 Ibid.
} 
composite image appears seamless, the plankton are a vivid variety of shapes, colours, and sizes all against a solid black background (Fig. 21).

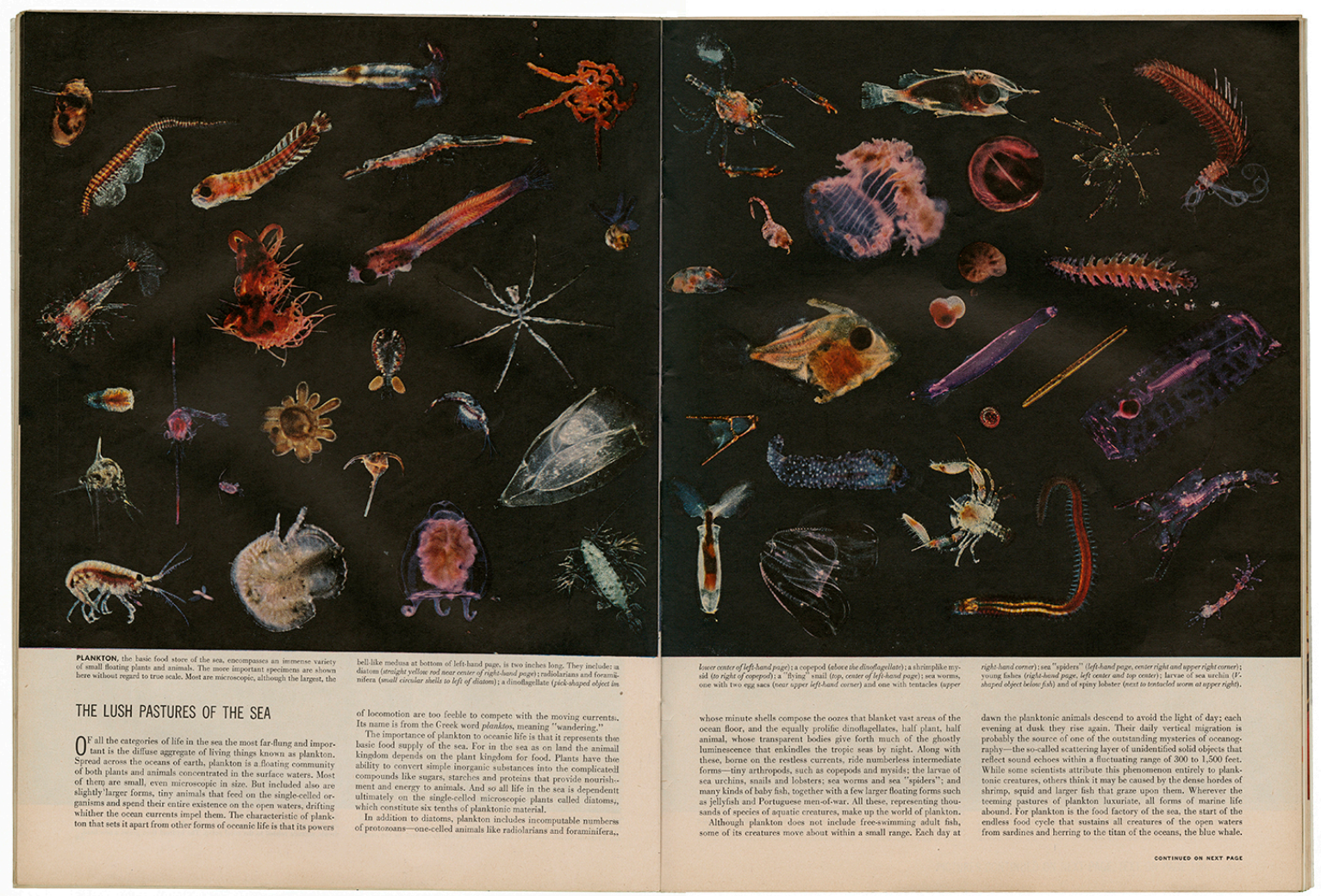

Fig. 21. "Creatures of the Sea," Photographed by Roman Vishniac, LIFE, November 30, 1953, 98-99. From the collection of the Ryerson Image Centre.

On page 82, another photograph looks like a black-and-white twin of Vishniac's microscopic composite plankton image. This is a composite image from a series of photographs, but this time taken from ocean depths between 1,300 to 3,600 feet, sixty miles off the coast of California. ${ }^{193}$ These remarkable photographs were made by a collaboration between photographer J. R. Eyerman and inventor Otis Barton. Eyerman modified a camera and flash for Barton, who then took the images from inside his benthoscope, a submersible chamber which he lowered via suspension cable to 3,600 feet below the surface of the Pacific

193 Ibid. 
Ocean. ${ }^{194}$ In doing so, he took the deepest undersea photographs of sea life in existence at the time of publication, made without the assistance of remote-control equipment. ${ }^{195}$ LIFE editors composited the photographs of the luminescent sea creatures that Eyerman and Barton captured into a C-shaped monochrome composite image that bracketed text identifying the creatures and an explanation of the photographic process by which they were made (Fig. 22).

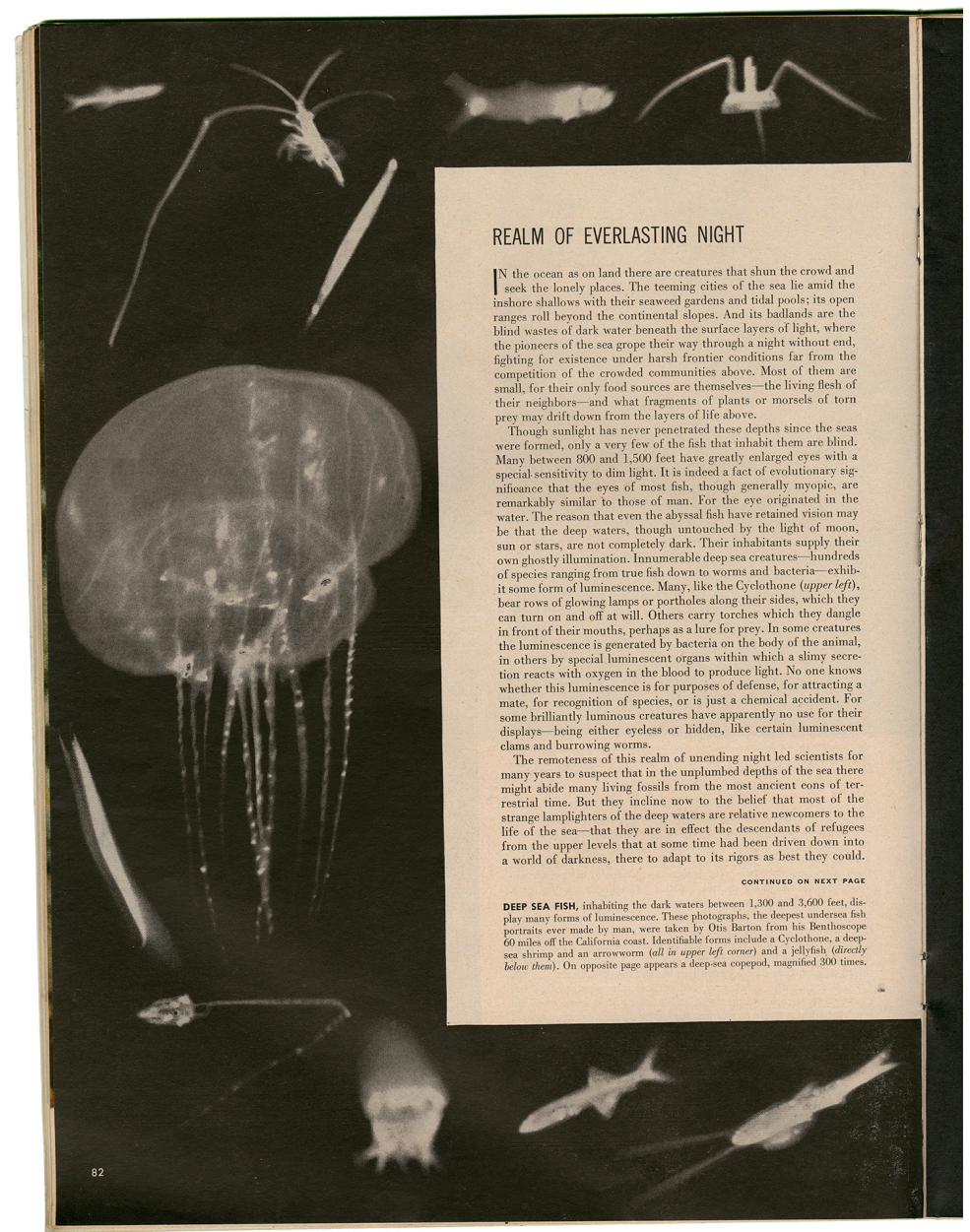

Fig. 22. "Creatures of the Sea," Photographed by J. R. Eyerman and Otis Barton. LIFE, November 30, $1953,82$. From the collection of the Ryerson Image Centre.

In both of these examples, the final edited composite images are clean, minimalist presentations that emphasize the beauty of the photographs over their extreme technicality

\footnotetext{
194 Ibid.

195 “Creatures of the Sea," LIFE, November 30, 1953, 82.
} 
or scientific merit. It is only through the accompanying text that readers learn of these details. In this layout, the traditional scientific framing of the picture illustrating technical text has been reversed. Instead, the text illustrates and reveals the extreme degrees of technicality in otherwise 'pretty' photographs.

Not all pictures in The World We Live In set technical records like Eyerman and Barton's underwater images, but they all did have a common visual allure. To enhance this, LIFE often reported on the dramatic process of how the pictures were made in order to add to their mystique. This type of 'behind-the-scenes' reportage about the process of image making occurs in numerous issues of The World We Live In. In some cases, like the previously-mentioned stories of Goro, Vishniac, and Eyerman in "Creatures of the Sea," and others from "The Pageant of Life" and "The Coral Reef," adventurous accounts of the photographers and illustrators occur in the issue's summary above the Table of Contents. In the opening synopsis of the February 8,1954 issue of LIFE, it is reported that a team which included photographer Fritz Goro, reporter Axel Poignant and assistants travelled to photograph the Great Barrier Reef to create images for "The Coral Reef" essay of the series. ${ }^{196}$ Goro and Poignant are mentioned by name and were reportedly attacked by a shark during their time in Australia. ${ }^{197}$ The synopsis also highlights Goro's technical ingenuity by explaining how he rigged a homemade scaffold to a waterproof camera so that he could manually plunge the camera "down to coral depth" and take the "spectacular pictures" for the issue. ${ }^{198}$ A small black-and-white photograph of Goro, an assistant, and the underwater camera attached to the scaffold is centred above the text and the headline in a diptych with a portrait image of Emmet Hughes (who was reporting from the Soviet Union

\footnotetext{
196 “The Lowdown on Red Coral and Red Morale," LIFE, February 8, 1954, 21. 197 Ibid. 198 Ibid.
} 
that week.) The photograph of the scaffold, the description of Goro's technical ingenuity, and the casually-mentioned shark attack all heighten the dramatic buildup to the images in "The Coral Reef" essay. Goro is cast as a character, and the process of creating the photographs becomes a notable subplot of this 'story of science.'

Another episode in the 'odyssey' of the series chronicles the labour involved in compiling each detail published in the articles. In this case, the summary section above the September 7, 1953 issue's Table of Contents notes that LIFE editors and reporters, with "the guidance of botanists, zoologists, paleontologist, geologists, and chemists," had spent nine months assembling and fact-checking "The Pageant of Life" essay and the illustrations of "some 280 species shown." 199 The summary specifically notes that during this process, "word suddenly came in" that a recent discovery changed current scientific understanding of the shell markings of the nautiloid, a large undersea predator that lived 400 million years ago. ${ }^{200}$ This information required necessary last-minute changes to the illustration of the nautiloid in "The Pageant of Life" essay prior to publication. Reporting these otherwise minor details of the editorial process provides further anecdotal 'evidence' of LIFE's dedication to accurate and cutting-edge science and the scientific legitimacy of the text and illustrations in "The Pageant of Life."

In other issues of The World We Live In, reportage of 'science in the making' was expanded even further. Issue X: “The Arctic Barrens," features an entirely separate pictorial essay called "LIFE's Expedition to the Tundra" that recounts the adventures of photographer Fritz Goro and reporter Jim Goode, who with a guide and assistants spent seven weeks 450

\footnotetext{
199 "Stories Can Be Told in an Eon or an Instant," LIFE, September 7, 1953, 17. 200 Ibid.
} 
miles northwest of Churchill, Manitoba, in the Canadian Arctic. ${ }^{201}$ The subjects of two landscape, black-and-white reportage photographs convey the theme of the adventure on the opening page of the second pictorial essay (Fig. 23).

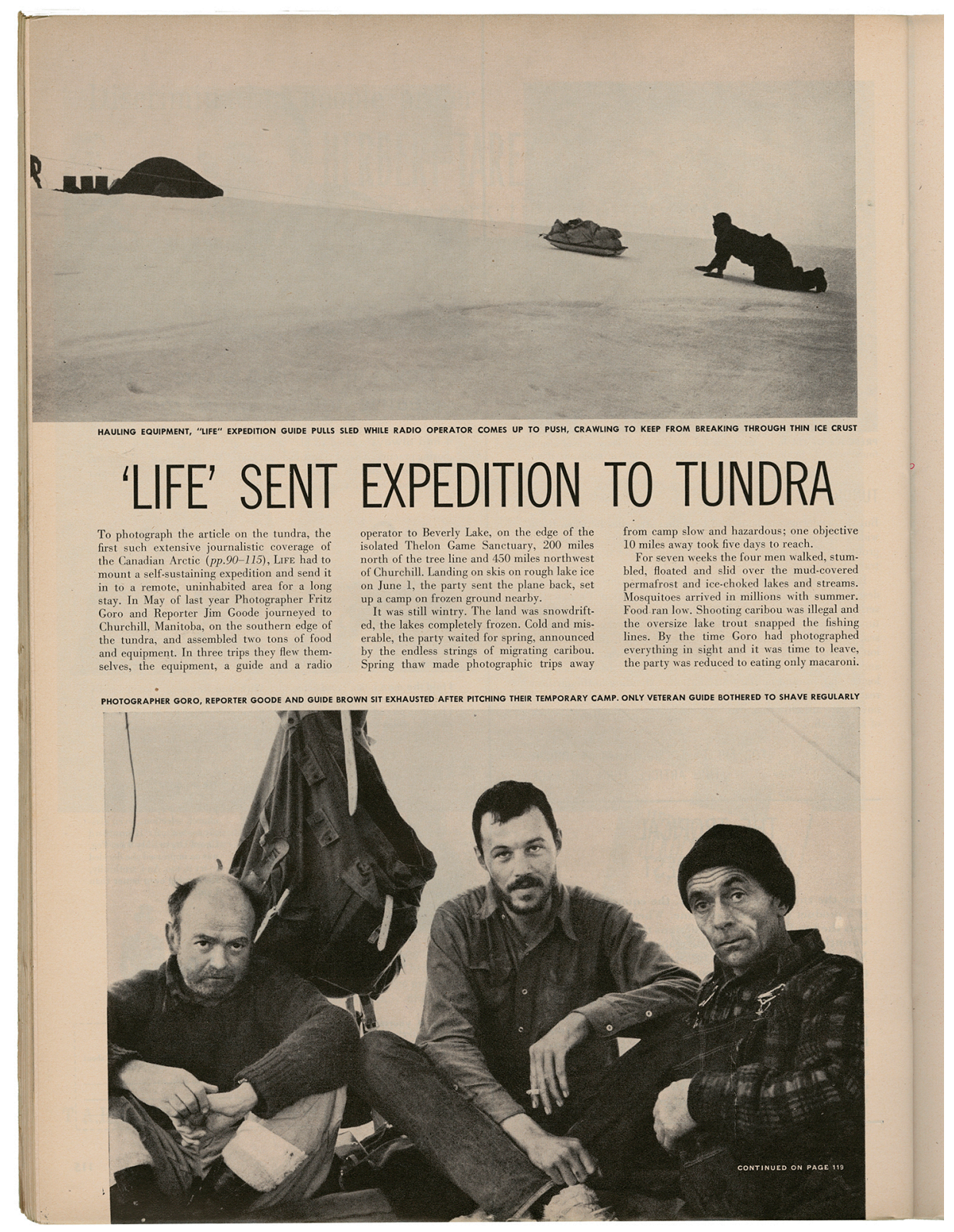

Fig. 23. "LIFE Sent Expedition to Tundra," Photographed by Fritz Goro. LIFE, June 7, 1954, 116. From the collection of the Ryerson Image Centre.

The upper image shows a giant sheaf of ice with a small figure of a man pulling a sled across the ice, while another man follows behind the sled crawling on his hands and knees. The 201 “LIFE's Expedition to the Tundra," LIFE, June 7, 1954, 116. 
pulled-back perspective of the photograph juxtaposes the tiny human silhouettes against the vastness of the arctic landscape, while the caption reveals that the two men are members of the expedition who had to cross the ice this way with their gear to avoid falling through. The lower image is a closer portrait of three grim looking men, roughly clothed and seated on the ground looking directly at the camera. The caption notes that the left figure is photographer Fritz Goro, the centre figure is reporter Jim Goode, and at right is their guide, "the veteran" who was the only one "who bothered to shave regularly." 202 The caption also notes that because it was illegal to shoot caribou and fish for trout, by the end of the trip the "exhausted" team was reduced to "surviving only on macaroni." ${ }^{203}$ The six photographs in the shorter four-page "LIFE's Expedition to the Tundra" essay are presented exclusively in black-and-white as reportage, which emphasizes the stark Arctic landscape and team's extreme experience in the tundra. ${ }^{204}$ The visual narrative of this essay is devoted exclusively to the drama of the expedition and the process of 'getting the picture'; other than a brief mention of why the trip was formed, science does not make an appearance in this essay. By contrast, the expedition photographs taken by Goro are presented in the preceding pictorial essay "The Artic Barrens" almost exclusively in full-colour over twenty-three pages. ${ }^{205}$ By positioning the two essays back-to-back, the reader is in hindsight able to appreciate photographs in "The Arctic Barrens" in a new light - as the hard-won results of Goro's labour - now shown in all their glory. The adventures in the arctic become an integral part

\footnotetext{
202 Ibid.

203 Ibid.

204 Ibid, 116-120.

205 There are two small, black-and-white photographs at the very end of the essay, one of a Finnish reindeer herd and one of a salt dome, neither of which are taken by Goro. "The Arctic Barrens" LIFE, June 7, 1954, 112, 115.
} 
of the narrative of the "The Arctic Barrens" pictorial essay and heighten the overall appeal of the photographs.

Publishing The World We Live In as a series of pictorial essays prioritized a different narrative than had been seen in other sections of LIFE magazine, and was key to the series' identity as a cohesive, visual portfolio of the 'story of science.' The essays' length, themes, unusual layouts, overwhelming use of colour, and dramatization of the pictures' creators and their processes of image making recast scientific knowledge as an epic adventure that every reader could access. In this narrative, understanding science was exciting, seductive, and tangible, and people doing science were protagonists in the ongoing quest for scientific progress. The World We Live In tantalized the palettes of the casual LIFE reader with the wonders of science and would reveal layer upon layer of increasingly detailed information as the reader became more enthralled and lingered over its pages. This seductive 'story of science' reached a different, wider public within LIFE's readership than the dedicated (and literally subscribed) professional elite who read the succinct synopsis in its science section. 


\section{Gestalt}

The 'Bigger Picture' of The World We Live In, Series in LIFE, and Conquest through Progress in the 'American Century'

If the adventurous tales of science that comprised The World We Live In were an odyssey of scientific knowledge, they were also a story of conquest, akin to the original Homeric Odyssey. Each protagonist in an epic needs a series of challenges to conquer and threats to subdue. Within this narrative, scientific knowledge and those who practiced it were presented as victors over ignorance. In turn, advancing scientific knowledge strengthened the 'enlightenment' of American intellectualism and culture that was promoted by LIFE and Luce as a challenge to the perceived urgent threat of global Communism.

To achieve this goal, Luce employed a number of strategies within the pages of LIFE. Editorially speaking, the "Renaissance Man" essay commenced the pictorial essay section within LIFE, but it was also the first of a series This essay was the inaugural issue of The History of Western Culture, which was published as nine separate issues of LIFE between March 3, 1947 and November 22, 1948. Series function as a distinct, coherent bodies of work across multiple issues of a publication. They have a long history in the media, and have been known as series, serials, or periodicals across both in print and other forms of media, such as radio or television, throughout the twentieth century. ${ }^{206}$ In LIFE, the introduction of series was a part of a larger editorial re-envisioning of the magazine that occupied Luce and his editors. Luce was notorious for micromanaging, and turnover in senior editing staff was

\footnotetext{
${ }^{206}$ Series, first developed in the seventeenth century with the advance of moveable type. They became popular in Victorian literature, partly due to the cost of printing. See Roger Hagerdorn, "Technology and Economic Exploitation: The Serial as a Form of Narrative Presentation," Wide Angle: A Film Quarterly of Theory, Criticism, and Practice 10, vol. 4 (1988), 4-12.
} 
high during the late 1940s. Edward K. Thompson was the third man Luce had hired for the job in as many years, and he proved willing to handle Luce's irregular and often untimely intercessions in editorial decisions at the magazine. One such instance occurred in 1946 when Luce drafted a memo proposing to take the magazine to new heights by "seizing what he [Luce] believed was America's great moment, its unprecedented opportunity ... to reshape the world." ${ }^{207}$ After some mulling over what this meant, one of the editors suggested a "Western Culture" project, which Luce seized upon and "grandiosely insisted should aspire to 'add up to a coherent interpretation of history'."208

This project was a part of a larger post-war re-imagining of LIFE, which shifted it towards more serious content alongside its lighthearted entertainment staple coverage. Principally guided "by faith," Luce believed that "journalism must fight its way through to a better and brighter world," and that LIFE could achieve this "by chronicling the West's (and America's) march to democratic greatness." ${ }^{209}$ The History of Western Culture series was a particularly personal and lofty editorial vision for the magazine and a hybrid between two editorial identities in the magazine, pictorial essay and series. The aptly titled first essay "Renaissance Man" represented a renewed effort by Luce and LIFE to strengthen and spread what it perceived to be the key intellectual and cultural values in American society in the post-war years. In the introduction to The History of Western Culture, LIFE proclaimed that the series" purpose "is to give Americans a perspective on history. Americans need perspective on their past so they can determine their future." ${ }^{210}$ However, hearkening back to "The American Century," published six years earlier, Luce believed that "in addition to

\footnotetext{
207 Brinkley, 329.

208 Ibid.

209 Ibid.

210 "LIFE Announces a Series of Articles on The History of Western Culture," LIFE, March 3, 1947, 69.
} 
ideals and notions which are especially American, we are the inheritors of all the great principles of Western civilization ... it now becomes our time to be the powerhouse from which the ideals spread throughout the world." ${ }^{211}$ For Luce and LIFE, educating the American public also meant advancing American values in a global context.

The World We Live In, when announced in the November 24, 1952 issue of LIFE, crowed that it was "comparable to LIFE's History of Western Culture" and that "the subject of the new series, the most fascinating in the world, is the world itself." ${ }^{212}$ Like the historical concepts of The History of Western Culture, the scientific subject matter of The World We Live In was presented as "present knowledge born of human curiosity about the forces which shape the familiar features of nature and shape our everyday life." ${ }^{213}$ Fundamental to understanding this subject matter was seeing science. The series' uniqueness lay in its efforts to "translate the newest scientific findings into the finest of paintings and photographs." ${ }^{214}$ LIFE took this both the aesthetic and scientific burdens of this undertaking seriously. This accounts for the considerable time, money, and labour the magazine spent in creating, commissioning, producing, and editing the series, and its presentation as a cumulative 'portfolio' of science knowledge meant to last. ${ }^{215}$ In producing the series, LIFE also took seriously the opportunity to expand the existing body of scientific knowledge and the visual record of science. As an example, in the final pages of "The Rainforest" essay, the editors devoted two pages to discussing the expedition that was undertaken in Surinam,

\footnotetext{
211 Henry R. Luce, “This American Century," LIFE, February 17, 1941, 65.

212 “Announcing the Greatest LIFE Science Series - The World We Live In," LIFE, November 24, $1952,129$.

213 Ibid.

214 Ibid.

215 “...and after 'The Earth,'” LIFE, December 8, 1952, 173.
} 
where because the rainforest at the time had "been sparsely explored and studied, LIFE had to undertake basic scientific research for its story." ${ }^{216}$ In this endeavour,

an editorial scout early in 1953 joined a Surinam government exploration where white men had first set foot a few months before. In October, a party went back to outfit a camp and study the forest. In November, Photographer Alfred Eisenstaedt, Artist Rudolph Zallinger, Reporter David Bergamini, and a safari of seven natives moved into camp to make the actual pictures ... When the party emerged after two months it brought back original contributions to rainforest knowledge. Bergamini's collection of fauna and flora contained previously unknown species. Zallinger's detailed paintings assembled facts hitherto incompletely described. Eisenstaedt's 4,000 Kodachrome exposures added notably to the world's meager archive of rainforest photographs in color. $^{217}$

This expedition was a literal conquest of unknown territory under the auspices of expanding scientific knowledge. LIFE's exclusively male, foreign team members (note the recorded occupations in the quote above) came into the rainforest with the purpose of creating pictures of science to educate and inform an American audience. The imperialist language of this description is striking. It lists the names, titles, and detailed contributions of the foreign journalists acting in the name of American scientific interests, while the "seven natives" and the "Surninam government exploration" remain anonymous background details of the story, is in keeping with the narrative of (cultural and scientific) conquest, and the ideals that preceded the series. ${ }^{218}$ Describing this expedition and the contributions of Eisenstaedt, Bergamini, and Zallinger in such detail in the magazine also became an another method of legitimizing the science content in the series, in the way that publishing the names of prominent contributing scientists and scientific institutions in the end credits of each essay lent credence to the article.

\footnotetext{
216 “Research at Source," LIFE, September 20, 1954, 105.

217 Ibid.

218 Ibid.
} 
The order of essay topics in The World We Live In also contributed to the narrative of American conquest through science. While the majority of the essays in the series were thematic, the first and last essays were chronological, and established an additional trajectory of knowledge. Though the first essay of the series was titled "The Earth is Born," the chronological story of the earth is contained entirely within the first image of the series, an illustrated graphic by painter Chelsey Bonestall (Fig. 24).

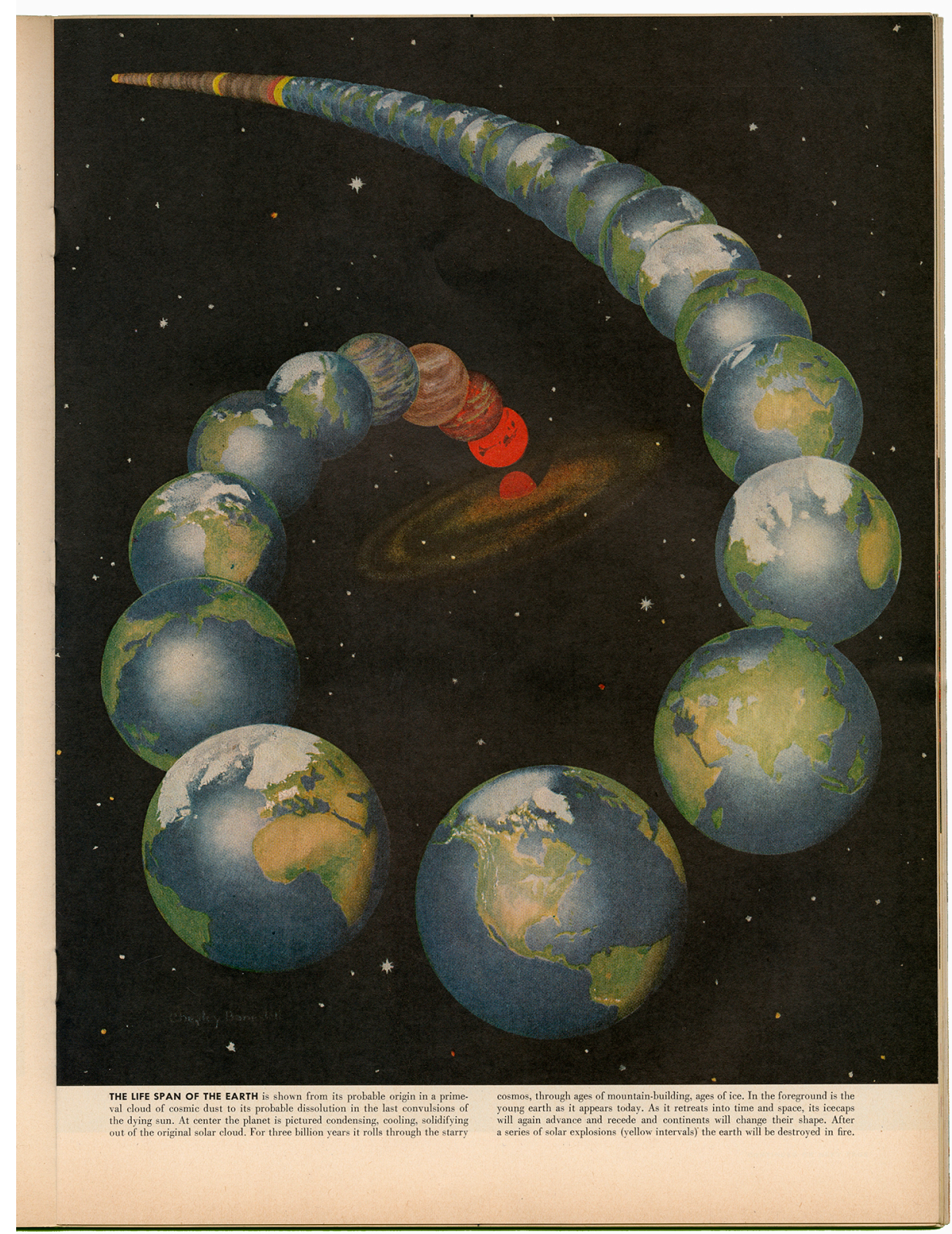

Fig. 24. "The Earth Is Born," Painted by Chelsey Bonestall. LIFE, December 8, 1952, 45. From the collection of the Ryerson Image Centre. 
Appropriately titled "The Life Span of the Earth," it shows a series of turning globes in a spiral, advancing towards the reader. The largest of the globes is located at the bottom of the image, intentionally at the widest point, which is meant to inform the reader of the apex of the earth's lifespan before it starts to spiral towards its demise. The continent facing the reader in this globe is North America. In the next iteration, the globe has partially turned, showing the Atlantic Ocean and is shown somewhat smaller. It advances onward in a tighter spiral and becomes ever smaller as it progresses towards its eventual fiery destruction, pictured as a solid orange globe engulfed by the sun directly above the largest, North American iteration. It appears an inevitable fate, and a somewhat grim opening visual message in a series titled The World We Live In.

However, there is a form of 'redemption' offered in the final essay of the series. "The Starry Universe" was published on December 20, 1954, in the second to last issue of the year. The cover, which offers a portrait of a potential future, is a full-colour illustration that was once again painted by Chelsey Bonestall (Fig. 25). This time, the perspective in the illustration is from ground level. The viewer is given the impression they are standing on the ground, somewhere, with the sky opening up overhead. The landscape is a barren expanse with a single rocky spire jutting upward in the centre of an otherwise flattened area. Directly above the narrow spire, the only identifiable feature and the brightest colour on the page (aside from the red LIFE logo and masthead) is a sun or another bright star. Beside the bright sun is a smaller orbital mass with a single ring. Humanity has transcended its earthly fate and arrived ... somewhere. In white block letters, the subtitle, which is in a larger than the actual title of the issue, reads "The Star-Studded Reaches of Measureless Space." 


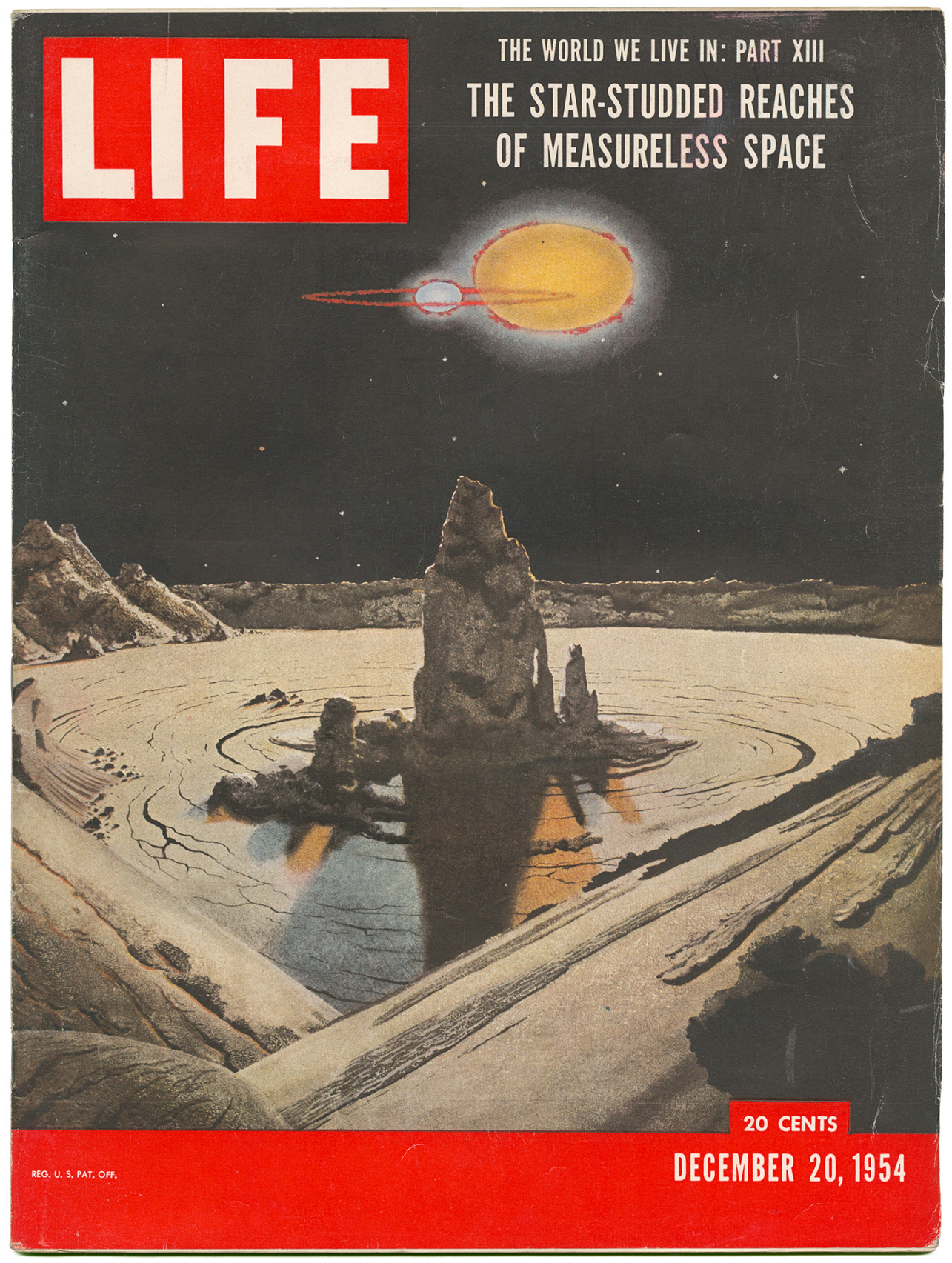

Fig. 25. "The Starry Universe," Painted by Chelsey Bonestall. LIFE, December 20, 1954. From the collection of the Ryerson Image Centre.

Another implicit subtext of this image appearing on the final cover of series in LIFE is that the United States, specifically, has achieved this viewpoint. ${ }^{219}$ This visual narrative portrays another successful conquest, this time of space, by American scientific efforts.

219 By 1954, the United States was actively engaged in a 'space race' with the Soviet Union. From the early 1950 s to 1957 , these efforts were focused on launching a successful satellite mission, which the Soviet Union 
Inside the issue, the opening text for "The Starry Universe" is a quote from the Biblical book of Genesis. It reads "Let there be lights in the firmament to divide the day from the night; and let them be for signs, and for seasons, and for days, and years." ${ }^{220}$ As in the original biblical context, the "lights of the firmament" represent a beginning, but this time the starry sky is both a hypothetical new frontier for human life and a present literal frontier of human knowledge. The subsequent essay is a visual accounting of the known universe and different types of stars. Bonestall's cover illustration is repeated on page 60 of the issue and, via the caption, the image is revealed to be a view of the double star RW Persei from a hypothetical planet.

While the imagined future is represented by Bonestall's paintings, the present state of scientific knowledge is represented in photography. One of these images is a blurry blackand-white photograph with a series of fuzzy white dots scattered across the image. A star is discernable in the upper right-hand corner of the image and appears to be the only recognizable subject. There are a series of white arrows, obviously later editorial annotations, pointing at other tiny white specks of various sizes. The size of the photograph is also notable. It is smaller than the majority of the essay's other images, only covering the top quarter of the page and framed on all sided by a generous inch of white space. The title and caption provide some answers to the photograph's subject matter. Titled "The Farthest Galaxies," the photograph is in an image from the Mount Palomar telescope, one of the premier pieces of astronomy equipment in the United States in 1954 (Fig. 26).

achieved first on October 4, 1957 with the launch of Sputnik I. The Sputnik launch captured worldwide attention and galvanized the American government into action, leading to drastically increased scientific funding for American space exploration. "Space Race Timeline," PBS NOVA, accessed June 27, 2017; http://www.pbs.org/wgbh/nova/astrospies/time-nf.html. For a more comprehensive cultural historical account of these events see Deborah Cadbury, Space Race: The Epic Battle Between America and the Soviet Union for the Dominion of Space, New York: Harper Perennial, 2007.

220 "The Starry Universe," LIFE, December 20, 1954, 55. 


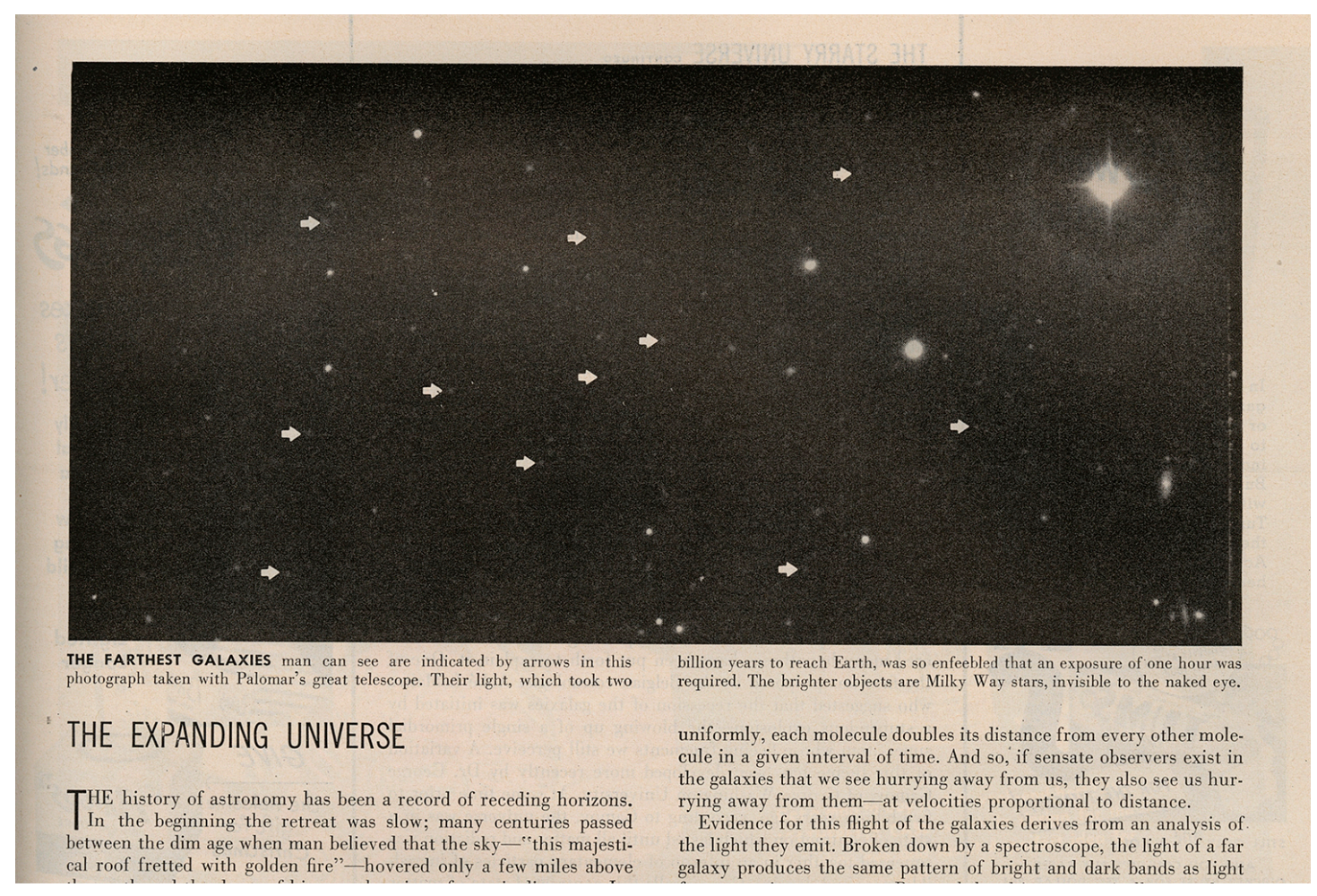

Fig. 26. "The Starry Universe," Photographed by Mt. Wilson and Palomar Observatories, LIFE, December 20, 1954, 89. From the collection of the Ryerson Image Centre.

The caption further explains that the photograph is a one-hour exposure because the light, "which took two billion years to reach earth" is so weak. The brightest objects in the image are stars of the Milky Way, "normally invisible to the human eye."221 The subsection title and initial paragraph text below the Palomar photograph reveals a final, important piece of information about the context of the image's subject matter. The subsection is titled "The

Expanding Universe" and the paragraph reads:

The history of astronomy has been a record of receding horizons. In the beginning the retreat was slow; many centuries passed between the age when man believed that the sky - "this majestical roof fretted with golden fire" - hovered only a few miles above the earth and the dawn of his apprehension of cosmic distances. Indeed, it was not until the beginning of our century that the focus of astronomy shifted from planets to stars. Only within the last 25 years has it comprehended the galaxies of outer space. ${ }^{222}$

\footnotetext{
221 "The Starry Universe," LIFE, December 20, 1954, 63. 222 Ibid.
} 
The article goes on to recount a discovery by Edwin Hubble, who proved via published photographs in 1924 that the hazy images astronomers believed to dust and gas were in fact distant galaxies. The text also explains the basic mathematical principles of the HubbleHumason law: the cosmological that equation Hubble and fellow astronomer Milton Humason developed in 1929 from tracking the receding velocity of galaxies. Via the HubbleHumason law (known today as Hubble's law), scientists are able to surmise that the universe is expanding. ${ }^{223}$

While this particular scientific principle literally expanded the boundaries of the known universe, it also provides an alternative for the ominous future of humanity, who in Bonestall's original illustration in "The Earth is Born" appear destined for obvious and final oblivion along with the earth. But in a counter-narrative presented in the furthest reaches of a starry expanse, captured in of the blurry photograph taken using the Palomar telescope, science becomes the answer to the problem of humanity's physical, as well as intellectual, limitations. While the original illustration shows the earth eventually spiralling away, smaller and smaller, towards oblivion, the photograph confirms an expanding universe, and with it, expanding opportunities. Pursuing scientific knowledge thus advances toward epistemological and physical "receding horizons." 224 The specific visual iconography of the Palomar telescope photograph also supports this narrative. Marcel LaFollete writes that using equipment like microscopes and telescopes were common tropes in the mass media, "especially in astronomy, where mechanical aids to vision took on almost a metaphysical importance, helping astronomers peer into the future, just as microscopes helped biologists

223 “The Starry Universe," LIFE, December 20, 1954, 63. Hubble's law is often still cited as part of the support for the 'Big Bang' model in physical cosmology.

224 Ibid. 
see beneath 'the surface of things' ${ }^{\prime 225}$ She further mentions that this preoccupation was born particularly out of fascination with and coverage of "the construction of the new 200inch telescope at Mt. Palomar" in $1935 .^{226}$

This overarching, sequential series narrative of a hopeful future in the expanding horizons of space, ensured by scientific progress, parallels the other narratives of scientific conquest throughout individual issues in the series. It also fitted succinctly into the larger narrative of promoting American values in its (then) present-day context, mimicking its language and visual imagery. Indeed, in "The American Century" Henry Luce wrote:

Other nations can survive simply because they have endured so long sometimes with more and sometimes with less significance. But this nation, conceived in adventure and dedicated to the progress of man - this nation cannot truly endure unless there courses strongly through its veins ... the blood of purposes and enterprise and high resolve ... It is in this spirit and capacity that all of us are called, each to his own measure of capacity, and each in the widest horizon of his vision, to create the first great American century. $^{227}$

The series' summary message was that scientific progress was American progress. In turn, LIFE's message was that American progress, in the manner conceived by Luce, was beneficial and necessary to the future of all humankind.

The editorial concept of the series became a useful tool for Luce's message. The editors built tidy, multi-part, narratives that emphasized a sequential order of constructive knowledge. LIFE's series were a gestalt, in which the whole - the concept of humanity's (and particularly the dominant white, middle-class American readership of LIFE) undeniable quest for betterment; "to see and be amazed; to see and be instructed" - was greater than

\footnotetext{
225 LaFolette, 112.

226 Ibid, 116.

227 Henry R. Luce, "The American Century," LIFE, February 17, 1941, 65. Words not italicized in the original publication.
} 
the sum of its parts. ${ }^{228}$ LIFE's series were also particularly well suited to the syndicate model, in which similar content was repackaged into various specific iterations and mediums. The World We Live In was published three separate times in book format (in 1955, 1958, and 1962) after its initial debut in the magazine between 1952 and 1954. It was also turned into educational filmstrips that could be purchased through LIFE. Other series, including The History of Western Civilization were republished as books. Such series became a frequent sight in LIFE in the five years following the final issue of The World We Live In, and appeared in other sections of the magazine besides that of the pictorial essay. No less than eight new series appeared between January 1955 and December 1959. Topics included America's Arts and Skills, The World's Great Religions, The Age of Psychology, Segregation, Great Adventures, and The Epic of Man. The latter of these was advertised as "a new series on the origins of civilization in the style of The World We Live In." It debuted in the November 7, 1955 issue of LIFE, all ten parts were written by The World We Live In author Lincoln Barnett, and all but one issue appeared as pictorial essays in LIFE.

\footnotetext{
228 Taken from the poetic opening paragraphs of LIFE's original prospectus, co-authored by Luce and Archibald MacLeish. See Brinkley, 114 for part of the text.
} 


\section{Conclusion}

Within the sections of this 'general interest' magazine, LIFE editors used strong picture-based narratives in diverse layouts to tell different stories of scientific progress to a variety of audiences within its readership. However, the overall constructed narrative portrayed by editorial practices of science content in LIFE was that scientific progress was American progress, and that American progress was necessary and beneficial for the world. Henry Luce envisioned a future for the twentieth century grounded in American exceptionalism, and used the editorially-constructed visual narratives in the pages of LIFE to 'picture' this future. In the immediate decade after World War II, this picture of American hegemony through a narrative civic, cultural, and technical progress captured the public's interest. The United States entered a brief period of 'postwar prosperity', and LIFE's subscription rates peaked. ${ }^{229}$

By the end of the 1950s, the editorial visions and corresponding categories that defined LIFE were transforming. Thierry Gervais notes that the "compartmentalization of sections were gradually losing their relevance." ${ }^{230}$ The magazine's ongoing, simplified nationalist narrative of American military, cultural, and scientific hegemony was also less attractive than in the immediate post-World War Il years. The United States was increasingly engaged in a complex series of ongoing international and domestic events that lacked the cohesion and decisive victories of the 1940s. The Korean War, the ongoing Cold

\footnotetext{
${ }^{229}$ The term 'postwar prosperity' is a commonly recognized, albeit contested, term for the period of economic, technological, cultural upturn and the supposed triumph of middle-class values in the 1950s United States. See "The Postwar Period Through the 1950s." In Encyclopedia of American Social History, edited by Mary Kupiec Cayton, Elliott J. Gorn, and Peter W. Williams (New York: Charles Scribner's Sons, 1993), accessed June 27, 2017; http://link.galegroup.com/apps/doc/BT2313026907/UHIC?u=oldt1017\&xid=6851f7a0. For TIME's own narrative of this period see Claire Suddath, "The Middle Class," TIME (online edition), February 27 (2009), accessed June 27, 2017; http://content.time.com/time/nation/article/0,8599,1882147,00.html. ${ }^{230}$ Gervais, 181.
} 
War with the Soviet Union, the Space Race, Civil Rights, and Second Wave Feminism are just a few of examples of the many events that challenged Luce's editorial vision of using LIFE, and the photography presented in its pages, "to forge [a] cohesive, nationalistic iconography."231

Shifting technologies played a significant role in media consumption habits after 1955 , as television became more widely available across the United States. ${ }^{232}$ The escalation of the United States into a full-blown Cold War with the Soviet Union, and the ever-present threat of atomic warfare, oft repeated across media networks, made science's role in policy much more public. In turn, the American public (in this case, voting citizens) grew increasingly wary of the relative autonomy that scientists enjoyed under Vannevar Bush's post-World War II policies. Somewhat ironically, the American government and professional science's desire for a more informed public that recognized the significance of science in everyday life was fulfilled. "Science - the Endless Frontier" still had its theoretical freedoms, but citizens increasingly questioned science's motives and demanded government intervention. ${ }^{233}$ As in the past, the press played an important role in facilitating ongoing discussions about science and science communication between professional science and scientists, the government, and the American public. Media coverage of the Nazi medicine trials, the increase in biomedical research, and the emergence of bioethics are examples of public scrutiny towards more traditional 'science knows best' narratives. ${ }^{234}$

\footnotetext{
231 McLemore, 127.

232 Marcel LaFollette cites the rise of television as the main factor in confining her analysis of mass-media magazines prior to 1956. See LaFolette, 3.

233 See LaFollette, 127-140 for detailed account of the emergence of public regulation of science in America in the later 1950s.

234 LaFollette, 139.
} 
If science communication lies at a nexus between a myriad of bodies, spaces, organizations, and interests, so to does the historical exploration of the arrangement of science words and images on the pages of magazines. The vast array of people, motivations, and circumstances that influenced, created, edited, and produced LIFE requires a dedicated contextual dialogue, with material objects as historical actors in their own right. Successful editing, by its very nature, demanded interdisciplinarity; a sensitivity to not only the individual words and pictures, but more importantly to the gestalt of the layout and the publication as a whole entity. In the late 1940s and early 1950s, LIFE's editorial team produced beautiful, technical, pictorial narratives of science that reached a variety of audiences and advanced Luce's agenda of publicizing American capitalist, conservative, middle-class values as morally superior, forward thinking, and universally applicable. 


\section{Appendix A}

Table 1)

This table shows data from an analysis of thirteen sampled science section articles from 1952. They appeared explicitly in the 'Science' section and not in the related topic sections listed in Graph 1. The thirteen sample articles were generated from 1952, with at least one in article occurring in each month of that year. Thirteen articles were chosen to provide an equal number of articles and data to compare with the thirteen issues of the series The World We Live In. The sample was chosen from 1952, the year that The World We Live In debuted, in order to provide a similar historical context for the articles in both sections of LIFE magazine.

\begin{tabular}{|c|c|c|c|c|c|}
\hline Issue Date & Article Title & Total \# of Pages in Article & Total \# of Images & Total B+W Images & Total Colour Images \\
\hline 14-Jan-52 & "Torpedo Turbulence" & 2 & 5 & 5 & 0 \\
\hline 18-Feb-52 & "Wizard of 0000 s" & 1 & 1 & 1 & 0 \\
\hline 3-Mar-52 & "Dental Sand Blaster" & 1 & 3 & 3 & 0 \\
\hline 24-Mar-52 & "Modern Armor for Marines" & 1 & 2 & 2 & 0 \\
\hline 7-Apr-52 & "Fire in the Antarctic" & 3 & 7 & 5 & 2 \\
\hline 26-May-52 & "New Looks at the A-Bomb" & 3 & 7 & 5 & 2 \\
\hline 9-Jun-52 & "How the Eye Reveals Ills" & 2 & 10 & 2 & 8 \\
\hline 7-Jul-52 & "Jet Age Whirligig" & 3 & 7 & 7 & 0 \\
\hline 18-Aug-52 & "Man vs. Mesquite" & 3 & 8 & 7 & 1 \\
\hline 15-Sep-52 & "Smoke Eliminator" & 1 & 3 & 3 & 0 \\
\hline 27-Oct-52 & "Scientists Find Mid-Ocean Canyon" & 3 & 7 & 7 & 0 \\
\hline 24-Nov-52 & "The Trail of the Thunder Lizard" & 3 & 4 & 4 & 0 \\
\hline 1-Dec-52 & "Man's Breath Runs Typewriter" & 3 & 6 & 6 & 0 \\
\hline
\end{tabular}

\section{Table 2)}

This table shows the issue date, article title, inclusion of a cover image, section, and page numbers for each of the thirteen articles in the LIFE science series, The World We Live In. The title of each article has several iterations, a longer version listed in each issue's table of contents and a shorter version used on the first page. The short version is listed here.

\begin{tabular}{|c|c|c|c|c|c|}
\hline Issue Date & Order & Title & Cover Image & Section & Page Numbers \\
\hline 8-Dec-52 & 1 & The Earth is Born & yes & pictorial essay and article & $85-103$ \\
\hline 9-Feb-53 & 2 & The Miracle of the Sea & yes & pictorial essay and article & $58-82$ \\
\hline 15-Apr-53 & 3 & The Face of the Land & yes & pictorial essay & $86-109$ \\
\hline 8-Jun-63 & 4 & The Canopy of Air & no & pictorial essay & $74-98$ \\
\hline 7-Sep-53 & 5 & The Pageant of Life & yes & pictorial essay & $53-74$ \\
\hline $15-$ Oct-53 & 6 & The Age of Mammals & yes & pictorial essay & $90-109$ \\
\hline $30-N o v-53$ & 7 & Creatures of the Sea & yes & pictorial essay & $78-108$ \\
\hline $8-F e b-54$ & 8 & The Coral Reef & yes & pictorial essay & $74-94$ \\
\hline 5-Apr-54 & 9 & The Land of the Sun & yes & pictorial essay & $72-93$ \\
\hline 7-Jun-54 & 10 & The Arctic Barrens & yes & pictorial essay & $90-120$ \\
\hline 20-Sep-54 & 11 & The Rainforest & yes & pictorial essay & $76-106$ \\
\hline 8-Nov-54 & 12 & The Woods Close to Home & yes & pictorial essay & $78-100$ \\
\hline 20-Dec-54 & 13 & The Starry Universe & yes & pictorial essay & $44-70$ \\
\hline
\end{tabular}




\section{Graph 1)}

This graph shows the number of science section occurrences and number of science section articles per issue in the sample years of 1938, 1945, and 1952, which are spaced evenly seven years apart across a relevant timeline of inquiry for this thesis: from the debut of the science section in LIFE in August 1937 to the debut of The World We Live In in December 1952. Data shows that while the number of science sections per issue stayed consistent across these years, the number of science section articles per issue rose steadily from 1938 to 1952. For this analysis, LIFE's 'Science' section and the related topic sections of 'Nature,' 'Science and Industry,' 'Medicine,' 'Aviation,' 'Natural History,' 'Nature,' and 'Agriculture,' as well as the articles that appeared in these sections, were included in the calculations.

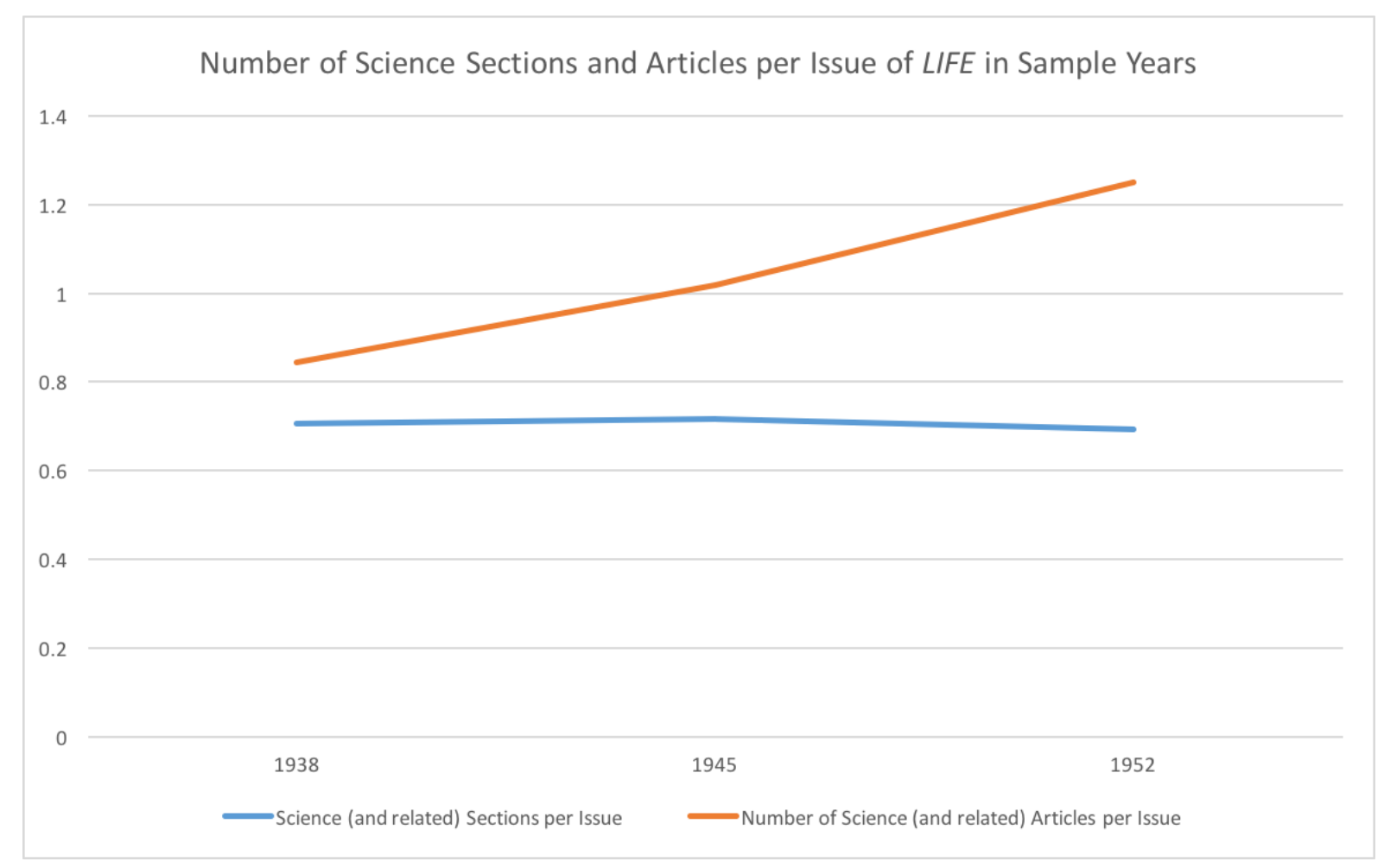




\section{Graph 2)}

This graph shows the percentage of colour images and the percentage of black-and-white images that were published in the thirteen issues of the series The World We Live In against thirteen sampled science section articles from 1952. The graph shows that the majority of the science sections' images were published in black-and-white while the majority of images published in the issues of The World We Live In were published in colour. Seventy images were analysed from the thirteen sample 'Science' section articles. A total of 394 images were analysed from the thirteen issues of The World We Live In. Cumulatively, the sampled articles' images from the 'Science' section were $81.43 \%$ black-and-white and $18.57 \%$ colour. Cumulatively, the images from the thirteen issues of The World We Live In were $23.8 \%$ black-and-white and $76.2 \%$ colour.

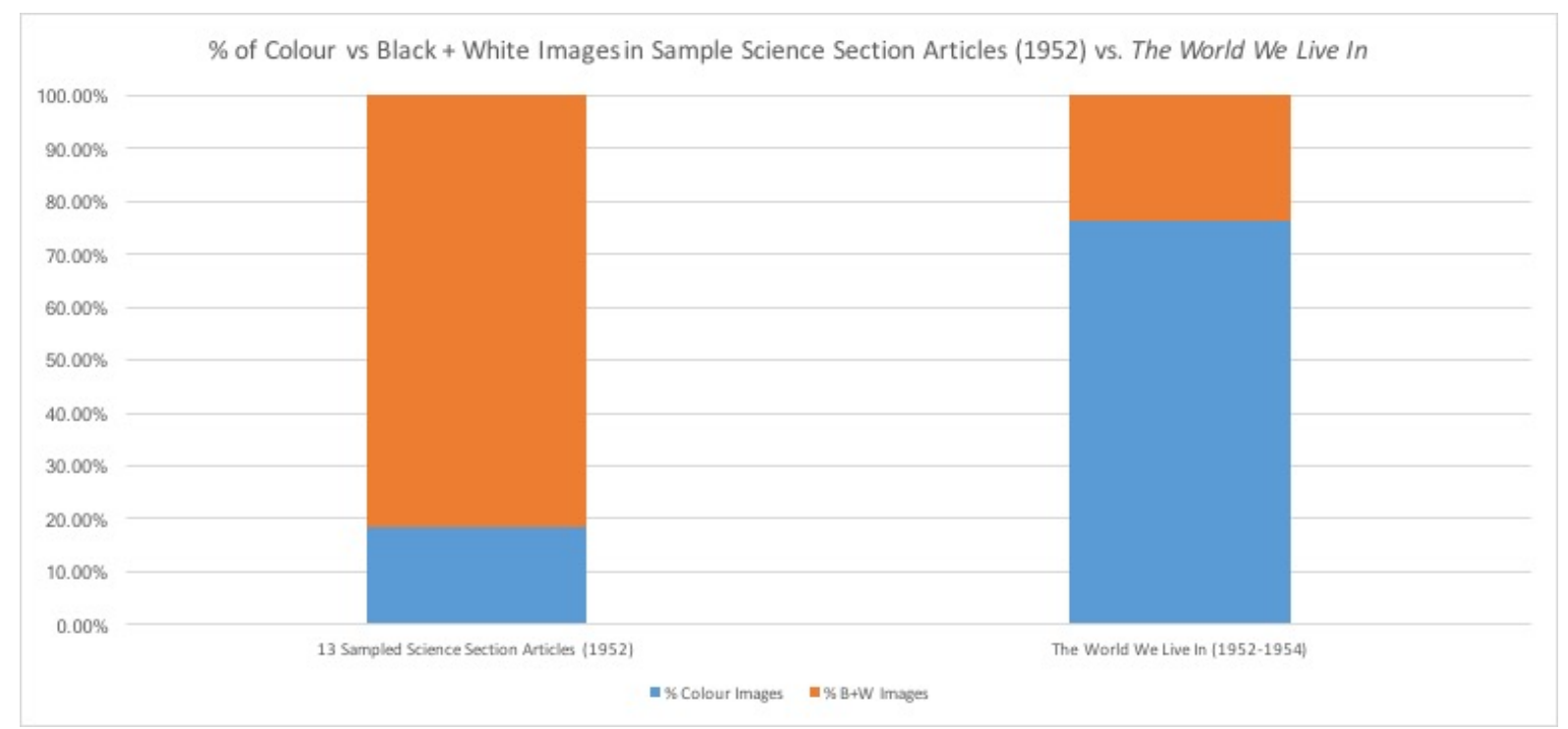




\section{Graph 3)}

This graph shows the percentage of colour images versus the percentage of black-and-white images that were published in each the thirteen issues of the series The World We Live In.

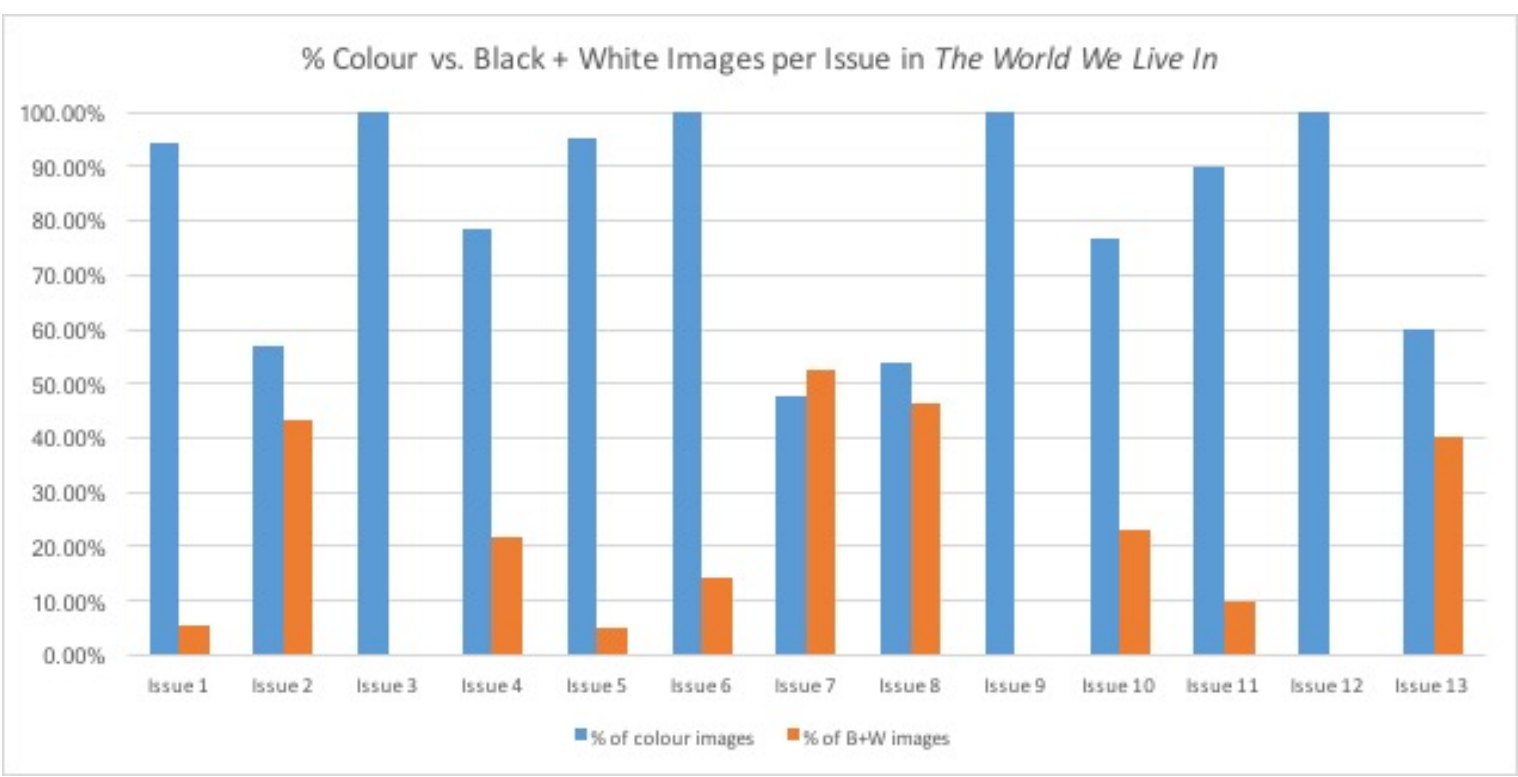

\section{Graph 4)}

This graph shows the percentage of photographs versus the percentage of illustrations and charts that were published in each the thirteen issues of the series The World We Live In. A total of 394 images were analysed. Two-hundred and sixty-eight of these images were photographs while 126 images were illustrations or charts. Cumulatively, sixty-eight percent of the images published in the issues of The World We Live In were photographs while thirty-two percent were illustrations or charts.

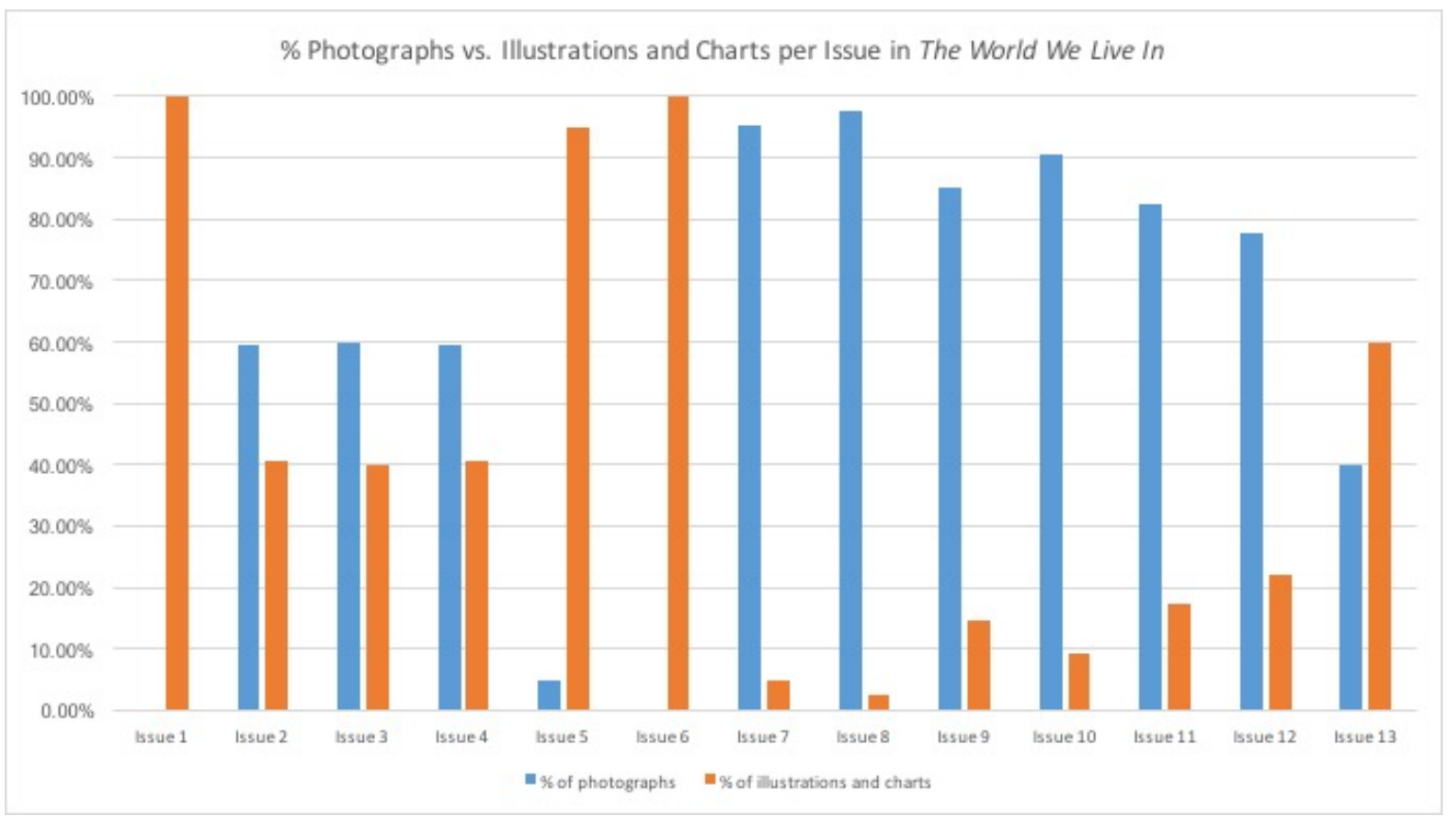




\section{Bibliography}

\section{LIFE Articles}

"LIFE Begins," LIFE, November 23, 1936.

"Franklin Roosevelt's Wild West," LIFE, November 23, 1936.

"The Camera as Essayist," LIFE, April 26, 1937.

Henry R. Luce, "The American Century", LIFE, February 17, 1941.

"Science and the Future," LIFE, October 20, 1941.

"The Atomic Age," LIFE, August 20, 1945.

"War's Ending," LIFE August 20, 1945.

"The Atomic Bomb: It's First Explosion into a new Era," LIFE, August 20, 1945.

"Manhattan Project: Its Scientists Have Harnessed Nature's Basic Force" LIFE, August 20, 1945.

"Transport Panel Board," LIFE, August 23, 1937.

"LIFE's Pictures," LIFE, August 23, 1937.

"Amputee's Gait", LIFE, July 1, 1946.

"LIFE Announces A Series of Articles on The History of Western Culture," LIFE, March 3, 1947.

"Renaissance Man," LIFE, March 3, 1947.

"New Looks at the A-Bomb," LIFE, May 26, 1952.

"Announcing the Greatest LIFE Science Series-The World We Live In," LIFE, November 24, 1952.

"The Earth is Born," LIFE, December 8, 1952.

“...and after 'The Earth,"' LIFE, December 8, 1952.

"The Miracle of the Sea," LIFE, February 9, 1953.

"A-Bomb vs. House," LIFE, March 3, 1953.

"The Face of the Land," LIFE, April 15, 1953.

"The Canopy of Air," LIFE, June 8, 1953.

"The Pageant of Life," LIFE, September 7, 1953.

"Stories Can Be Told in an Eon or an Instant," LIFE, September 7, 1953.

"The Age of Mammals," LIFE, October 15, 1953.

"Salt Water and a Neurotic Octopus," LIFE, November 30, 1953.

"Creatures of the Sea," LIFE, November 30, 1953.

"The Lowdown on Red Coral and Red Morale," LIFE, February 8, 1954.

"The Coral Reef," LIFE, February 8, 1954.

"The Land of the Sun," LIFE, April 5, 1954.

"Green Gold," LIFE, April 5, 1954.

"LIFE's Expedition to the Tundra," LIFE, June 7, 1954.

"The Arctic Barrens," LIFE, June 7, 1954.

"The Rainforest," LIFE, September 20, 1954.

"Research at Source," LIFE, September 20, 1954.

"The Woods Close to Home," LIFE, November 8, 1954.

"The Starry Universe," LIFE, December 20, 1954. 


\section{Additional Primary Sources}

Bush, Vannevar. Science - the Endless Frontier: A Report to the President on a Programme for Postwar Scientific Research, July 1945. Reprint, National Science Foundation: Washington D.C., 1960.

Camera Three. Conversations with Editors Part III. Television. James Macandrew and Gerard Piel. July 4, 1965, WCBS-TV. On Vinyl LP, 1965.

Dorsey, N. Ernest and J. O'H. Cosgrave. "The Writing of Popular Science." Science 55, no. 1431 (June 2, 1922), 593-595.

Roosevelt, Franklin D. Copy of letter from Franklin D. Roosevelt to Vannevar Bush, November 17, 1944. In Ava Helen and Linus Pauling Papers, Oregon State University Libraries Special Collections and Archive Research Centre; http://scarc.library.oregonstate.edu/coll/pauling/war/corr/sci13.006.4-rooseveltbush-19441117-01.html.

"An Announcement to Our Readers." Scientific American, January 1948.

"Table of Contents." Scientific American, May 1948.

"The Future of the Amazon." Scientific American, May 1948.

Scripps, E. W. "Disquisition by Scripps, E. W., American society for the dissemination of science, March 5, 1919," E.W. Scripps Papers Series 4, Box 04, Vol. 07, Ohio University Libraries, Mahn Center for Archives and Special Collections; http://media.library.ohiou.edu/cdm/compoundobject/collection/scripps/id/5792/re $\mathrm{c} / 4$

\section{Secondary Sources}

"Space Race Timeline." PBS NOVA. Accessed June 27, 2017; http://www.pbs.org/wgbh/nova/astrospies/time-nf.html.

"The Postwar Period Through the 1950s." In Encyclopedia of American Social History. Edited by Mary Kupiec Cayton, Elliott J. Gorn, and Peter W. Williams. New York: Charles Scribner's Sons, 1993. Accessed June 27, 2017; http://link.galegroup.com/apps/doc/BT2313026907/UHIC?u=oldt1017\&xid=6851f7a 0 .

Bacevich, Andrew. The Short American Century: A Postmortem. Cambridge, Mass.: Harvard University Press, 2012.

Baughman, James L. Henry R. Luce and the Rise of the American News Media. Boston: Twayne Publishers, 1987. 
Baughman, James L. "Who Read LIFE?: The Circulation of America's Favorite Magazine." In Looking at Life Magazine, edited by Erika Doss, Washington, D.C.: Smithsonian Institution Press, 2001.

Baughman, James L. "Henry Luce and Twentieth-Century Consumer Culture." Business and Economic History Online 9, no. 1 (2011), 1-10;

http://www.thebhc.org/sites/default/files/baughman.pdf

Bennet, Cynthia D. "Science Service and the Origins of Science Journalism, 1919-1950." Doctoral dissertation, lowa State University, 2013.

Bredekamp, Horst, Vera Dünkel, and Birgit Schneider. The Technical Image: A History of Styles in Scientific Imagery. Chicago: University of Chicago Press, 2015.

Brinkley, Alan. The Publisher: Henry Luce and His American Century. New York: Knopf Doubleday Publishing Group, 2010.

Broks, Peter. Understanding Popular Science. Maidenhead, Berkshire: Open University Press, 2006.

Burnham, John C. How Superstition Won and Science Lost: Popularising Science and Health in the United States. New Brunswick, NJ: Rutgers University Press, 1987.

Cadbury, Deborah. Space Race: The Epic Battle Between America and the Soviet Union for the Dominion of Space. New York: Harper Perennial, 2007.

Campbell, Mary B. and Mark Rollins. Begetting Images: Studies in Art and Science of Symbol Production. New York: Peter Lang, 1989.

Childs, William R. "Henry Luce and the Business of Journalism." Business and Economic History Online 9, no. 1 (2011), 1-8; http://www.thebhc.org/sites/default/files/childs.pdf

Christiansen, Jen. "Evolution of the Scientific American Logo," Scientific American (blog), March 6, 2014, Accessed on May 14, 2017; https://blogs.scientificamerican.com/savisual/evolution-of-the-scientific-american-logo/.

Cookman, Claude. American Photojournalism: Motivations and Meanings. Evanston, Illinois: Northwestern University Press, 2009.

Cooter, Roger and Stephen Pumfrey. "Separate Spheres and Public Places: Reflections on the History of Science Popularization and Science in Popular Culture." History of Science 32, no. 3 (September 1994), 237-267; https://doi.org/10.1177/007327539403200301

Daston, Lorraine. Things That Talk: Object Lessons from Art and Science. Cambridge, Mass.: Zone Books, 2004. 
Doss, Erika. "Introduction Looking at LIFE: Rethinking America's Favorite Magazine, 19361972." Looking at Life Magazine, edited by Erika Doss. Washington, D.C.:

Smithsonian Institution Press, 2001.

Edgerton, Harold and James Rhyne Killian. Moments of Vision: The Stroboscopic Revolution in Photography. Cambridge, Mass.: MIT Press, 1979.

Edwards, Elizabeth and Janice Hart. Photographs Objects Histories: On the Materiality of Images. London; New York: Routledge, 2004.

Engelhardt, Tom. The End of Victory Culture: Cold War America and the Disillusioning of a Generation. Boston: University of Massachusetts Press, 2007.

Gervais, Thierry and Gaëlle Morel. La fabrique de l'information visuelle: photographies et magazines d'actualité. Paris: Textuel, 2015.

Gigante, Maria E. "A Portrait of Exclusion: The Archetype of the Scientist at Work in Life Magazine." Rhetoric Review 34, no. 3 (June 2015), 292-314; http://www.tandfonline.com.ezproxy.lib.ryerson.ca/doi/full/10.1080/07350198.201 5.1040305 .

Graf, Catharina. "The Birth of the Photo Essay: The First Issues of LIFE and LOOK." Presentation at "Raumgeflechte/Spatial Relations" Summer School at the University of Zurich, Zurich, June 10, 2014.

Griffith, Robert. "The Selling of America: The Advertising Council and American Politics, 1942-1960." Business History Review 57, no. 3 (1983), 388-412; https://doi.org/10.2307/3114050

Guimond, James. American Photography and the American Dream. Chapel Hill: The University of North Carolina Press, 1991.

Hagerdorn, Roger. "Technology and Economic Exploitation: The Serial as a Form of Narrative Presentation." Wide Angle: A Film Quarterly of Theory, Criticism, and Practice 10, vol. 4 (1988), 4-12.

Hales, Peter Beacon. "Imagining the Atomic Age: LIFE and the Atom." Looking at Life Magazine, edited by Erika Doss. Washington, D.C.: Smithsonian Institution Press, 2001.

Hariman, Robert and John Louis Lucaites. No Caption Needed: Photographs, Public Culture and Liberal Democracy. Chicago: University of Chicago Press, 2007.

Hayes, Brian. “Dennis Flanagan, 1919-2005," American Scientist 93, no. 2 (March-April 2005), 1; http://www.americanscientist.org/issues/pub/dennis-flanagan-1919-2005. 
Henriksen, Margot A. Dr. Strangelove's America: Society and Culture in the Atomic Age. Berkeley: University of California Press, 1997.

Hentschel, Klaus. Visual Cultures in Science and Technology: A Comparative History. Oxford, Oxford University Press, 2015.

Herzstein, Robert E. Henry R. Luce: A Political Portrait of the Man Who Created the American Century. New York: Scribner's, 1994.

Hill, Jason and Vaness R. Schwartz. Getting the Picture: The Visual Culture of the News. London, Bloomsbury Academic, a division of Bloomsbury Publishing PIc, 2015.

Huppauf, Bernd, and Peter Weingart. "Images In and Of Science." Science Images and Popular Images of the Sciences, edited by Bernd Huppauf and Peter Weingart. New York: Routledge, 2008: 3-31.

Jordanova, Ludmilla. The Look of the Past: Visual and Material Evidence in Historical Practice. Cambridge, Cambridge University Press, 2012.

Jordanova, Ludmilla and Roy S. Porter. Images of the Earth: Essays in the History of Environmental Sciences. Chalfont St Giles: British Society for the History of Science, 1979.

Keller, Corey. Brought to Light: Photography and the Invisible, 1840-1900. San Francisco: San

Francisco Museum of Modern Art; New Haven: In association with Yale University Press, 2009.

Koj, Aleksander and Piotr Sztompka. Images of the World: Science, Humanities, Art. Kraków: Jagiellonian University, 2001.

Kozol, Wendy. LIFE's America. Philadelphia: Temple University Press, 1994.

LaFollette, Marcel C. Making Science Our Own: Public Images of Science 1910-1955. Chicago:

University of Chicago Press, 1990.

Lewenstein, Bruce V. "Science Books Since 1945." The Enduring Book: Print Culture in Postwar America. Edited by David Paul Nord, Joan Shelley Rubin, and Michael Schudsen. Chapel Hill, NC: American Antiquarian Society in association with the University of North Carolina, 2009.

Lewenstein, Bruce V. "Magazine Publishing and Popular Science After World War II." American Journalism, 6, no. 4 (1989), 218-234; http://dx.doi.org/10.1080/08821127.1989.10731208

Lewenstein, Bruce V. "'Public understanding of science' in America, 1945-1965." Doctoral 
Dissertation, University of Pennsylvania, 1987.

Lewenstein, Bruce V. "The Meaning of 'Public Understanding of Science' in the United States After World War II." Public Understanding of Science, 1, no. 1 (Jan 1992), 45-68; http://dx.doi.org/10.1088/0963-6625/1/1/009

McLemore, Elaine. "War in Words and Pictures: Photography and Aestheticization of Politics in LIFE Magazine, 1936-1972." Doctoral dissertation, Claremont Graduate University, 2013.

Middleton, Peter. Physics Envy: American Poetry and Science in the Cold War and After. Chicago: University of Chicago Press, 2015.

Mili, Gjon. Gjon Mili: Photography and Recollections. Boston: New York Graphic Society, 1980.

"Mission \& History." Society for Science \& the Public. Accessed April 19, 2017. https://www.societyforscience.org/mission-and-history.

Mitchell, W.J.T. Image Science: Iconology, Visual Culture, and Media Aesthetics. Chicago: University of Chicago Press, 2015.

Mitchell, W. J. T. What Do Pictures Want? The Lives and Loves of Images. Chicago: University of Chicago Press, 2004.

Mitman, Gregg and Kelley Wilder. Documenting the World: Film, Photography, and the Scientific Record. Chicago: The University of Chicago Press, 2016.

Mirzoeff, Nicholas. How to See the World: An Introduction to Images, from Selfies, Maps and Movies, and More. New York: Basic Books, 2016.

Morel, Gaëlle, Sarah M. Miller, and Terri Weissman. Berenice Abbott. Paris: Éditions Hazan, 2012.

National Science Foundation, "NSF at a Glance," National Science Foundation, Accessed May 10, 2017; https://www.nsf.gov/about/glance.jsp.

Nelkin, Dorothy. "The Culture of Science Journalism," Society 24, no. 6 (1987), 17-25.

Panzer, Mary. Things As They Are: Photojournalism in Context since 1955. London, World Press Photo, 2005.

Pauwels, Luc. Visual Cultures of Science: Rethinking Representational Practices of Knowledge Building and Science Communication. Hanover, NH: Dartmouth College Press, 2006.

Scientific American. "About Scientific American." Scientific American. Accessed May 2, 2017; https://www.scientificamerican.com/page/about-scientific-american/. 
Speiser, David and Kim Williams. Crossroads: History of Science, History of Art. Basel: Birkhäuser, 2011.

Stimson, Blake. The Pivot of the World: Photography and Its Nation. Cambridge, Mass.: MIT Press, 2006.

Stromberg, John Robert. Art and "Fortune": Machine-Age Discourse and the Visual Culture of Industrial Modernity. Doctoral dissertation, Boston University, 1999.

Suddath, Claire. "The Middle Class." TIME (online edition), February 27, 2009. Accessed June 27, 2017; http://content.time.com/time/nation/article/0,8599,1882147,00.html.

Thomas, Ann and Marta Braun. Beauty of Another Order: Photography in Science. New Haven, CT: Yale University Press in association with the National Gallery of Canada, 1997.

Thurs, Daniel Patrick. Science Talk: Changing Notions of Science in American Popular Culture. New Brunswick, NJ: Rutgers University Press, 2007.

Tourney, Christopher P. Conjuring Science: Scientific Symbols and Cultural Meanings in American Life. New Brunswick, NJ: Rutgers University Press, 1996.

Tsuchiyama, Yoko. "Visual Representations of the Events of the Cold War as Depicted in LIFE Magazine." Visual Past 3, no. 1 (2016), 509-528.

Webb, Sheila. "The Tale of Advancement: Life Magazine's Construction of the Modern Success Story." Journalism History 32, no. 1 (Spring 2006), 2-12.

Weissman, Terri. "Documentary Photography and Communicative Action: The Realisms of Berenice Abbott." Doctoral thesis, Columbia University, 2006.

Wilder, Kelley. Photography and Science. London: Reaktion Books, 2009. 